\title{
Penicimeroterpenoids A-C, Meroterpenoids with Rearrangement Skeletons from the Marine-derived Fungus Penicillium sp. SCSIO 41512
}

Xia Cheng $^{\dagger, \pm}$, Xiao Liang ${ }^{\dagger}$, Zhi-Hui Zheng ${ }^{\S}$, Xue-Xia Zhang ${ }^{\S}$, Xin-Hua Lu ${ }^{\S}$, Fei-Hua $\mathrm{Yao}^{\dagger, \grave{\perp}}$, Shu-Hua Qi ${ }^{\dagger+, * *}$

${ }^{\dagger}$ CAS Key Laboratory of Tropical Marine Bio-resources and Ecology, Guangdong Key Laboratory of Marine Materia Medica, Innovation Academy of South China Sea Ecology and Environmental Engineering, South China Sea Institute of Oceanology, Chinese Academy of Sciences, 164 West Xingang Road, Guangzhou, 510301, China

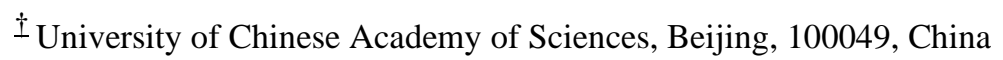

${ }^{\ddagger}$ Southern Marine Science and Engineering Guangdong Laboratory (Guangzhou), 1119 Haibin Road, Nansha District, Guangzhou 511458, China

${ }^{\S}$ New Drug Research \& Development Co., Ltd, North China Pharmaceutical Group Corporation, Shijiazhuang, Hebei 050015, China

Corresponding Authors E-mail: shuhuaqi@scsio.ac.cn 





Table S13. Important thermodynamic parameters of $\mathbf{3}$.

Table S14. Conformational analysis of 3 .

Table S15. Inhibiting activity of $\mathbf{1}-\mathbf{3}$ against 11 enzymes

\section{MATERIALS AND METHODS}

General Experimental Procedures. Optical rotations were measured with a MCP 500 polarimeter (Anton Paar). ECD and UV spectra were measured with a Chirascan circular dichroism spectrometer (Applied Photophysics Ltd.). The crystallographic data were collected on a Rigaku MicroMax 007 diffractometer equipped with $\mathrm{Cu}-\mathrm{K \alpha}$ radiation and a graphite monochromator. ${ }^{1} \mathrm{H},{ }^{13} \mathrm{C}$ NMR and 2D NMR spectra were acquired with a Bruker AVANCE III HD 700 MHz NMR spectrometer (Bruker) with TMS as reference. ESIMS and HRESIMS spectroscopic data were acquired with an amaZon SL ion trap mass spectrometer and MaXis quadrupole-time-of-flight mass spectrometer (Bruker), respectively. Preparative reversed-phase (P-RP) HPLC was performed on a Shimadzu LC-20A preparative liquid chromatography system with an YMC-Pack ODS column, $250 \times 20 \mathrm{~mm}, \mathrm{~S}-5 \mu \mathrm{m}, 12 \mathrm{~nm}$, and Semi-preparative reversed-phase (SP-RP) HPLC was performed on a Shimadzu LC-20A preparative liquid chromatography system with an YMC-Pack ODS column, $250 \times 10 \mathrm{~mm}$, S-5 $\mu \mathrm{m}, 12 \mathrm{~nm}$. RP-MPLC (reversed-phase-medium pressure preparative liquid chromatography) was carried out using the CHEETAH MP200 system (Agela Technologies) and Claricep Flash columns filled with ODS (40-63 $\mu \mathrm{m}$, YMC). Sephadex LH-20 (GE Healthcare) was used for column chromatographic column (CC). Silica gel (200-300 mesh) for CC and GF254 for TLC were obtained from Yantai Jiangyou Silica Gel Development Co., Ltd.

Fungal material. The fungus Penicillium sp. SCSIO 41512 (GenBank: MT436778) was isolated from a soft coral collected from off the coast of Fiery Cross Reef in the south China sea $\left(9^{\circ} 39^{\prime} 29.75^{\prime \prime} \mathrm{N}\right.$ and $\left.112^{\circ} 59^{\prime} 09.84^{\prime \prime} \mathrm{E}\right)$. The strain was identified by using MEA medium (malt extract $20 \mathrm{~g} / \mathrm{L}$, sea salt $30 \mathrm{~g} / \mathrm{L}$, agar $20 \mathrm{~g} / \mathrm{L}$ ) according to ITS sequence, and the similarity with Penicillium sp. (GenBank: GU985208) was 99\%, South China Sea Institute of Oceanology, Chinese Academy of Science.

Extraction and isolation. The fungus Penicillium sp. SCSIO 41512 was cultured on potato dextrose agar (PDA) plate including 3\% sea salt at $28{ }^{\circ} \mathrm{C}$ for 3 days. Subsequently, the spores were added to $3 \times 500 \mathrm{~mL}$ Erlenmeyer flasks each 
containing $150 \mathrm{~mL}$ potato dextrose (PD) medium (2\% glucose, 20\% potato, $3 \%$ sea salt), then cultures were fermented by using a thermostatic shaker (200 r/min) for 3 days at $28{ }^{\circ} \mathrm{C}$. And then $3 \mathrm{~mL}$ of spore suspension was transferred into $200 \times 1 \mathrm{~L}$ Erlenmeyer flasks each containing $300 \mathrm{~mL}$ PD medium. Static fermentation was performed for 28 days at $26{ }^{\circ} \mathrm{C}$, and then mycelia were filtered and disposed with acetone. After removal of acetone under reduced pressure, a crude extract was obtained, which was suspended in $\mathrm{H}_{2} \mathrm{O}$ and extracted with EtOAc (six times) to afford an EtOAc extract (40.3 g). The broth was adsorbed with XAD-16 resin, then was eluted with water and $15 \mathrm{~L}$ industrial ethonal, respectively. Next, recycled ethanol was carried out to yield a crude extract $(14.4 \mathrm{~g})$. The two crude extracts from broth and mycelia parts were combined and further isolated by chromatography methods.

The crude extracts $(54.7 \mathrm{~g})$ were fractionated by a medium-pressure column using a stepped gradient elution with $\mathrm{CH}_{2} \mathrm{Cl}_{2} / \mathrm{CH}_{3} \mathrm{OH}$ (v/v, 100:0, 95:5, 90:10, 80:20, 70:30, 60:40, 50:50; every gradient using $3 \mathrm{~L}$ elution mixture) to get 42 bottles each containing $500 \mathrm{~mL}$ elution. Based on TLC and HPLC analysis, the 42 bottles were combined to ten fractions (Fr.1-Fr.10). Fr.2 (6.5 g) was separated by using RP-MPLC (flow rate: $20 \mathrm{~mL} / \mathrm{min}$, detection wavelength: $210 \mathrm{~nm}$ ) eluting with $\mathrm{CH}_{3} \mathrm{OH} / \mathrm{H}_{2} \mathrm{O} / \mathrm{TFA}$ (v/v/v, from 5:95:0.03 to 100:0:0.03) to give 11 fractions (Fr.2-1-Fr.2-11). Fr.2-7 (150 mg) was separated by Sephadex LH-20 eluting with $\mathrm{CH}_{3} \mathrm{OH}$ to give two fractions (Fr.2-7-1 and Fr.2-7-2). Fr.2-7-1 (30 mg) was further purified by Semi-prep-HPLC eluting with $\mathrm{CH}_{3} \mathrm{OH} / \mathrm{H}_{2} \mathrm{O} / \mathrm{TFA}(\mathrm{v} / \mathrm{v} / \mathrm{v}, 70: 30: 0.03)$ to afforded compound 1 (5.1 mg, $\mathrm{t}_{\mathrm{R}}$ $=17.84 \mathrm{~min}$, flow rate: $3 \mathrm{~mL} / \mathrm{min})$. Fr.2-7-2 $(80 \mathrm{mg})$ was separated by Semi-prepHPLC eluting with $\mathrm{CH}_{3} \mathrm{OH} / \mathrm{H}_{2} \mathrm{O} / \mathrm{TFA}(\mathrm{v} / \mathrm{v} / \mathrm{v}, 65: 35: 0.03)$ to give $2\left(3.0 \mathrm{mg}, \mathrm{t}_{\mathrm{R}}=\right.$ $18.80 \mathrm{~min}$, flow rate: $3 \mathrm{~mL} / \mathrm{min})$ and Fr.2-7-2-1 $\left(5.1 \mathrm{mg}\right.$, $\mathrm{t}_{\mathrm{R}}$ from $19.00-21.00 \mathrm{~min}$, a mixture of 2, 3 and other small impurities). Fr.2-7-2-1 was further purified by Semiprep-HPLC eluting with $\mathrm{CH}_{3} \mathrm{OH} / \mathrm{H}_{2} \mathrm{O} / \mathrm{TFA}(\mathrm{v} / \mathrm{v} / \mathrm{v}, 65: 35: 0.03)$ to give $3\left(2.0 \mathrm{mg}, \mathrm{t}_{\mathrm{R}}=\right.$ $20.20 \mathrm{~min}$, flow rate: $3 \mathrm{~mL} / \mathrm{min}$ ).

\section{Compounds properties.}

Penicimeroterpenoid A (1): colorless crystals (in methanol); $[\alpha]_{\mathrm{D}}^{25}+17.5(c 0.1$, $\mathrm{MeOH}) ; \mathrm{CD}(\mathrm{MeOH}) \lambda_{\max }(\Delta \varepsilon) 200$ (+14.01), 240 (-6.36), 298 (+9.04); UV (MeOH) $\lambda_{\max }(\log \varepsilon) 202(4.49) \mathrm{nm} ;{ }^{1} \mathrm{H} \mathrm{NMR}\left(\mathrm{CD}_{3} \mathrm{OD}, 700 \mathrm{MHz}\right): \delta 4.95(\mathrm{~d}, 1 \mathrm{H}, J=4.7 \mathrm{~Hz})$, $4.57(\mathrm{~d}, 1 \mathrm{H}, J=2.5 \mathrm{~Hz}), 3.74$ (s, 3H), 3.35 (d, 1H, $J=3.4 \mathrm{~Hz}), 2.85$ (dd, 1H, $J=14.4$, 
$4.9 \mathrm{~Hz}$ ), 2.31 (d, 1H, J=3.4 Hz), 2.03 (m, 1H), 2.00 (s, 3H), 1.90 (overlap, 1H), 1.89 (overlap, 1H), $1.83(\mathrm{~s}, 3 \mathrm{H}), 1.75(\mathrm{~s}, 3 \mathrm{H}), 1.74(\mathrm{~m}, 1 \mathrm{H}), 1.66(\mathrm{~m}, 1 \mathrm{H}), 1.41(\mathrm{~s}, 3 \mathrm{H})$, $1.33(\mathrm{~m}, 1 \mathrm{H}), 1.21(\mathrm{~s}, 3 \mathrm{H}), 0.94(\mathrm{~s}, 3 \mathrm{H}), 0.85(\mathrm{~s}, 3 \mathrm{H}) ;{ }^{13} \mathrm{C}\left\{{ }^{1} \mathrm{H}\right\}$ NMR $\left(\mathrm{CD}_{3} \mathrm{OD}, 175\right.$ MHz): $\delta$ 207.1, 197.3, 180.6, 172.1, 170.4, 132.9, 129.7, 84.1, 78.9, 77.2, 76.4, 61.5, 55.7, 53.7, 52.3, 47.4, 45.8, 37.0, 35.8, 26.5, 26.4, 22.9, 22.7, 22.5, 20.9, 20.8, 18.9; 17.4; MS(ESI) $m / z:[\mathrm{M}+\mathrm{Na}]^{+}$539.3; HRMS (ESI-TOF) $m / z:[\mathrm{M}+\mathrm{Na}]^{+}$Calcd for $\mathrm{C}_{28} \mathrm{H}_{36} \mathrm{O} 9 \mathrm{Na}$ 539.2257; Found 539.2273.

Penicimeroterpenoid B (2): colorless oil; $[\alpha]_{\mathrm{D}}^{25}+4.10$ (c 0.1, $\left.\mathrm{MeOH}\right) ; \mathrm{CD}(\mathrm{MeOH})$ $\lambda_{\max }(\Delta \varepsilon) 209$ (-1.79), $223(-3.42), 254(+0.54), 332(+0.38) ; \mathrm{UV}(\mathrm{MeOH}) \lambda_{\max }(\log \varepsilon)$ 200 (3.97) nm; ${ }^{1} \mathrm{H}$ NMR (CD ${ }_{3} \mathrm{OD}, 700 \mathrm{MHz}$ ): $\delta 5.77$ (br s, $\left.1 \mathrm{H}\right), 4.84$ (d, $1 \mathrm{H}, J=4.6$ Hz), 4.65 (br s, 1H), 3.70 (s, 3H), 2.48 (br s, 1H), 2.40 (d, 1H, J=14.2 Hz), 2.17 (dd, $1 \mathrm{H}, J=13.9,3.6 \mathrm{~Hz}), 2.06$ (s, 3H), 1.99 (dd, 1H, $J=14.2,4.6 \mathrm{~Hz}), 1.90$ (br s, 1H), $1.83(\mathrm{~s}, 3 \mathrm{H}), 1.73(\mathrm{~m}, 2 \mathrm{H}), 1.41(\mathrm{~m}, 1 \mathrm{H}), 1.38(\mathrm{~s}, 3 \mathrm{H}), 1.19(\mathrm{~s}, 3 \mathrm{H}), 1.11(\mathrm{~s}, 3 \mathrm{H}), 0.98$ (s, 3H), $0.88(\mathrm{~s}, 3 \mathrm{H}) ;{ }^{13} \mathrm{C}\left\{{ }^{1} \mathrm{H}\right\}$ NMR $\left(\mathrm{CD}_{3} \mathrm{OD}, 175 \mathrm{MHz}\right): \delta$ 211.1, 181.2, 172.0, $169.3,141.7,122.9,88.5,83.5,78.5,77.3,57.8,53.5,52.7,52.3,45.4,41.6,39.2$, 35.6, 26.5, 23.1, 22.7, 22.4, 22.2, 21.9, 20.8, 17.6, 17.1; HRMS (ESI-TOF) $m / z$ : [M + $\mathrm{Na}]^{+}$Calcd for $\mathrm{C}_{27} \mathrm{H}_{36} \mathrm{O}_{8} \mathrm{Na}, 511.2308$; Found 511.2300 .

Penicimeroterpenoid C (3): colorless oil; $[\alpha]_{\mathrm{D}}^{25}-25.6$ (c 0.1, $\left.\mathrm{MeOH}\right) ; \mathrm{CD}(\mathrm{MeOH})$ $\lambda \max (\Delta \varepsilon) 217$ (-19.29), 255 (+0.33), 340 (-2.00); UV (MeOH) $\lambda_{\max }(\log \varepsilon) 202$ (4.17) nm; ${ }^{1} \mathrm{H}$ NMR (CD $\left.3 \mathrm{OD}, 700 \mathrm{MHz}\right): \delta 5.77$ (br s, $\left.1 \mathrm{H}\right), 4.84(\mathrm{~d}, 1 \mathrm{H}, J=4.2 \mathrm{~Hz})$, 4.63 (t, $J=2.4 \mathrm{~Hz}, 1 \mathrm{H}), 3.75$ (s, 3H), 3.01 (br s, 1H), 2.98 (d, 1H, $J=14.6 \mathrm{~Hz}), 2.53$ (br s, 1H), $2.16(\mathrm{~m}, 1 \mathrm{H}), 2.08(\mathrm{dd}, 1 \mathrm{H}, J=14.6,4.8 \mathrm{~Hz}), 2.04(\mathrm{~s}, 3 \mathrm{H}), 1.83(\mathrm{~s}, 3 \mathrm{H})$, $1.71(\mathrm{~m}, 2 \mathrm{H}), 1.55$ (s, 3H), 1.53 (s, 3H), $1.32(\mathrm{~m}, 1 \mathrm{H}), 0.95$ (s, 3H), $0.88(\mathrm{~s}, 3 \mathrm{H}), 0.78$ $(\mathrm{s}, 3 \mathrm{H}) ;{ }^{13} \mathrm{C}\left\{{ }^{1} \mathrm{H}\right\}$ NMR $\left(\mathrm{CD}_{3} \mathrm{OD}, 175 \mathrm{MHz}\right): \delta$ 220.2, 182.2, 172.5, 172.2, 139.2, 124.6, 87.9, 80.0, 77.5, 67.2, 65.5, 53.3, 51.4, 51.2, 45.4, 41.6, 39.8, 35.4, 27.1, 26.5, 25.7, 23.2, 22.6, 20.8, 20.8, 20.6; HRMS (ESI-TOF) $\mathrm{m} / \mathrm{z}:[\mathrm{M}+\mathrm{Na}]^{+}$Calcd for $\mathrm{C}_{27} \mathrm{H}_{36} \mathrm{O}_{8} \mathrm{Na}, 511.2308$; Found 511.2306.

Phosphatase Enzyme Inhibition Assays. Recombinant human phosphatase CDC25B, TCPTP, SHP1, MEG2, SHP2, PTP1B, and CD45 were expressed in Escherichia coli and purified. The enzyme inhibition assays were measured using $p$ nitrophenyl phosphate (pNPP) as a substrate in a 96-well plate with a final volume of $100 \mu \mathrm{L}$. Human recombinant CD25B, TCPTP, SHP1, MEG2, SHP2, PTP1B, or CD45 $(0.05 \mu \mathrm{g})$ in $50 \mu \mathrm{L}$ reaction buffer (pH 6.5) containing $50 \mathrm{mM}$ HEPES, 100 
$\mathrm{mM} \mathrm{NaCl}, 1 \mathrm{mM}$ EDTA, and $1 \mathrm{mM}$ dithiothreitol (DTT) and test compounds were added to each well of a 96-well plate. $\mathrm{Na}_{3} \mathrm{VO}_{4}$ was used as the positive control and DMSO as the negative control to evaluate the high-throughput screening (HTS) system. After preincubation for $15 \mathrm{~min}$ at room temperature, $50 \mu \mathrm{L}$ of reaction buffer containing $50 \mathrm{mM}$ pNPP was added and incubated at $37{ }^{\circ} \mathrm{C}$ for 60 min. The phosphatase activity was determined by measuring the absorbance at $405 \mathrm{~nm}$ for the amount of produced $p$-nitrophenol. The concentration used in the study for the tested compounds was $6.7 \mu \mathrm{g} / \mathrm{mL}$. Each compound was assayed in triplicate. Because their inhibition ratios were low, their $\mathrm{IC}_{50}$ values were not further tested.

HLE and Trypsin Enzyme Inhibition Assays. The inhibiting activity towards human leukocyte elastase (HLE) was measured according to the previous method. ${ }^{1}$ Briefly, $50 \mu \mathrm{l}$ reaction buffer ( $N$-(2-hydroxyethyl) piperazine- $N$ '-2-ethanesulfonic acid (HEPES) pH 6.5, 0.5 M NaCl) containing 0.0015 unit HLE (one unit will release one nanomole of $p$-nitrophenol per second from BOC-L-alanine $p$-nitrophenyl ester at $\mathrm{pH}$ 6.5 at $37^{\circ} \mathrm{C}$ ) was incubated with $2 \mu \mathrm{L}$ test compounds (dissolved in DMSO) or DMSO (as blank control) in 96-well plate at room temperature for $15 \mathrm{~min}$, the reaction was started by addition of $50 \mu \mathrm{l}$ substrate solution containing a $300 \mu \mathrm{M}$ final concentration of $\mathrm{N}$-MeO-Suc-Ala-Ala-Pro-Val- $p \mathrm{NA}$. After incubation at $37^{\circ} \mathrm{C}$ for $30 \mathrm{~min}$, the hydrolysis product of $p$-nitroaniline was measured by the optical density (OD) at 405 $\mathrm{nm}$ using a microplate reader. The concentration used in the study for the tested compounds was $40 \mu \mathrm{g} / \mathrm{mL}$.

The activity of trypsin was assayed with the same procedure as that of HLE, except for using $300 \mu \mathrm{M}$ Bz-Ile-Glu-Gly-Arg- $p$ NA as substrate, and the buffer used was $0.05 \mathrm{M}$ Tris- $\mathrm{HCl}$ containing $0.15 \mathrm{M} \mathrm{NaCl}, \mathrm{pH}$ 7.2.

Cathepsin L Enzyme Inhibition Assay. The procedure was the same as described in the literature. ${ }^{2}$ Briefly, $20 \mu \mathrm{L}$ of $2 \mu \mathrm{M}$ recombinant human cathepsin L (rhCTSL) (Sigma-Aldrich Inc) and $60 \mu \mathrm{l}$ of buffer (400 mM NaOAc, 4 mM EDTA, pH 5.5) containing the tested compounds were incubated at $37{ }^{\circ} \mathrm{C}$ for $4 \mathrm{~h}$. Then the rhCTSL/compound mixtures were incubated further with $20 \mu \mathrm{L}$ of $50 \mu \mathrm{M}$ (Z-PheArg)2-R110. After $4 \mathrm{~h}$, the fluorescence was tested by a fluorometer with excitation at $488 \mathrm{~nm}$ and emission at $510 \mathrm{~nm}$. The concentration used in the study for the tested 
compounds was $40 \mu \mathrm{g} / \mathrm{mL}$. Because their inhibition ratios were low, their $\mathrm{IC}_{50}$ values were not further tested.

Xanthine Oxidase Inhibition Assay. Xanthine oxidase (XO) activity was determined using the method of continuous spectrophotometric rate measurements as described in the literature. ${ }^{3}$ The reaction mixture contained uric acid in $67 \mathrm{mM}$ phosphate buffer (pH 7.4) and $20 \mathrm{nM} \mathrm{XO}$ with an activity of $5 \mathrm{mU} / \mathrm{mL}$, with or without the tested compounds. After pre-incubating the mixture for 1 to $5 \mathrm{~min}$ at $25^{\circ} \mathrm{C}, 50 \mu \mathrm{M}$ xanthine was added to initiate the formation of uric acid, and the increase of absorption of uric acid at $295 \mathrm{~nm}$ was monitored. Allopurinol was used as a positive control. All test compounds were dissolved in an aqueous solution. The concentration used in the study for the tested compounds was $40 \mu \mathrm{g} / \mathrm{mL}$.

ECD calculation methods. Molecular Merck force field (MMFF) and DFT/TDDFT calculations were performed with Spartan'14 software package (Wavefunction Inc., Irvine, CA, USA) and Gaussian 09 program package, ${ }^{4}$ respectively, using default grids and convergence criteria. MMFF conformational search generated low-energy conformers within a $10 \mathrm{kcal} / \mathrm{mol}$ energy window were subjected to geometry optimization using DFT method at the B3LYP/6-311G(d,p) level. Frequency calculations were run at the same level to estimate their relative thermal free energies $(\Delta G)$ at $298.15 \mathrm{~K}$. Energies of the low-energy conformers in $\mathrm{MeOH}$ were re-calculated at the B3LYP/def2-TZVP level. Solvent effects were taken into account by using polarizable continuum model (PCM). The TDDFT calculations were performed using the hybrid M06 and BMK and the long-range corrected hybrid CAM-B3LYP functionals, and the Ahlrichs' basis set TZVP (triple zeta valence plus polarization). The ECD spectra were generated by the program SpecDis $^{5}$ using a Gaussian band shape with $0.24 \sim 0.38 \mathrm{eV}$ exponential half-width from dipole-length dipolar and rotational strengths. The equilibrium population of each conformer at 298.15K was calculated from its relative free energies using Boltzmann statistics. The calculated spectra of compounds 1-3 were generated from the low-energy conformers according to the Boltzmann weighting of each conformer in $\mathrm{MeOH}$ solution.

\section{X-ray crystallographic data of 1}

Penicimeroterpenoid A (1) was crystallized from methanol to give colorless 
crystals. Crystal data for 1 : $\mathrm{C}_{28} \mathrm{H}_{36} \mathrm{O}_{9}(M=516.57 \mathrm{~g} / \mathrm{mol})$ : orthorhombic, space group $\mathrm{P} 22_{12} 2{ }_{1}$ (no. 19), $a=7.21270(10) \AA, b=15.2189(2) \AA, c=23.6427(5) \AA, V=$ 2595.24(7) $\AA^{3}, Z=4, T=99.9(8) \mathrm{K}, \mu(\mathrm{CuK \alpha})=0.813 \mathrm{~mm}^{-1}$, Dcalc $=1.322 \mathrm{~g} / \mathrm{cm}^{3}$, 12571 reflections measured $\left(7.478^{\circ} \leq 2 \theta \leq 148.302^{\circ}\right), 5088$ unique $\left(R_{\text {int }}=0.0386\right.$, $\mathrm{R}_{\text {sigma }}=0.0453$ ) which were used in all calculations. The final $R_{1}$ was 0.0424 (I > $2 \sigma(\mathrm{I}))$ and $w R_{2}$ was 0.1128 (all data). The Flack parameter is -0.02(10). Crystallographic data for penicimeroterpenoid $\mathrm{A}$ in this paper have been deposited with the Cambridge Crystallographic Data Centre as supplementary publication number CCDC 1987151.

\section{References}

(1) Zheng, Z.; Zhang, S.; Lu, X.; Ma, Y.; Fan, Y.; Shi, Y.; Dong, A.; Duan, B. Biol. Pharm. Bull. 2012, 35, 2247-2251.

(2) Zhou, N.; Pan, T.; Zhang, J.; Li, Q.; Zhang, X.; Bai, C.; Huang, F.; Peng, T.; Zhang, J.; Liu, C.; Tao, L.; Zhang, H. J. Biol. Chem. 2016, 291, 9218-9232.

(3) Lü, J. M.; Yao, Q.; Chen, C. Biochem Pharmacol. 2013, 86, doi:10.1016/j.bcp.2013.08.011.

(4) Frisch, M. J.; Trucks, G. W.; Schlegel, H. B.; Scuseria, G. E.; Robb, M. A.; Cheeseman, J. R.; Scalmani, G.; Barone, V.; Mennucci, B.; Petersson, G. A.; Nakatsuji, H.; Caricato, M.; Li, X.; Hratchian, H. P.; Izmaylov, A. F.; Bloino, J.; Zheng, G.; Sonnenberg, J. L.; Hada, M.; Ehara, M.; Toyota, K.; Fukuda, R.; Hasegawa, J.; Ishida, M.; Nakajima, T.; Honda, Y.; Kitao, O.; Nakai, H.; Vreven, T.; Montgomery, J. A.; Peralta, J. E.; Ogliaro, F.; Bearpark, M.; Heyd, J. J.; Brothers, E.; Kudin, K. N.; Staroverov, V. N.; Keith, T.; Kobayashi, R.; Normand, J.; Raghavachari, K.; Rendell, A.; Burant, J. C.; Iyengar, S. S.; Tomasi, J.; Cossi, M.; Rega, N.; Millam, J. M.; Klene, M.; Knox, J. E.; Cross, J. B.; Bakken, V.; Adamo, C.; Jaramillo, J.; Gomperts, R.; Stratmann, R. E.; Yazyev, O.; Austin, A. J.; Cammi, R.; Pomelli, C.; Ochterski, J. W.; Martin, R. L.; Morokuma, K.; Zakrzewski, V. G.; Voth, G. A.; Salvador, P.; Dannenberg, J. J.; Dapprich, S.; Daniels, A. D.; Farkas, O.; Foresman, J. B.; Ortiz, J. V.; Cioslowski, J.; Fox, D. J. Gaussian 09, revision C.01. Gaussian, Inc.: Wallingford CT, 2010.

(5) Bruhn, T.; Schaumlöffel, A.; Hemberger, Y.; Bringmann, G. Chirality 2013, 25, 243-249. 


\begin{tabular}{|c|c|c|c|c|c|c|}
\hline \multirow{2}{*}{ No. } & \multicolumn{2}{|l|}{1} & \multicolumn{2}{|l|}{2} & \multicolumn{2}{|l|}{3} \\
\hline & $\delta_{\mathrm{H}}$ & $\delta_{\mathrm{C}}$ & $\delta_{\mathrm{H}}$ & $\delta_{\mathrm{C}}$ & $\delta_{\mathrm{H}}$ & $\delta_{\mathrm{C}}$ \\
\hline 1 & Ha: $1.74(\mathrm{~m}), \mathrm{Hb}: 1.66$ (m) & 22.7 & $\begin{array}{l}\text { Ha: } 2.17 \mathrm{dd}(13.9,3.6) \\
\text { Hb: } 1.41(\mathrm{~m})\end{array}$ & 21.9 & Ha: $2.16(\mathrm{~m}), \mathrm{Hb}: 1.32(\mathrm{~m})$ & 22.6 \\
\hline 2 & Ha: $2.03(\mathrm{~m}), \mathrm{Hb}: 1.33(\mathrm{~m})$ & 20.9 & $1.73(\mathrm{~m})$ & 23.1 & $1.71(\mathrm{~m})$ & 23.2 \\
\hline 3 & $4.57(\mathrm{~d}, 2.5)$ & 77.2 & 4.65 (br s) & 77.3 & $4.63(\mathrm{t}, 2.4)$ & 77.5 \\
\hline 4 & & 35.8 & & 35.6 & & 35.4 \\
\hline 5 & 1.89 (overlap) & 61.5 & $1.90($ br s) & 57.8 & 2.53 (br s) & 53.3 \\
\hline 6 & $4.95 \mathrm{~d}(4.7)$ & 78.9 & $4.84 \mathrm{~d}(4.6)$ & 78.5 & $4.84 \mathrm{~d}(4.2)$ & 80.0 \\
\hline 7 & $\begin{array}{l}2.85 \text { dd }(14.4,4.9) \\
1.90 \text { overlap }\end{array}$ & 37.0 & $\begin{array}{l}2.40 \mathrm{~d}(14.2) \\
1.99 \mathrm{dd}(14.2,4.6)\end{array}$ & 39.2 & $\begin{array}{l}2.98 \mathrm{~d}(14.6) \\
2.08 \mathrm{dd}(14.6,4.8)\end{array}$ & 39.8 \\
\hline 8 & & 47.4 & & 41.6 & & 41.6 \\
\hline 9 & $2.31 \mathrm{~d}(3.4)$ & 53.7 & 2.48 (br s) & 52.3 & $3.01(\mathrm{br} \mathrm{s})$ & 51.2 \\
\hline 10 & & 45.8 & & 45.4 & & 45.4 \\
\hline 11 & $3.35 \mathrm{~d}(3.4)$ & 55.7 & 5.77 (br s) & 122.9 & 5.77 (br s) & 124.6 \\
\hline 12 & & 129.7 & & 141.7 & & 139.2 \\
\hline 13 & & 132.9 & & 52.7 & & 65.5 \\
\hline 14 & & 76.4 & & 83.5 & & 67.2 \\
\hline 15 & & 207.1 & & 211.1 & & \\
\hline 16 & & 84.1 & & 88.5 & & 87.9 \\
\hline 17 & & 197.3 & & & & 220.2 \\
\hline 18 & $1.41(\mathrm{~s})$ & 26.4 & $1.19(\mathrm{~s})$ & 17.6 & $1.53(\mathrm{~s})$ & 25.7 \\
\hline 19 & & 170.4 & & 169.3 & & 172.5 \\
\hline 20 & $1.75(\mathrm{~s})$ & 18.9 & $1.38(\mathrm{~s})$ & 17.1 & $1.55(\mathrm{~s})$ & 20.6 \\
\hline 21 & $1.83(\mathrm{~s})$ & 17.4 & $1.83(\mathrm{~s})$ & 22.2 & $1.83(\mathrm{~s})$ & 20.8 \\
\hline 22 & $1.21(\mathrm{~s})$ & 22.9 & $1.11(\mathrm{~s})$ & 22.4 & $0.78(\mathrm{~s})$ & 27.1 \\
\hline 23 & & 180.6 & & 181.2 & & 182.2 \\
\hline 24 & $0.94(\mathrm{~s})$ & 26.5 & $0.88(\mathrm{~s})$ & 22.7 & $0.88(\mathrm{~s})$ & 22.6 \\
\hline 25 & $0.85(\mathrm{~s})$ & 22.5 & $0.98(\mathrm{~s})$ & 26.5 & $0.95(\mathrm{~s})$ & 26.5 \\
\hline 26 & & 172.1 & & 172.0 & & 172.2 \\
\hline 27 & $2.00(\mathrm{~s})$ & 20.8 & $2.06(\mathrm{~s})$ & 20.8 & $2.04(\mathrm{~s})$ & 20.8 \\
\hline 28 & $3.74(\mathrm{~s})$ & 52.3 & $3.70(\mathrm{~s})$ & 53.5 & $3.75(\mathrm{~s})$ & 51.4 \\
\hline
\end{tabular}

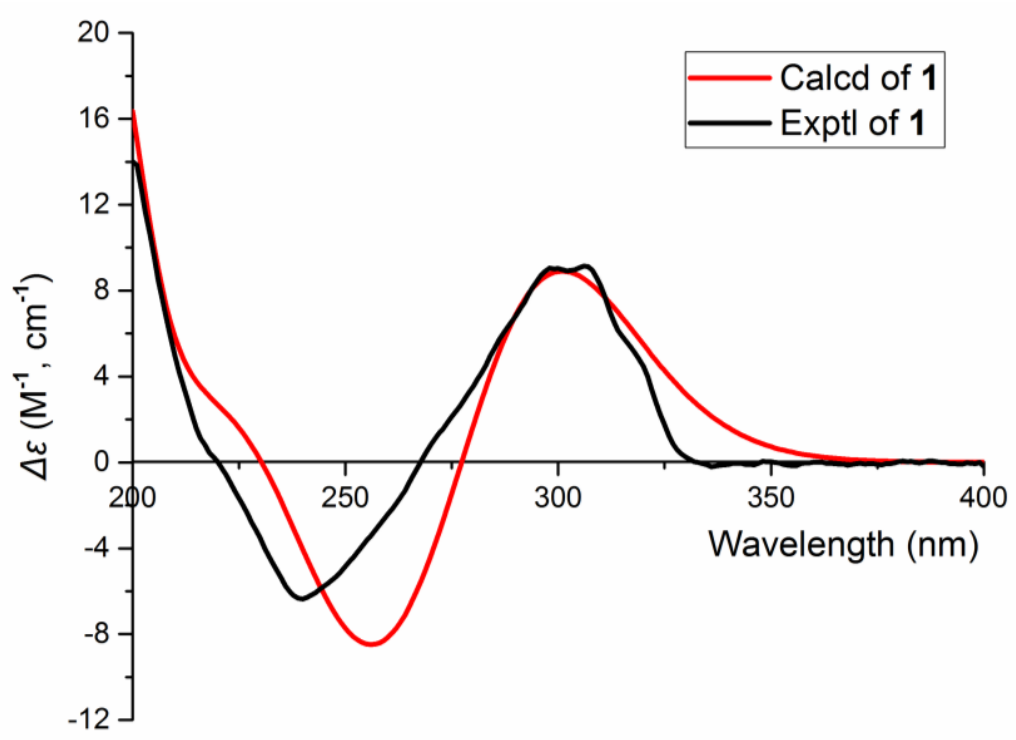

Figure S1. Comparison of the calculated ECD spectrum of $3 S, 5 R, 6 S, 8 S, 9 R, 10 R, 11 R, 14 R, 16 R$ at the $\mathrm{B} 3 \mathrm{LYP} / 6-311 \mathrm{G}(\mathrm{d}, \mathrm{p})$ level with the experimental ECD spectrum of 1 in $\mathrm{MeOH}, \sigma=0.38 \mathrm{eV}$, shift $=+0 \mathrm{~nm}$. 

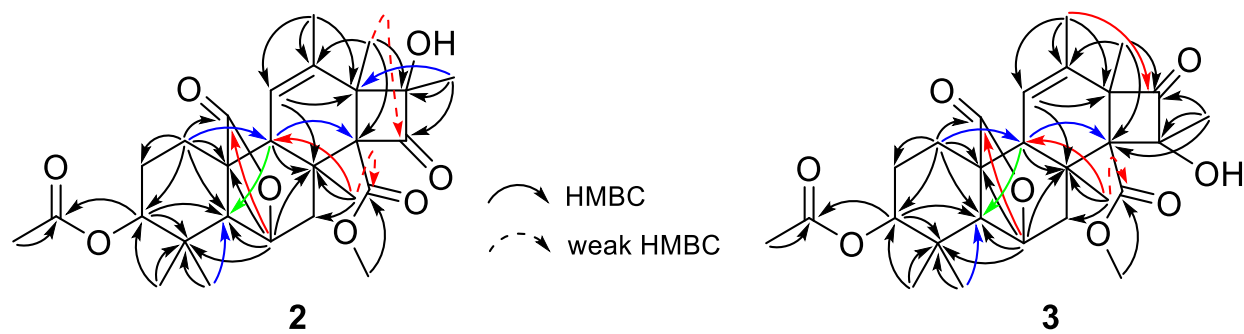

Figure S2. Key HMBC correlations of $\mathbf{2}$ and $\mathbf{3}$.
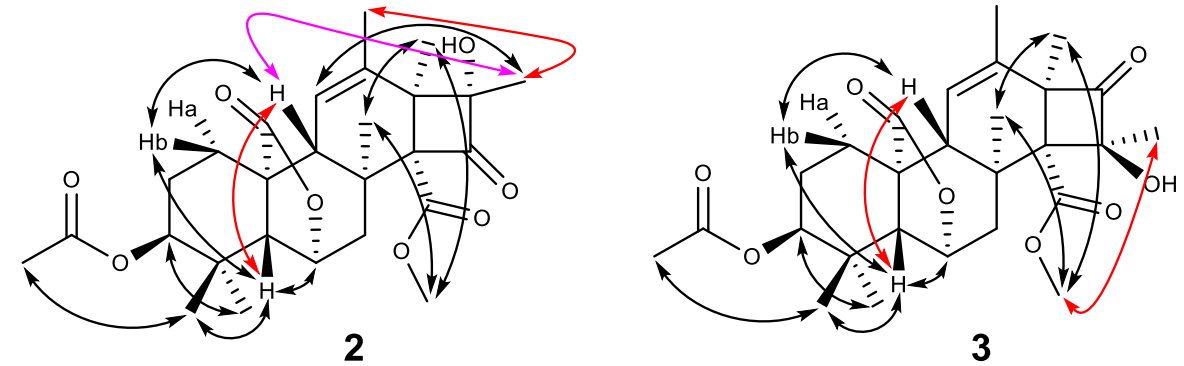

Figure S3. Key NOESY correlations of 2 and 3.

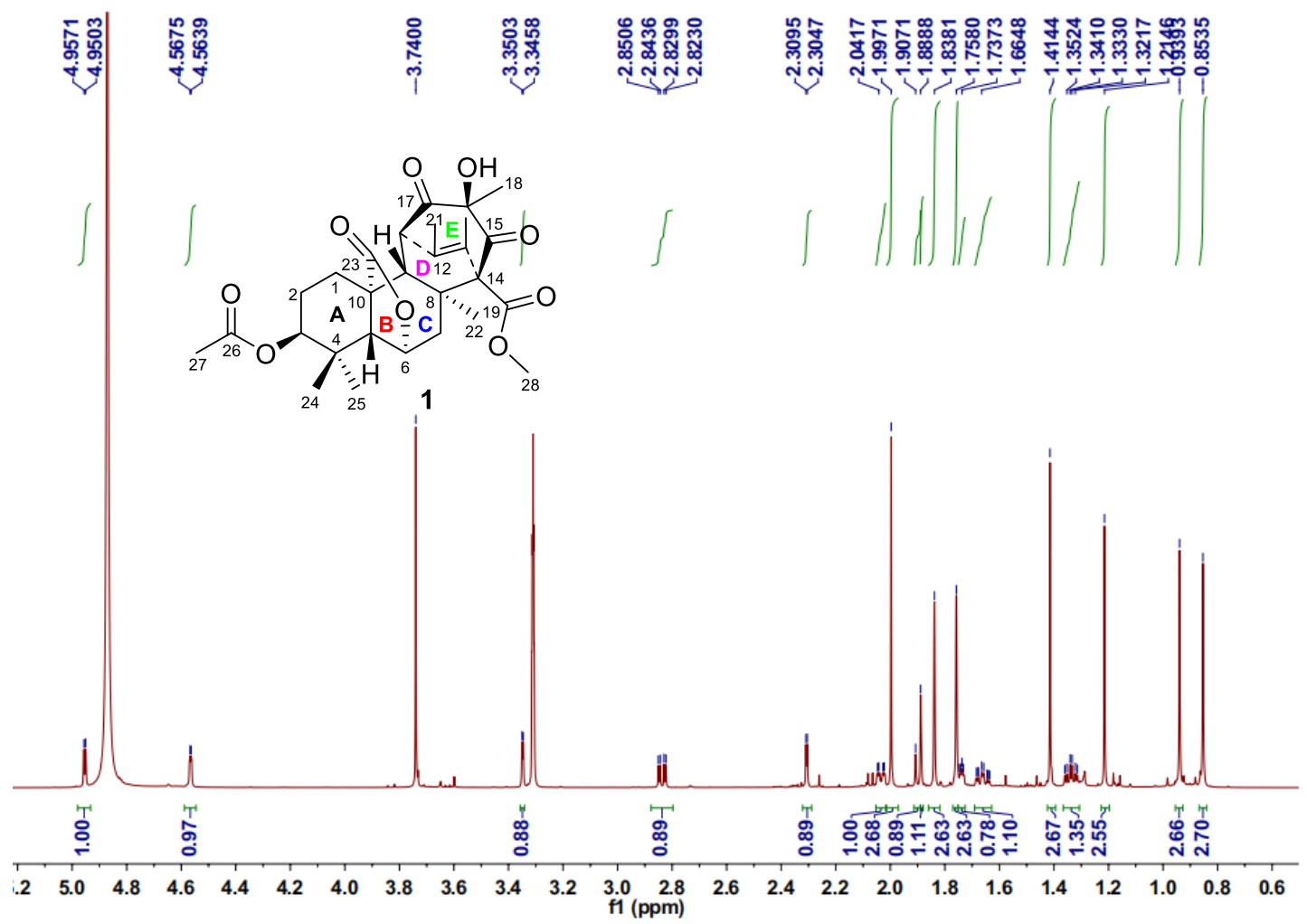

Figure S4. ${ }^{1} \mathrm{H}$ NMR spectrum of 1 in methanol- $d_{4}(700 \mathrm{MHz})$. 

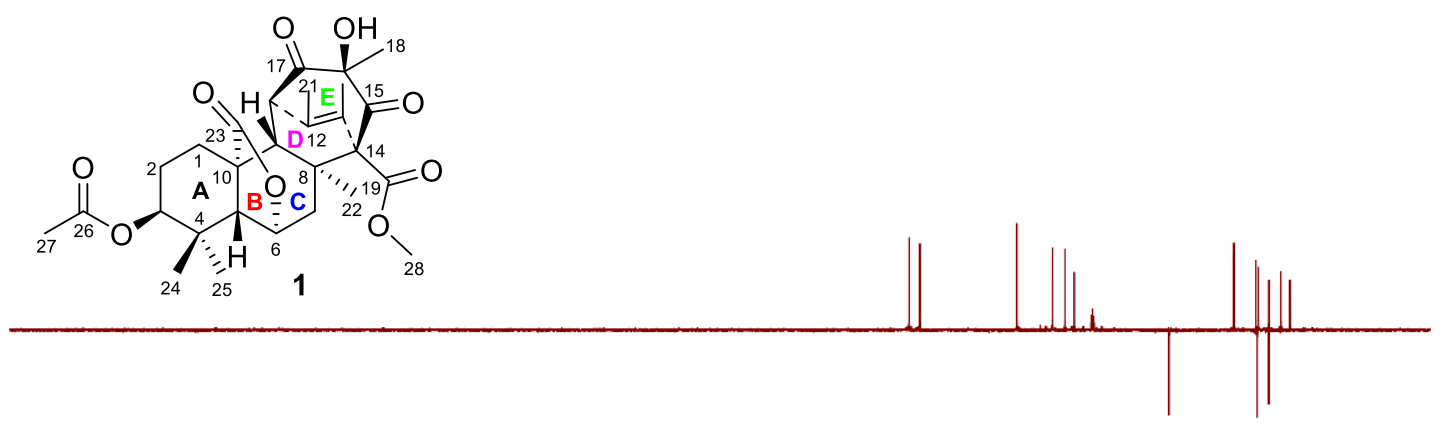

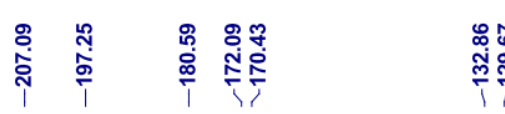

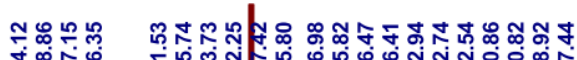

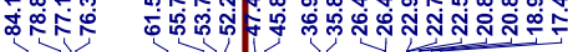

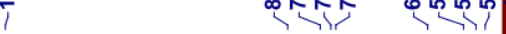

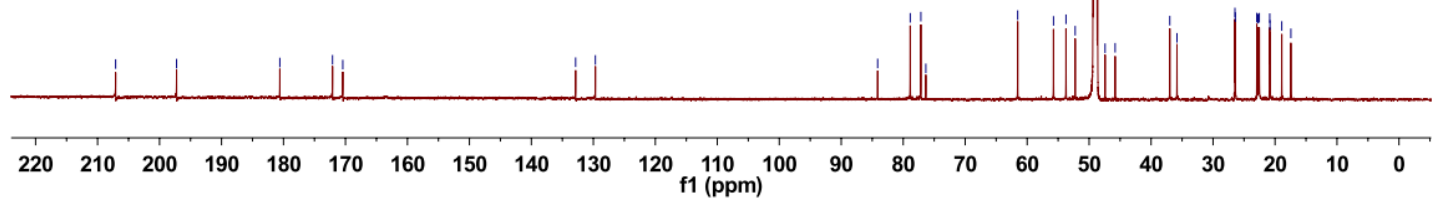

Figure S5. ${ }^{13} \mathrm{C}$ NMR and DEPT spectra of $\mathbf{1}$ in methanol- $d_{4}(175 \mathrm{MHz})$.

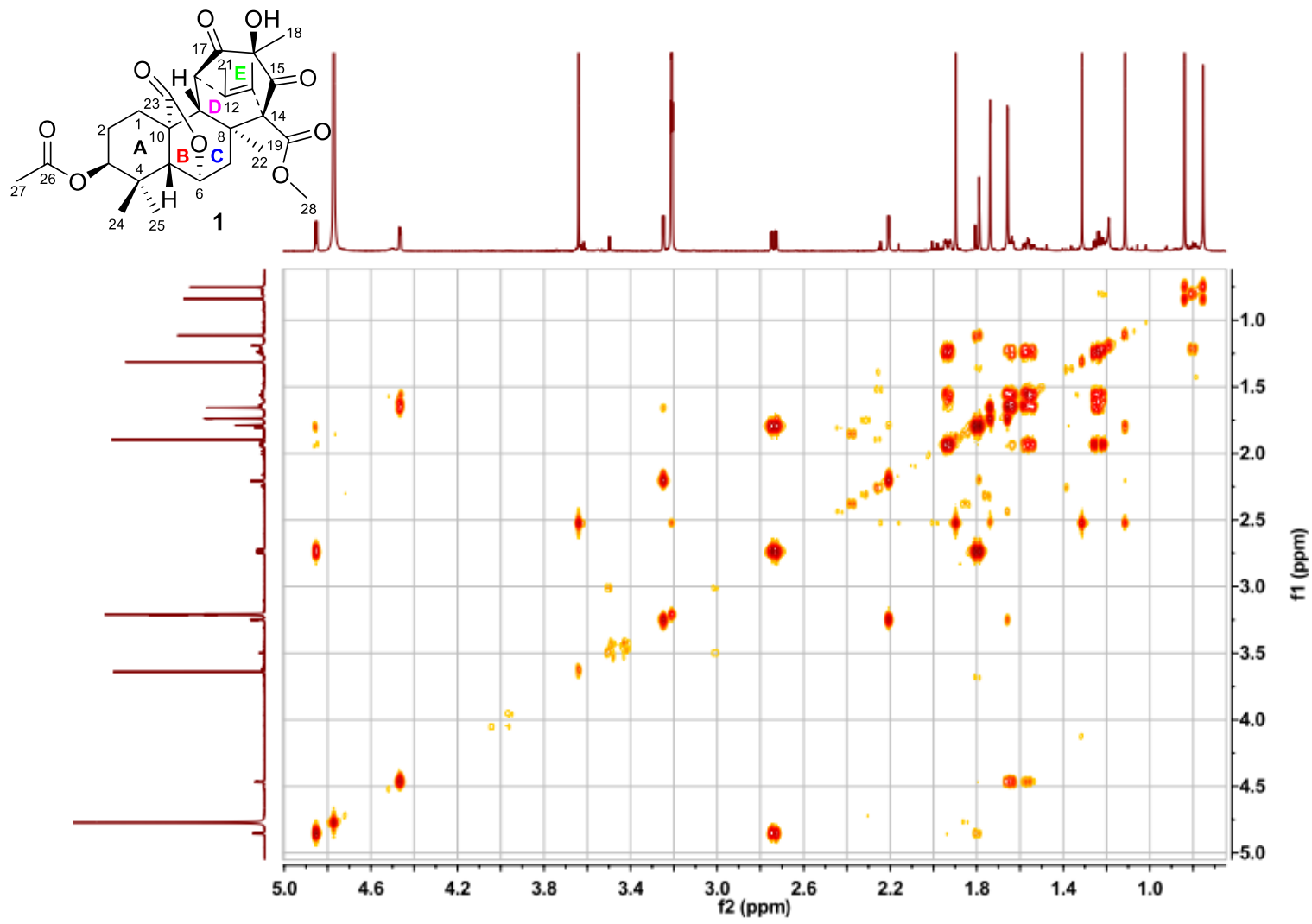

Figure S6. ${ }^{1} \mathrm{H}-{ }^{1} \mathrm{H}$ COSY spectrum of 1 in methanol- $d_{4}(700 \mathrm{MHz})$. 


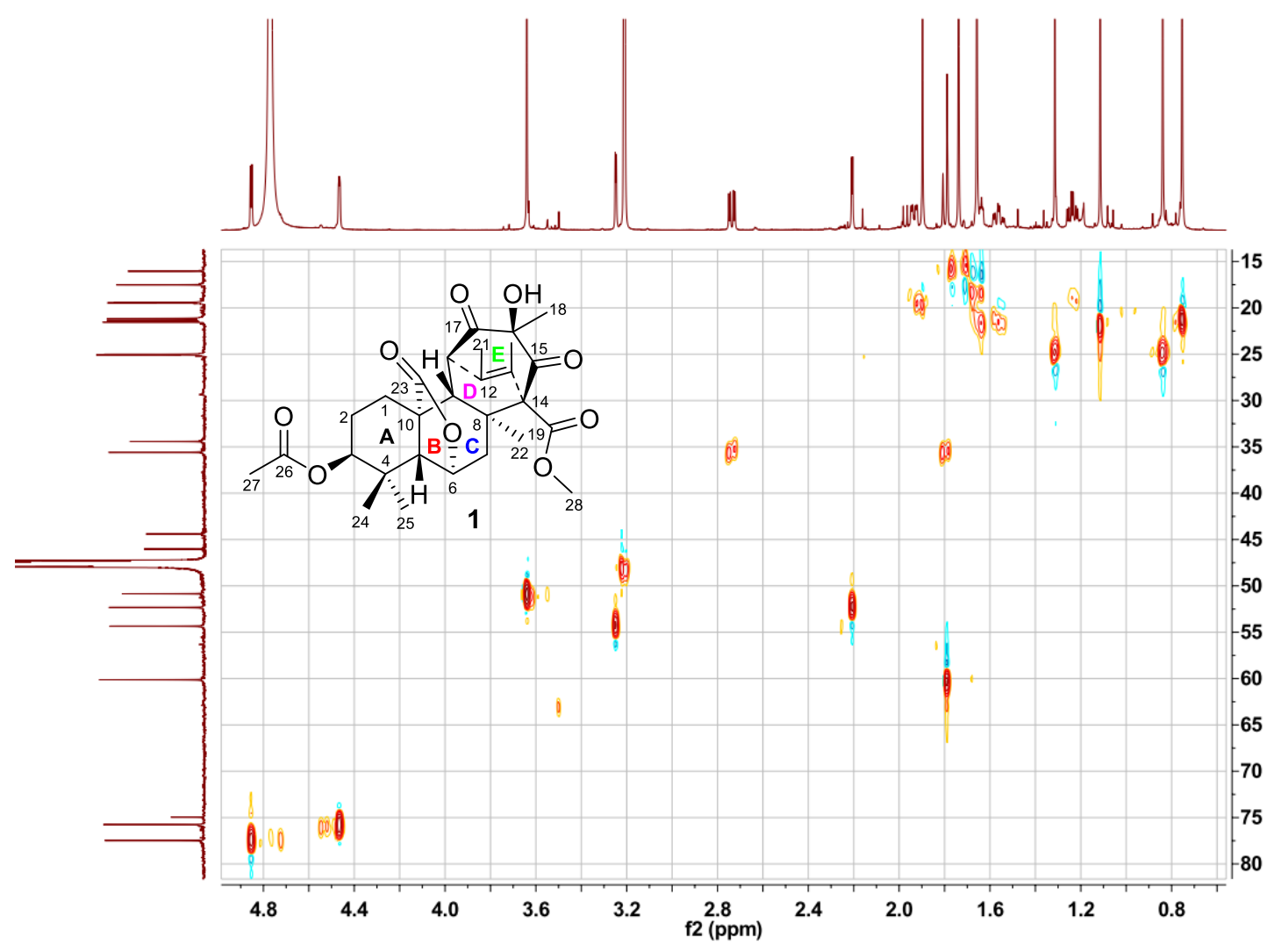

Figure S7. HSQC spectrum of 1 in methanol- $d_{4}(700 \mathrm{MHz})$.

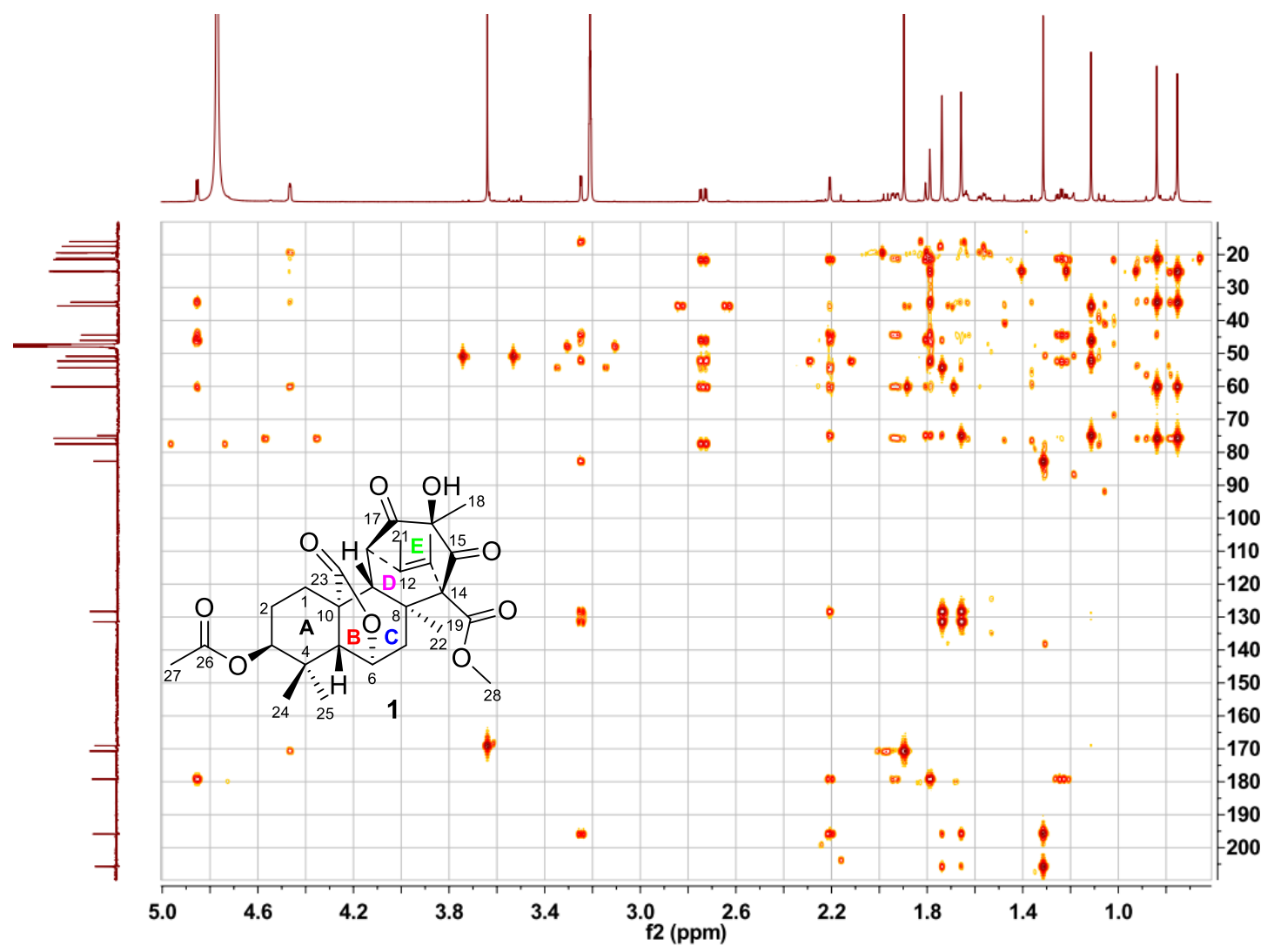

Figure S8. HMBC spectrum of 1 in methanol- $d_{4}(700 \mathrm{MHz})$. 


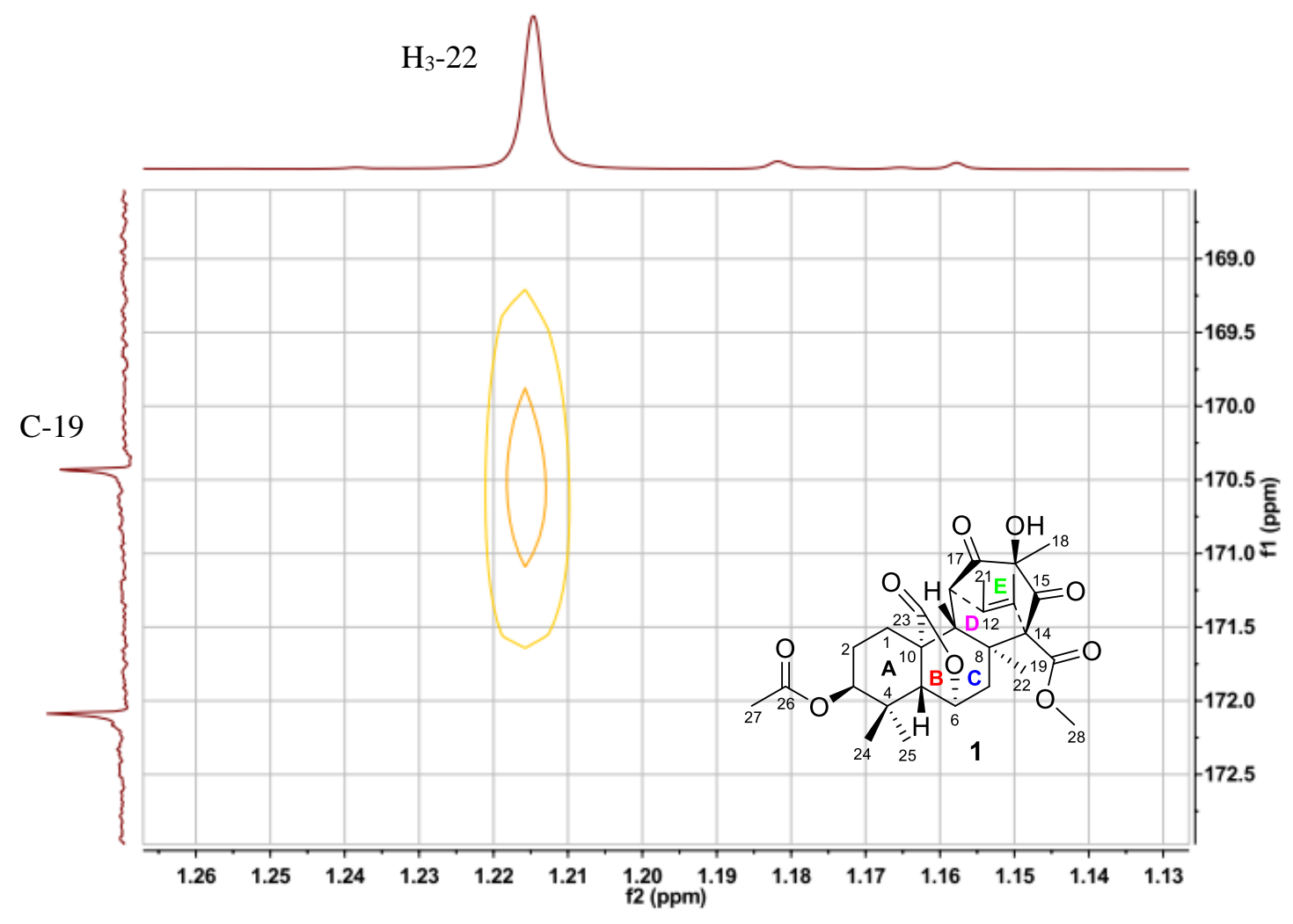

Figure S9. Enlarged HMBC spectrum of 1 in methanol- $d_{4}(700 \mathrm{MHz})$.

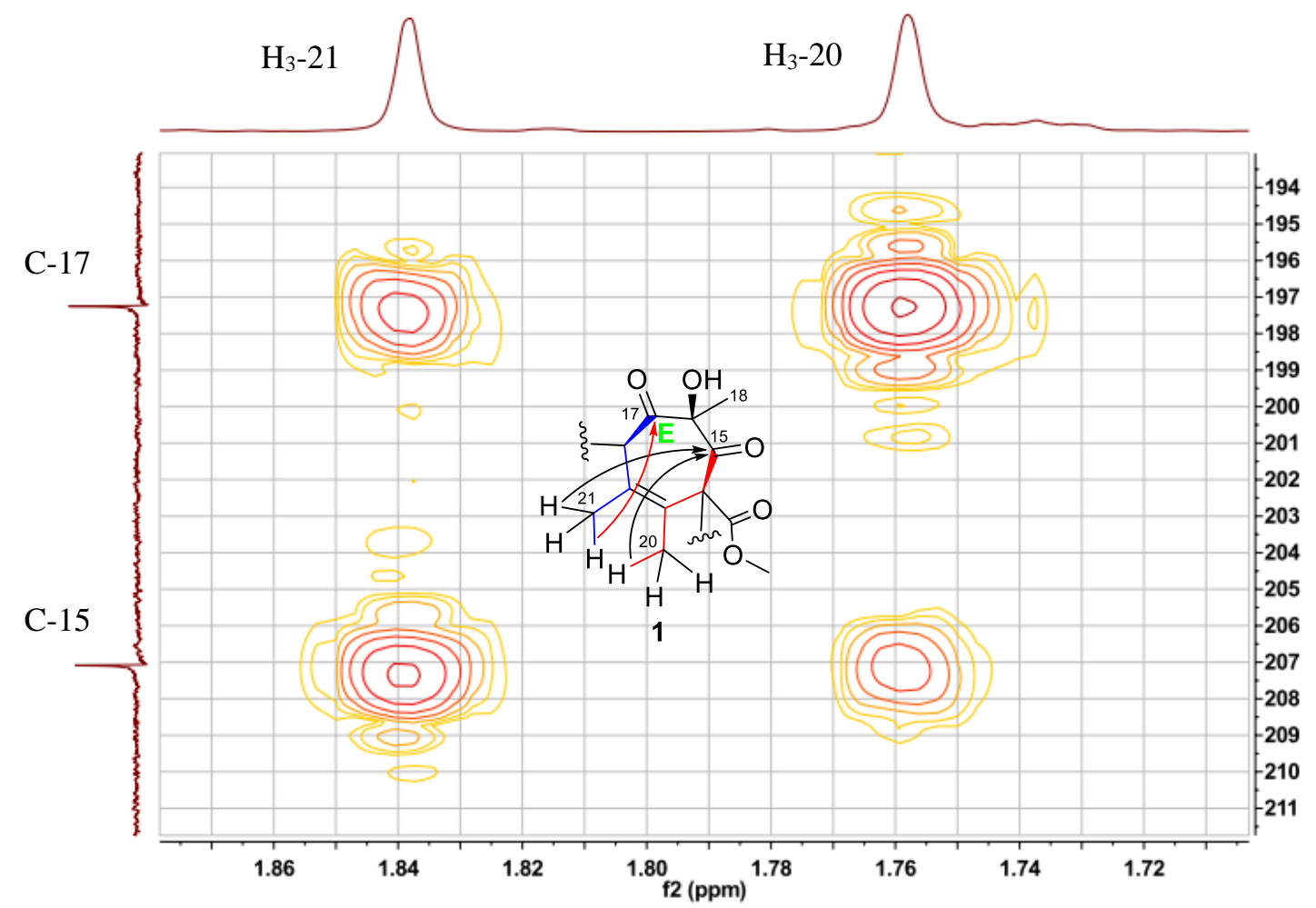

Figure S10. Enlarged HMBC spectrum of 1 in methanol- $d_{4}(700 \mathrm{MHz})$. 


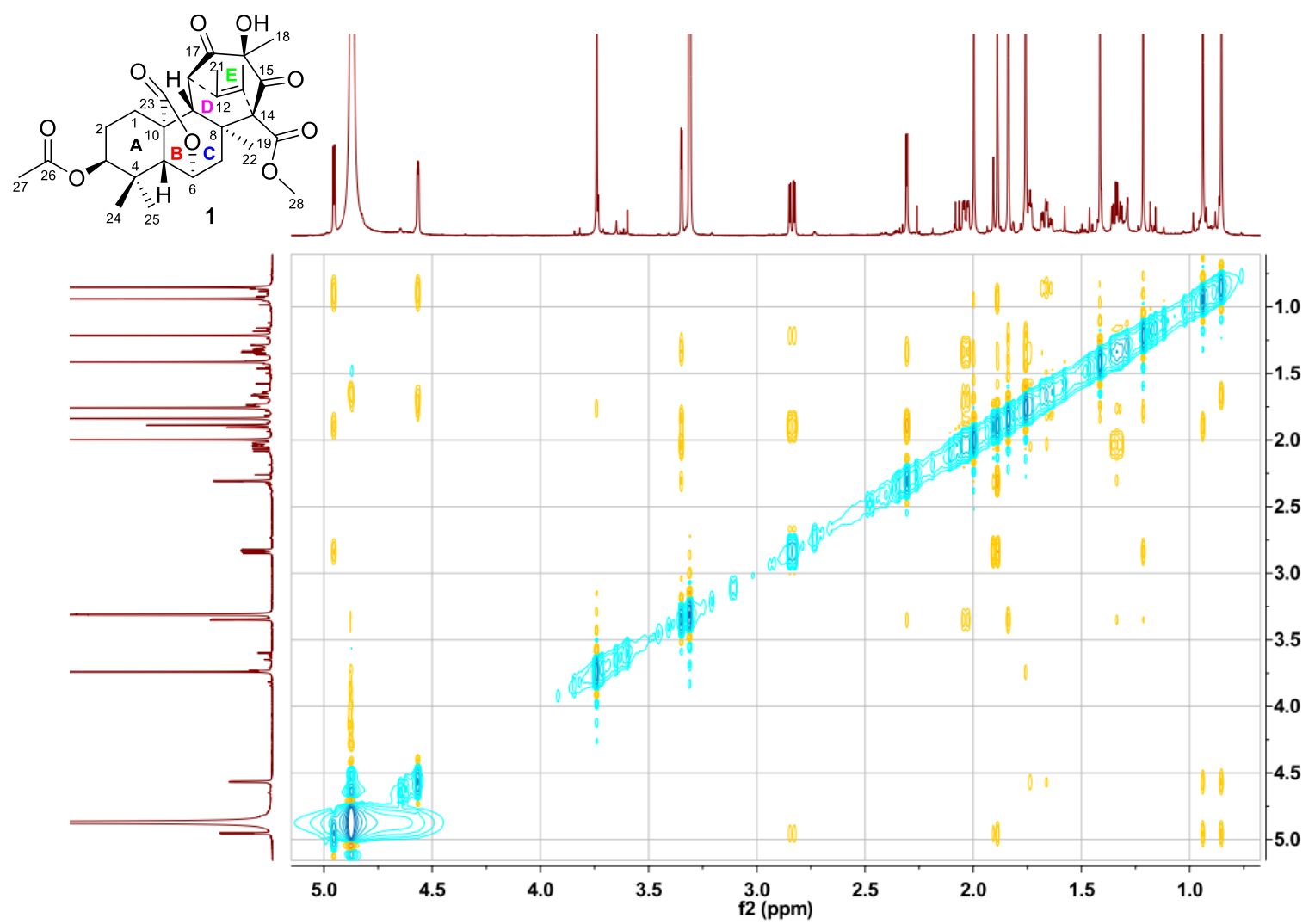

Figure S11. NOESY spectrum of 1 in methanol- $d_{4}(700 \mathrm{MHz})$.

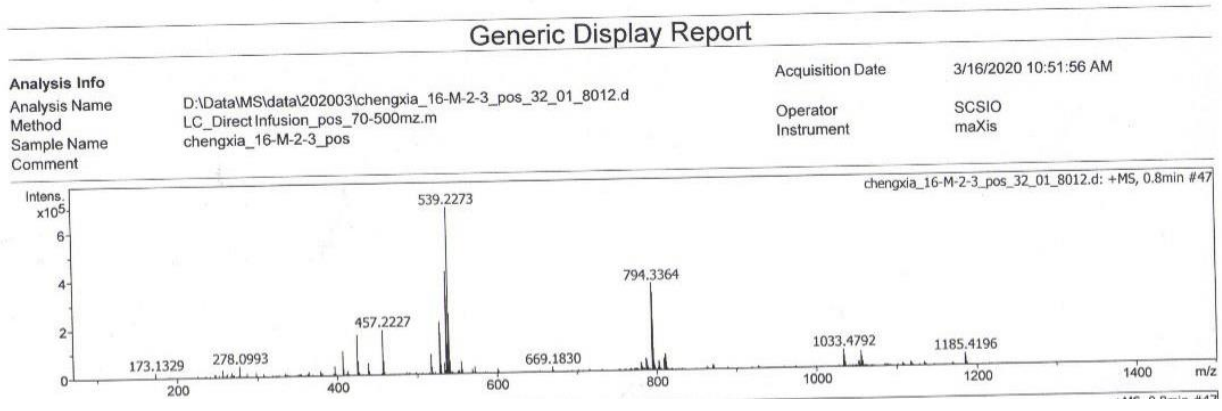

Figure S12. HRESIMS of 1. 


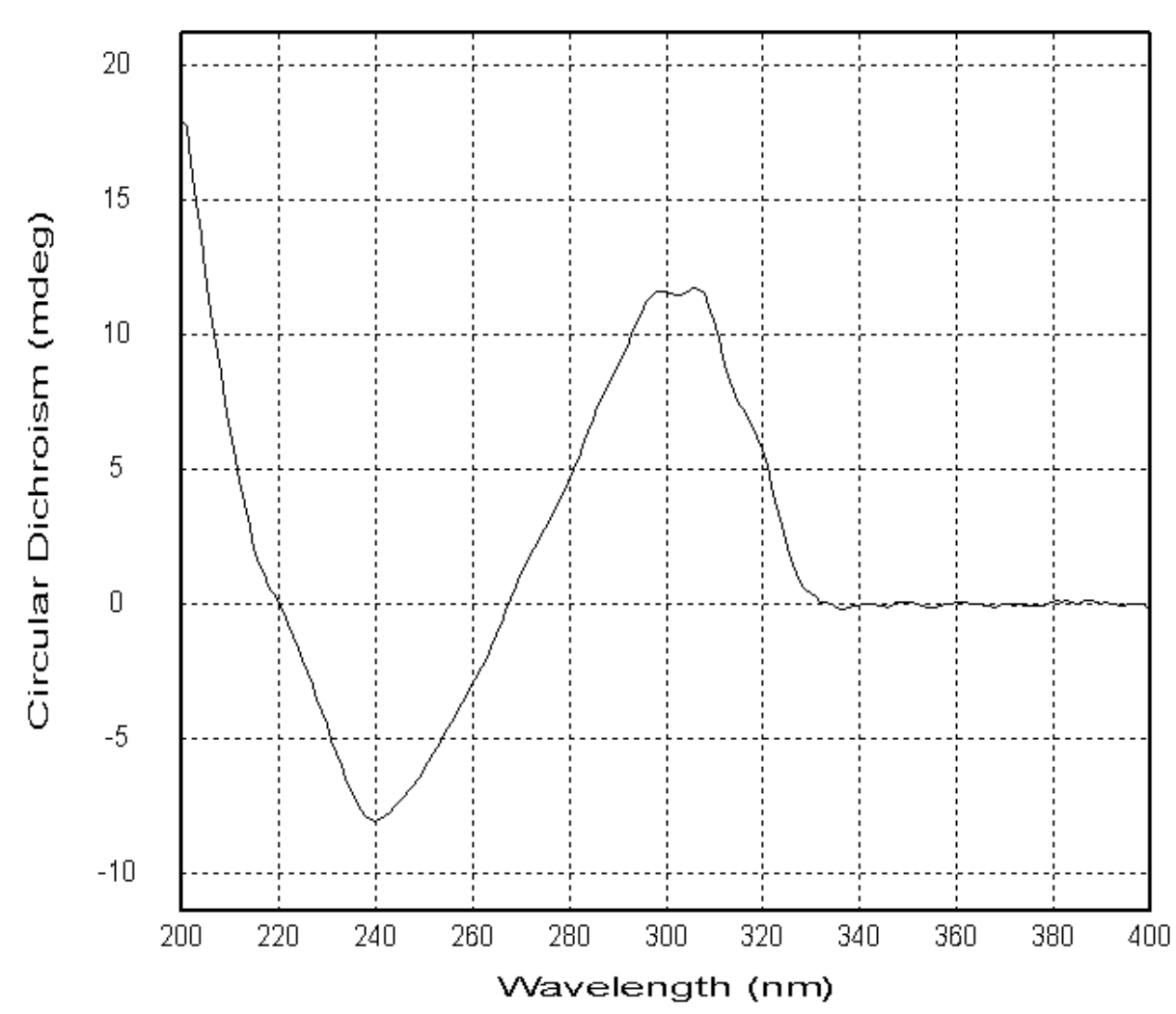

16-m-2-3.dsx::Smooth (s

Figure S13. CD spectrum of $\mathbf{1}$ in methanol

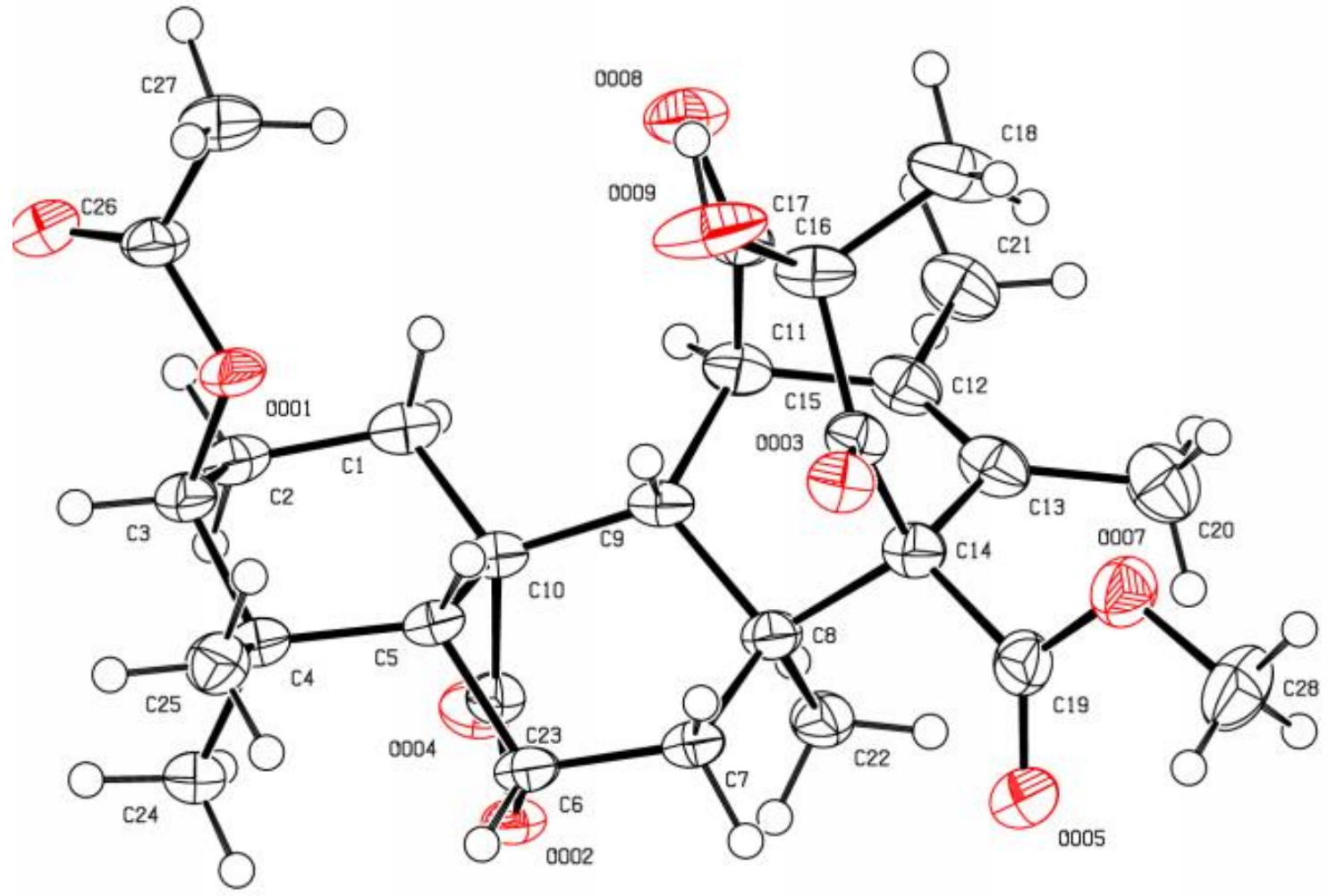

Figure S14. Ortep plot of the X-ray crystallographic data for 1 (displacement ellipsoids were drawn at the $30 \%$ probability level). 
Table S2. Crystal data and structure refinement for $\mathbf{1}$.

\begin{tabular}{|c|c|}
\hline Identification code & Compound 1 \\
\hline Empirical formula & $\mathrm{C}_{28} \mathrm{H}_{36} \mathrm{O}_{9}$ \\
\hline Formula weight & 516.57 \\
\hline Temperature/K & $99.9(8)$ \\
\hline Crystal system & orthorhombic \\
\hline Space group & $\mathrm{P} 2{ }_{1} 2_{1} 2_{1}$ \\
\hline $\mathrm{a} / \AA$ & $7.21270(10)$ \\
\hline $\mathrm{b} / \AA$ & $15.2189(2)$ \\
\hline $\mathrm{c} / \AA$ & $23.6427(5)$ \\
\hline$\alpha /{ }^{\circ}$ & 90 \\
\hline$\beta /{ }^{\circ}$ & 90 \\
\hline$\gamma /{ }^{\circ}$ & 90 \\
\hline Volume $/ \AA^{3}$ & $2595.24(7)$ \\
\hline $\mathrm{Z}$ & 4 \\
\hline$\rho_{\text {calc }} \mathrm{g} / \mathrm{cm}^{3}$ & 1.322 \\
\hline$\mu / \mathrm{mm}^{-1}$ & 0.813 \\
\hline $\mathrm{F}(000)$ & 1104.0 \\
\hline Crystal size $/ \mathrm{mm}^{3}$ & $0.15 \times 0.05 \times 0.04$ \\
\hline Radiation & $\mathrm{CuK} \alpha(\lambda=1.54184)$ \\
\hline $2 \theta$ range for data collection ${ }^{\circ}$ & 7.478 to 148.302 \\
\hline Index ranges & $\begin{array}{l}-6 \leq \mathrm{h} \leq 8,-18 \leq \mathrm{k} \leq 18,-23 \leq 1 \\
\leq 28\end{array}$ \\
\hline Reflections collected & 12571 \\
\hline Independent reflections & $\begin{array}{l}5088[\text { Rint }=0.0386, \text { Rsigma }= \\
0.0453]\end{array}$ \\
\hline Data/restraints/parameters & $5088 / 0 / 343$ \\
\hline Goodness-of-fit on $\mathrm{F}^{2}$ & 1.071 \\
\hline Final $R$ indexes $[\mathrm{I}>=2 \sigma(\mathrm{I})]$ & $\mathrm{R}_{1}=0.0424, \mathrm{wR}_{2}=0.1108$ \\
\hline Final $\mathrm{R}$ indexes [all data] & $\mathrm{R}_{1}=0.0457, \mathrm{wR}_{2}=0.1128$ \\
\hline Largest diff. peak/hole / e $\AA^{-3}$ & $0.27 /-0.18$ \\
\hline Flack parameter & $-0.02(10)$ \\
\hline
\end{tabular}




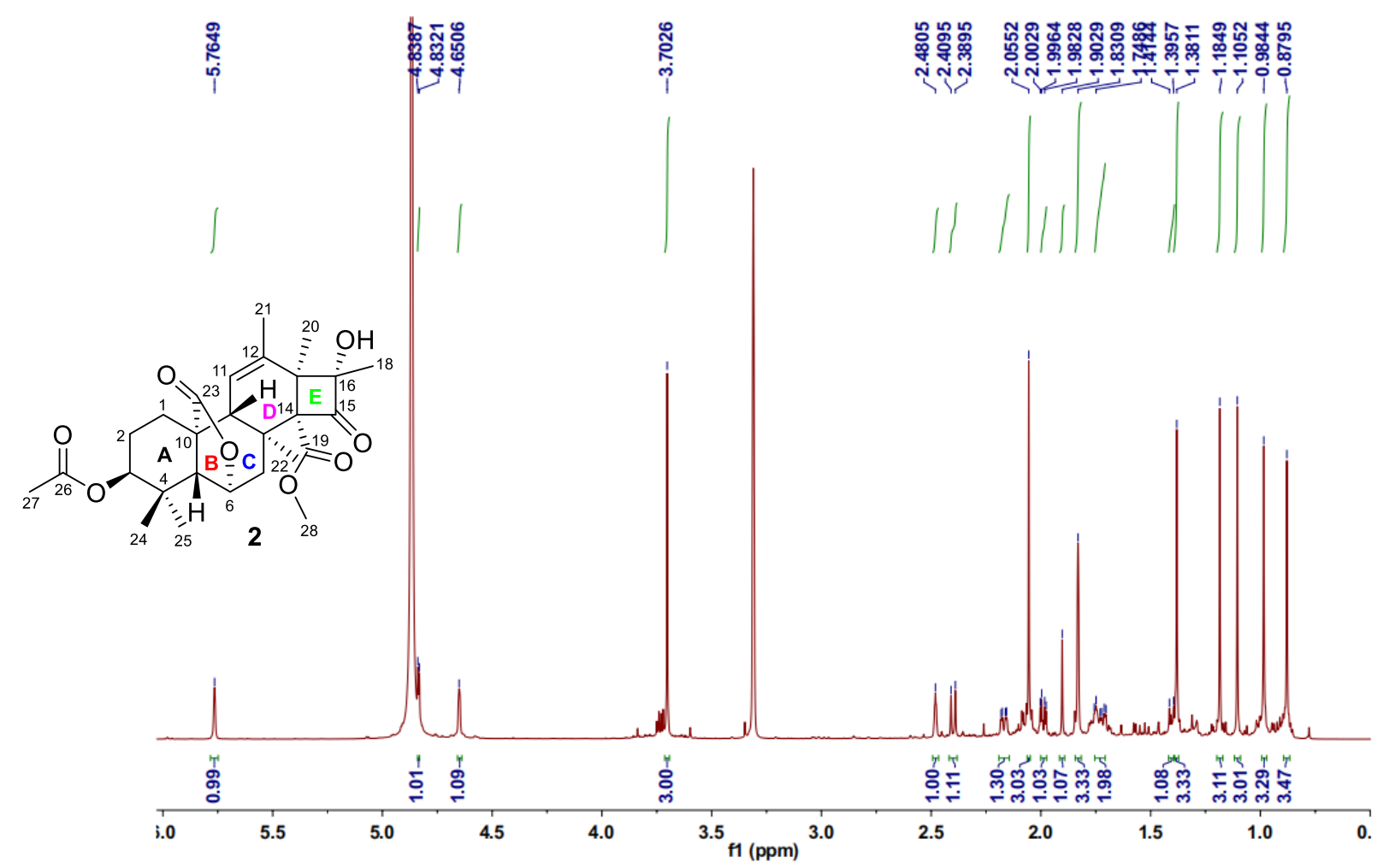

Figure S15. ${ }^{1} \mathrm{H}$ NMR spectrum of 2 in methanol- $d_{4}(700 \mathrm{MHz})$.
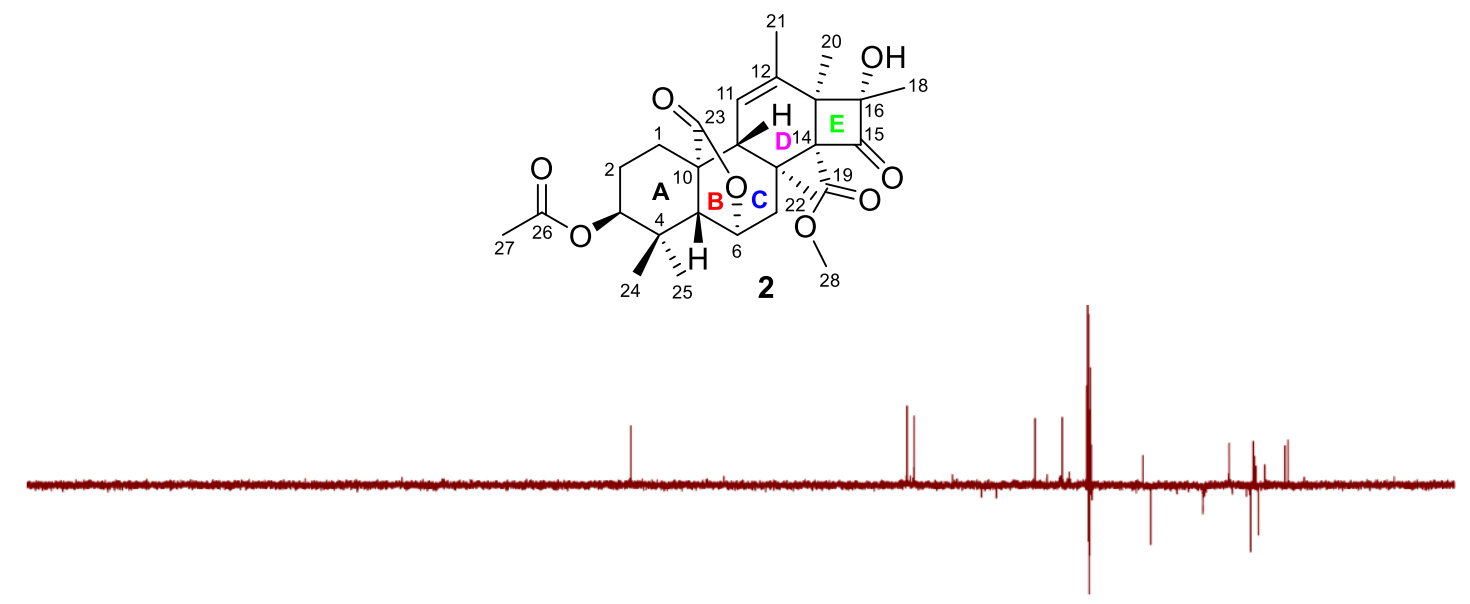

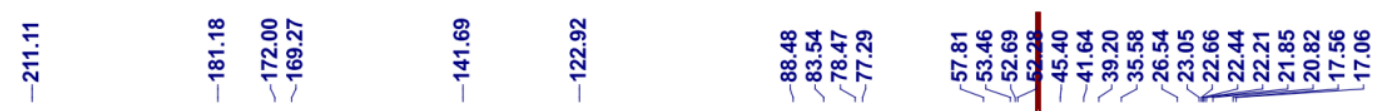

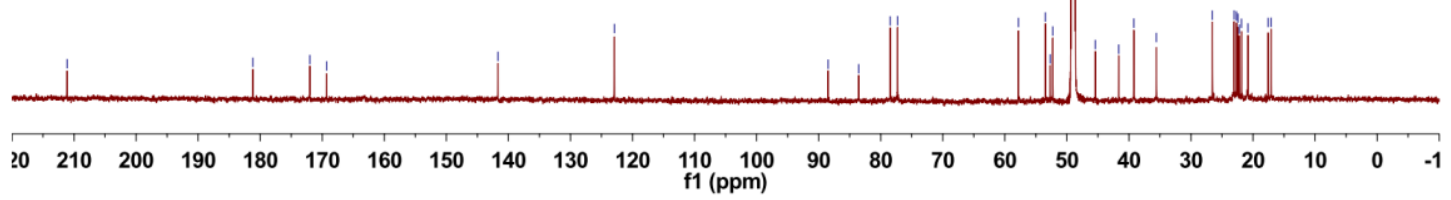

Figure S16. ${ }^{13} \mathrm{C}$ NMR and DEPT 135 spectra of 2 in methanol- $d_{4}(175 \mathrm{MHz})$. 


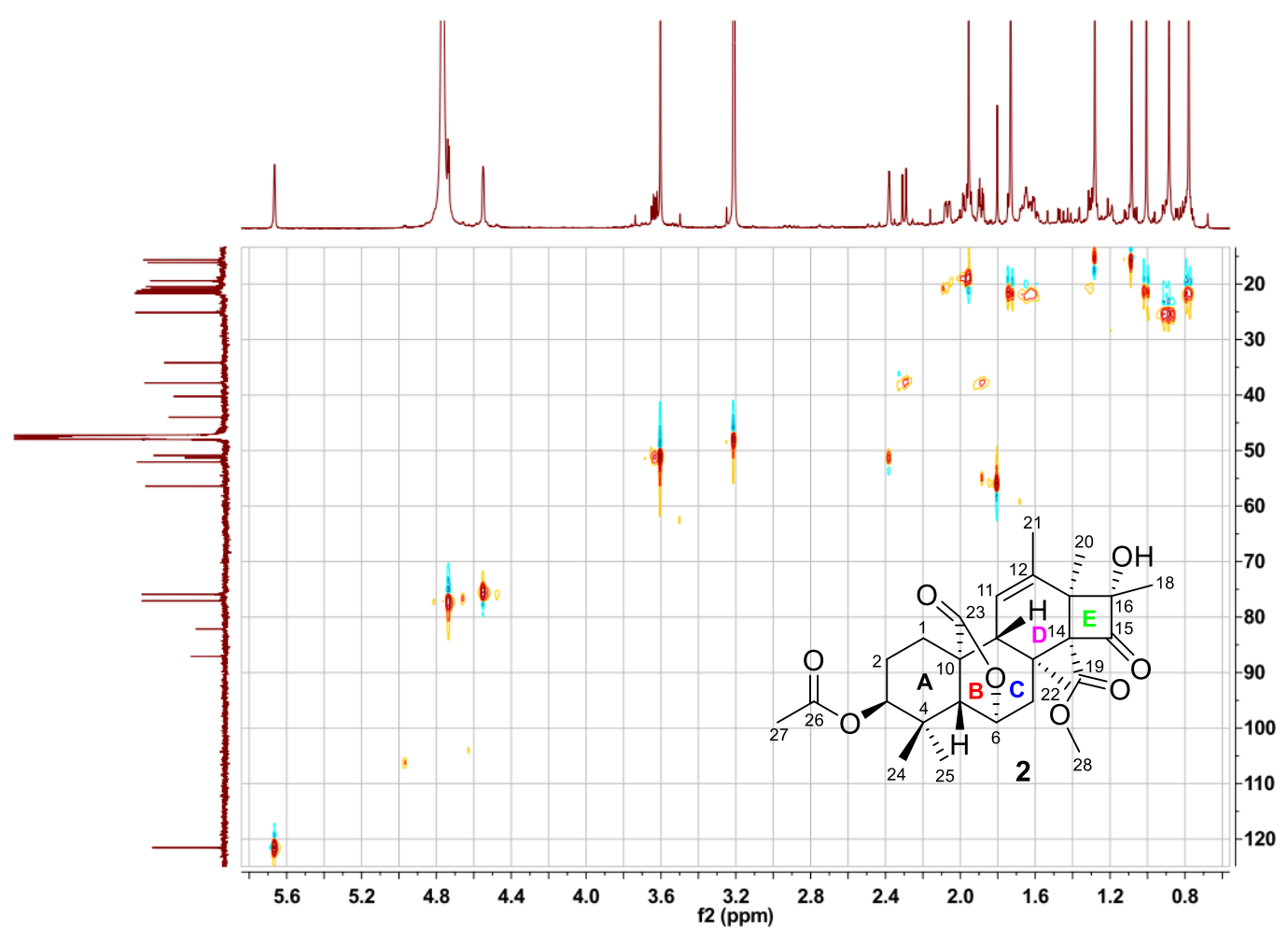

Figure S17. HSQC spectrum of 2 in methanol- $d_{4}(700 \mathrm{MHz})$.

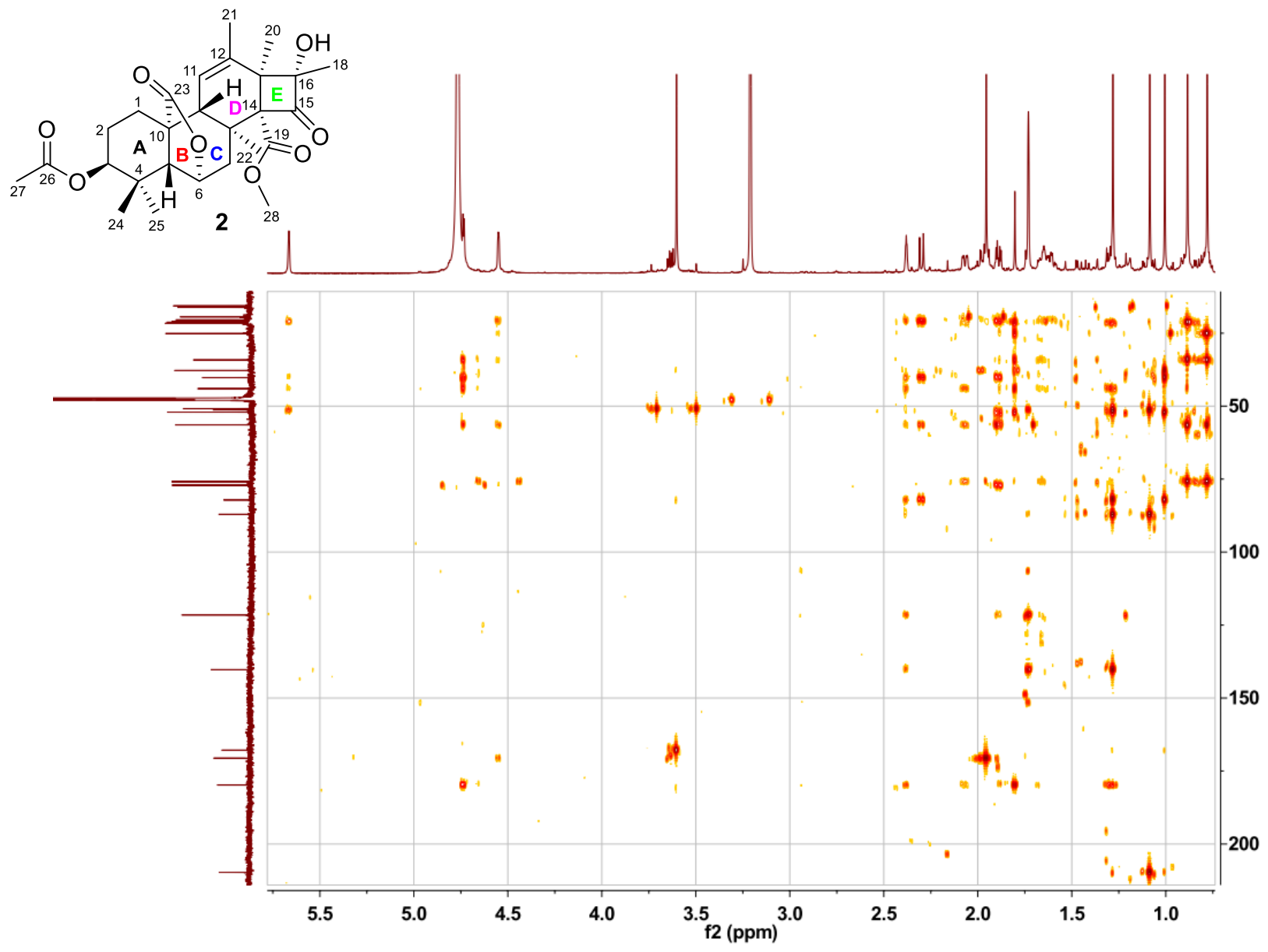

Figure S18. HMBC spectrum of 2 in methanol- $d_{4}(700 \mathrm{MHz})$. 


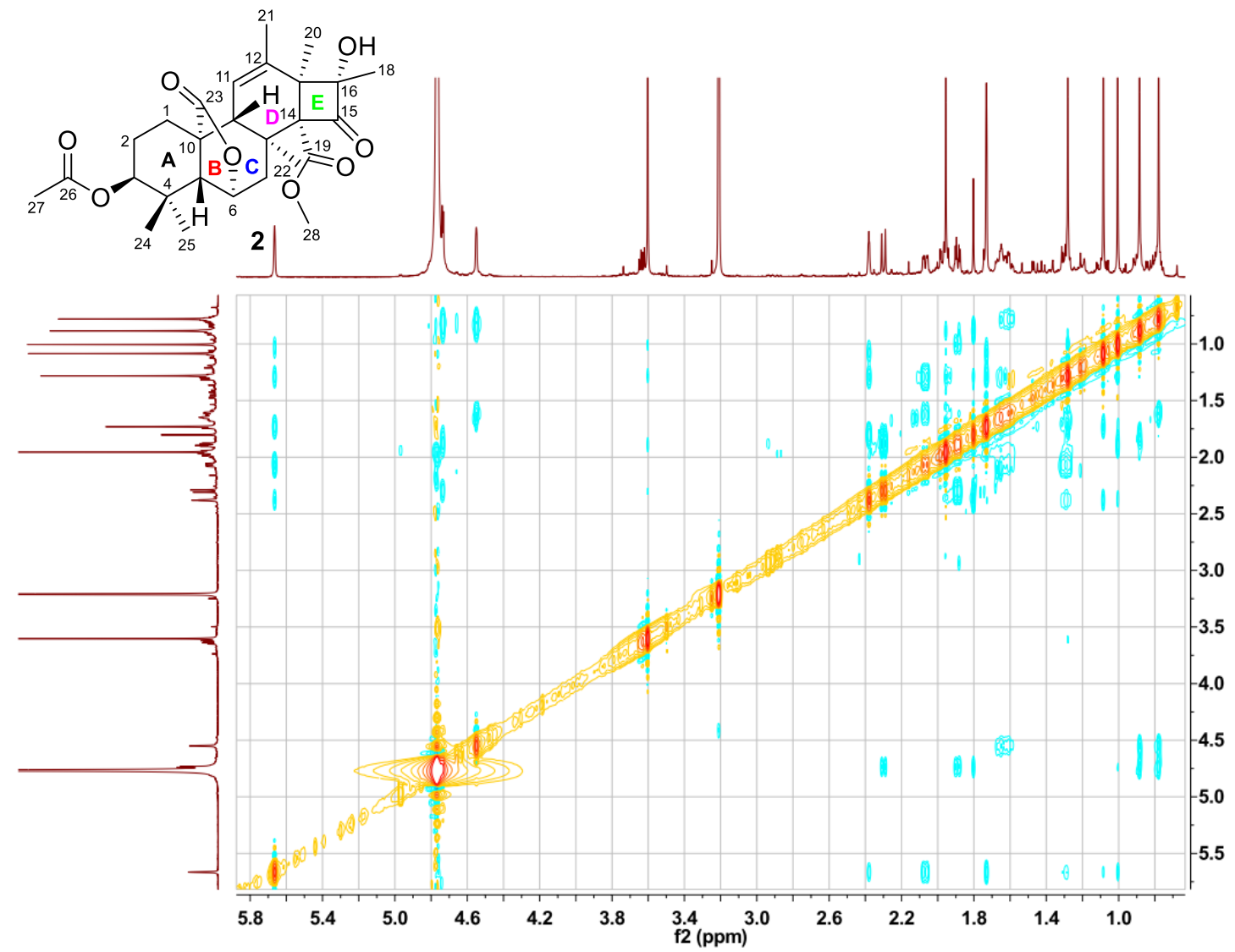

Figure S19. NOESY spectrum of 2 in methanol- $d_{4}(700 \mathrm{MHz})$.

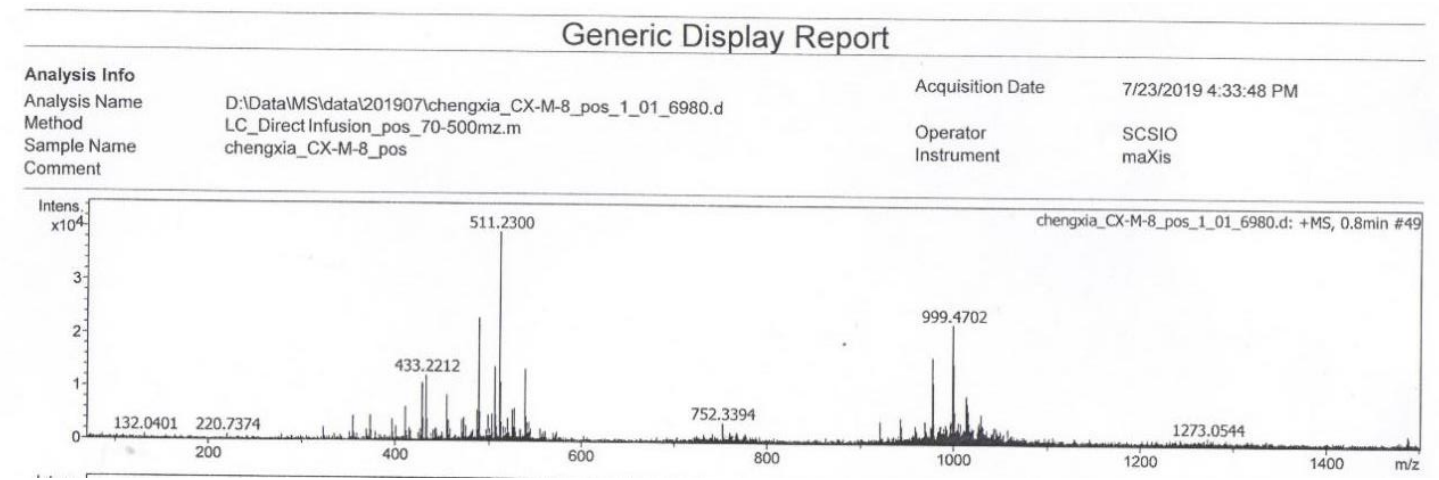

Figure S20. HRESIMS of 2. 


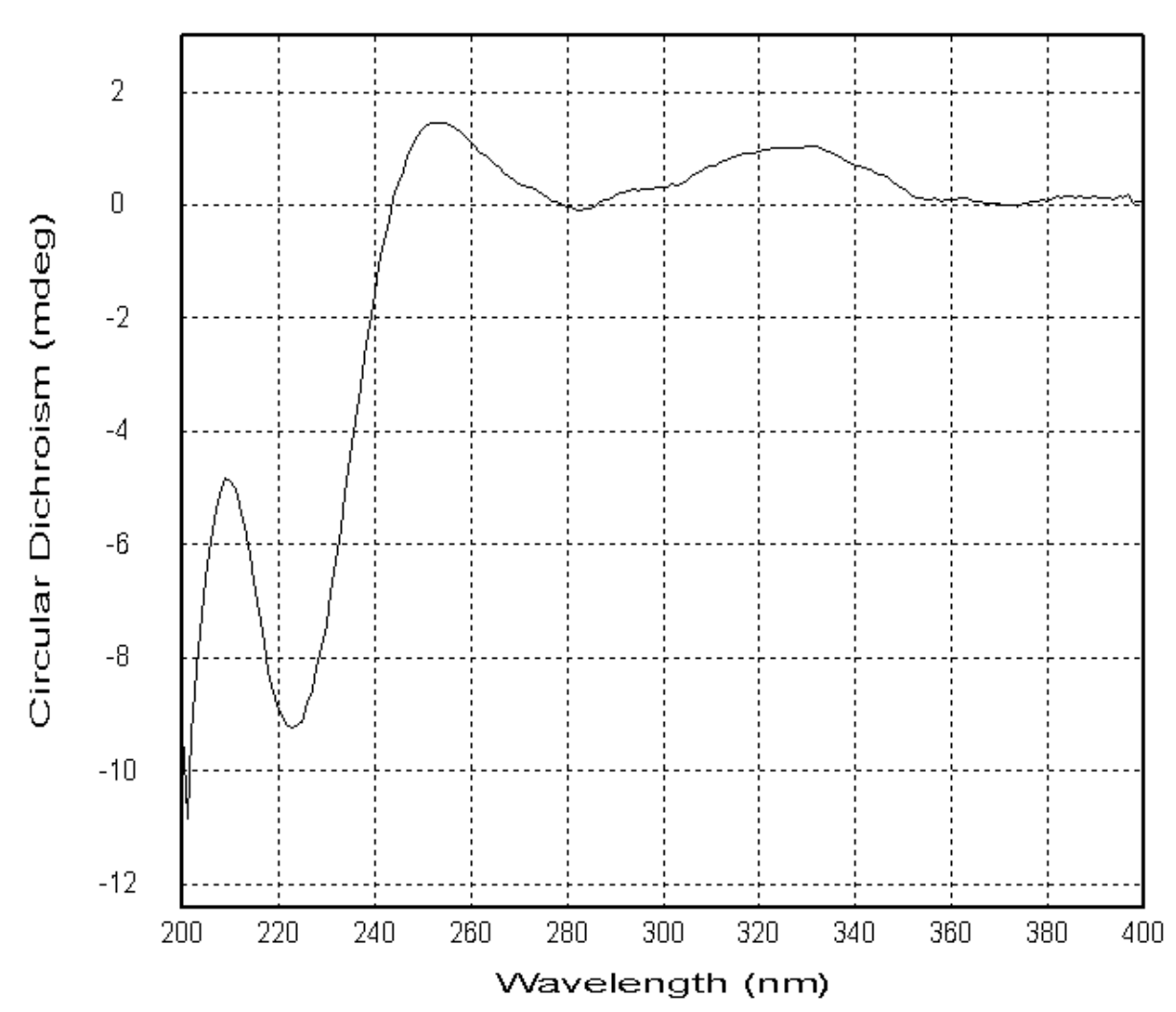

$\overline{C X-M}-8 . d s x:: S$ mooth (s):

Figure S21. CD spectrum of 2 in methanol.

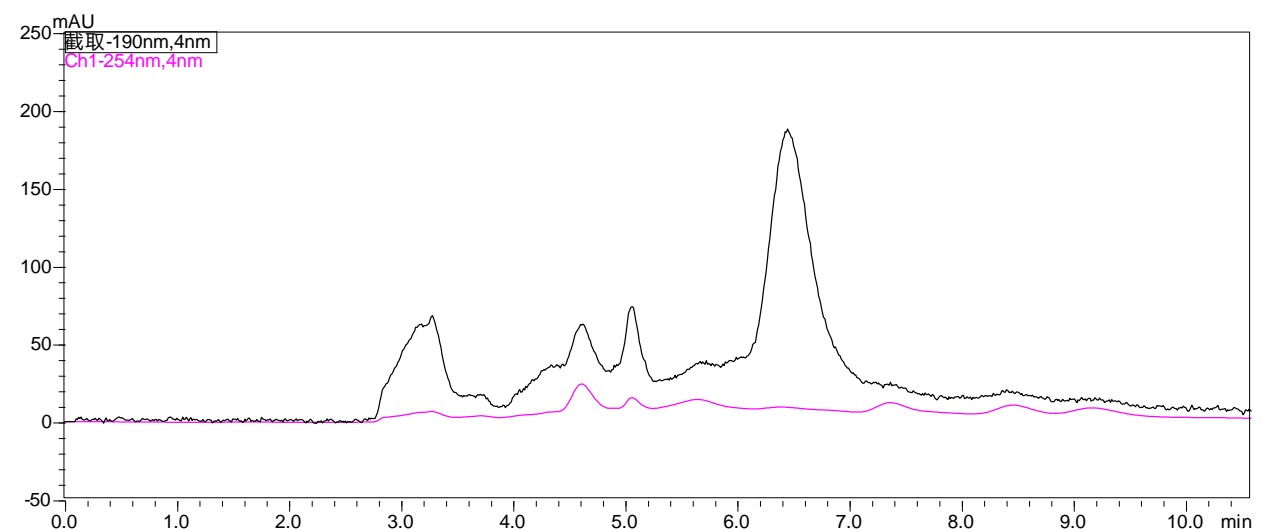

Figure S22. Chiral HPLC analysis of $\mathbf{2}\left(n\right.$-hexane/isopropanol, $75: 25 ; \mathrm{T}=30^{\circ} \mathrm{C}$, flow rate:

$1.0 \mathrm{~mL} / \mathrm{min}$; wavelength: $190 \mathrm{~nm}$ and $254 \mathrm{~nm}$ ). 


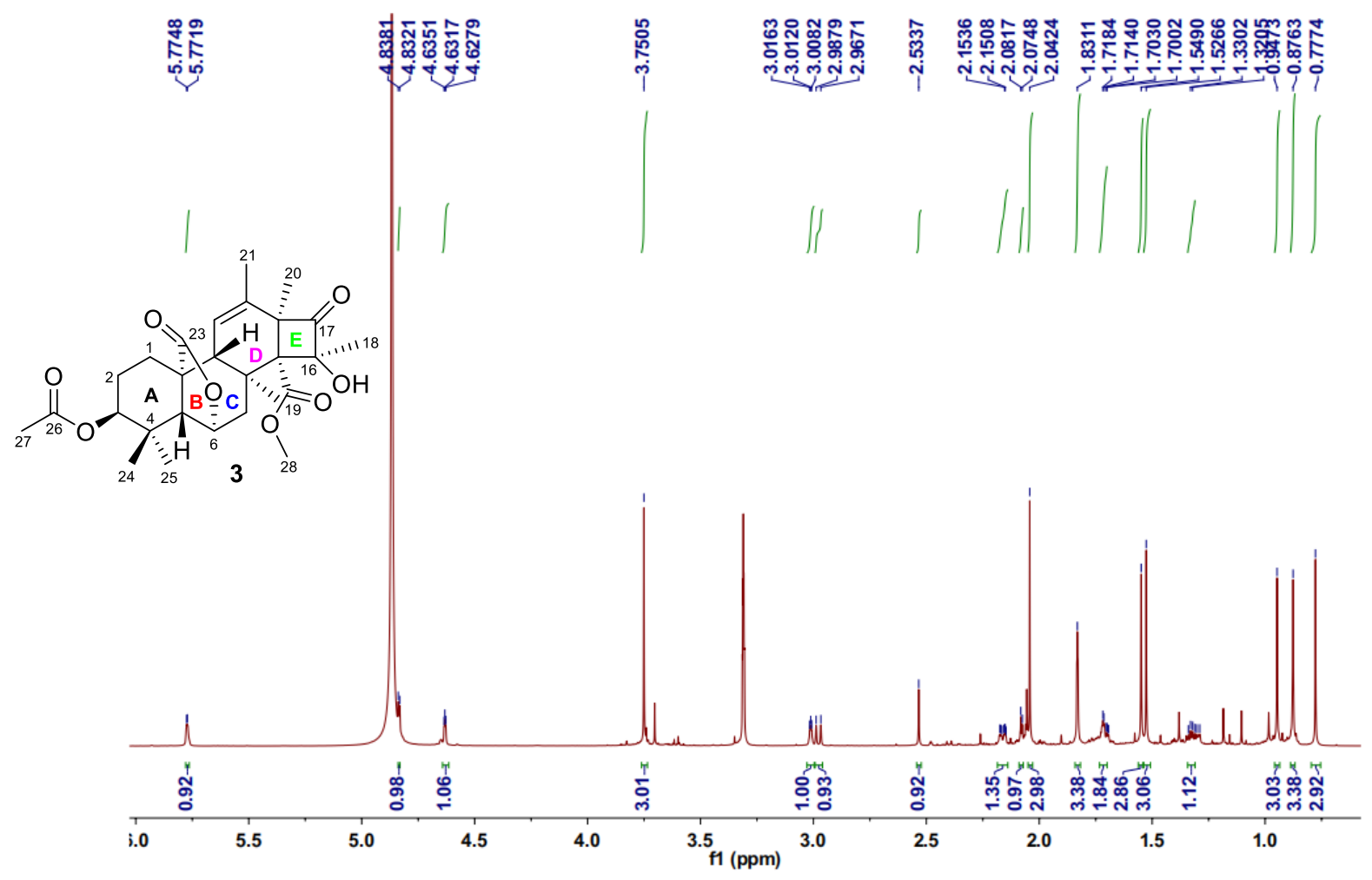

Figure S23. ${ }^{1} \mathrm{H}$ NMR spectrum of 3 in methanol- $d_{4}(700 \mathrm{MHz})$.

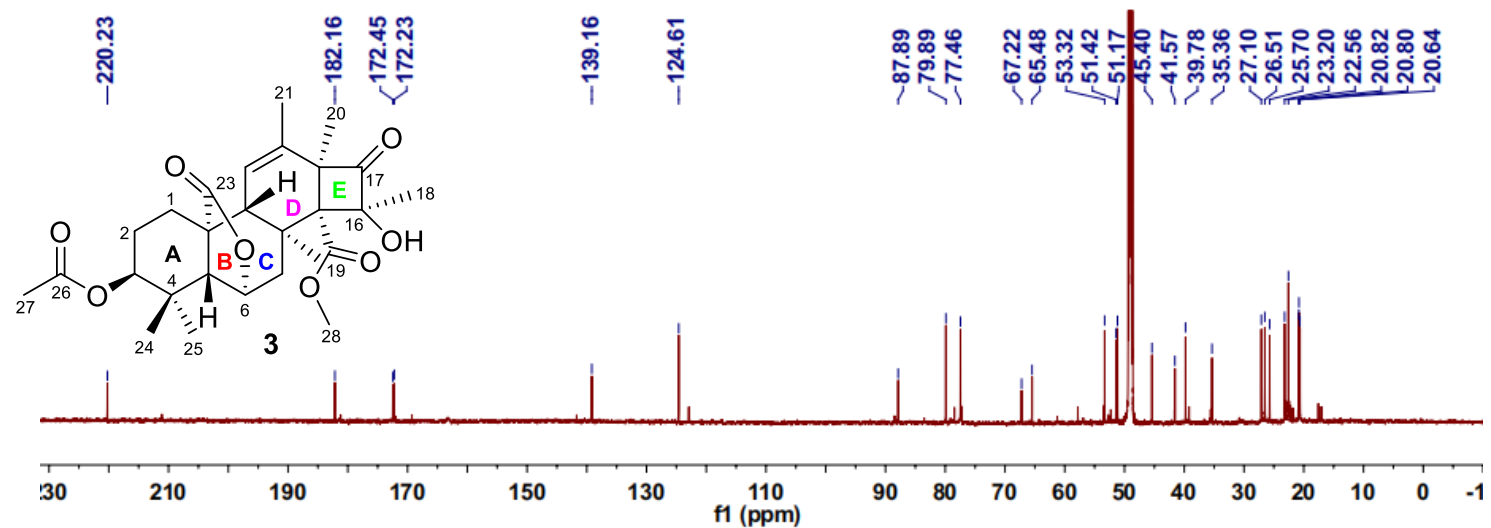

Figure S24. ${ }^{13} \mathrm{C}$ NMR spectrum of 3 in methanol- $d_{4}(175 \mathrm{MHz})$. 


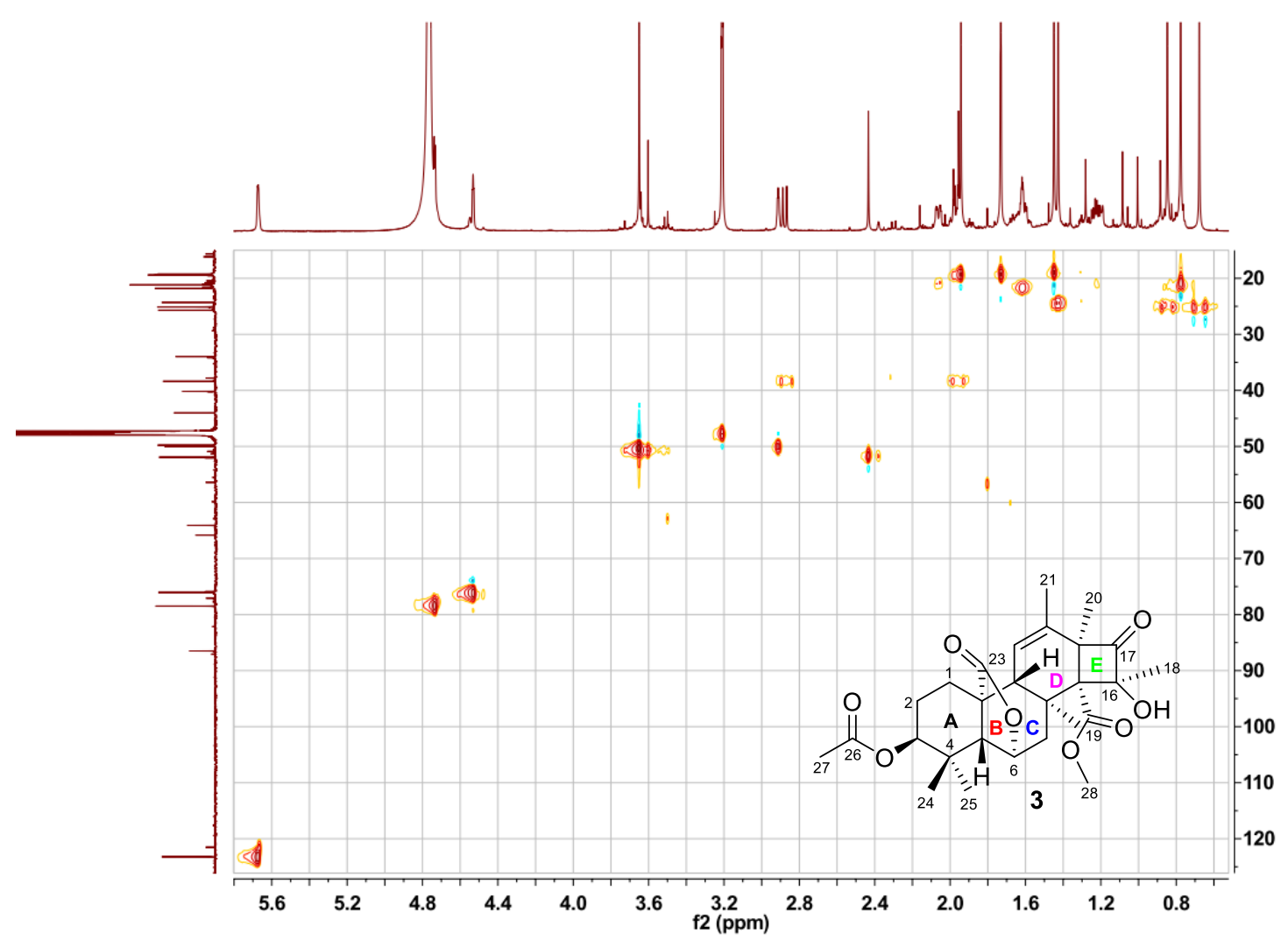

Figure S25. HSQC spectrum of 3 in methanol- $d_{4}(700 \mathrm{MHz})$.

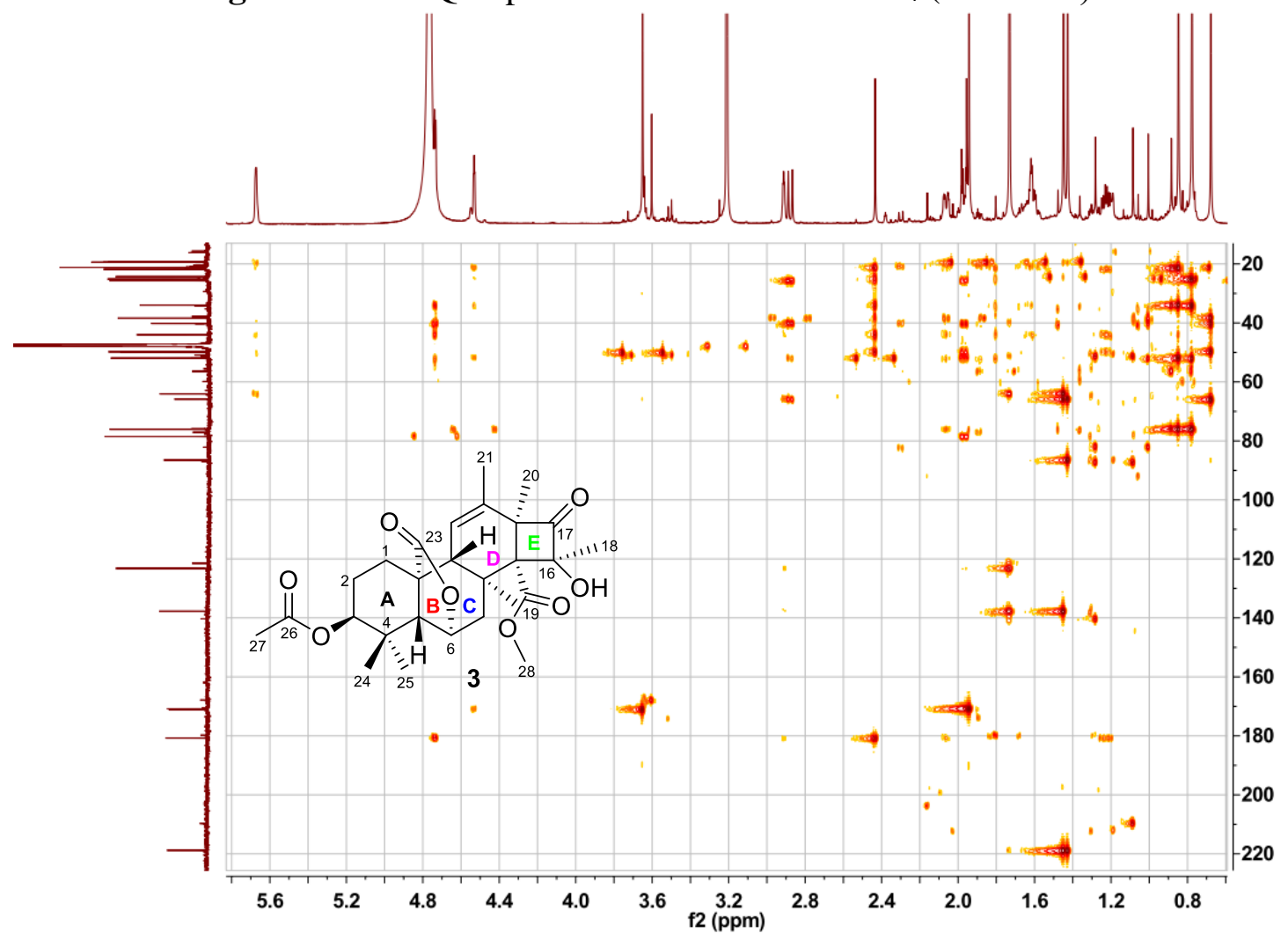

Figure S26. HMBC spectrum of $\mathbf{3}$ in methanol- $d_{4}(700 \mathrm{MHz})$. 


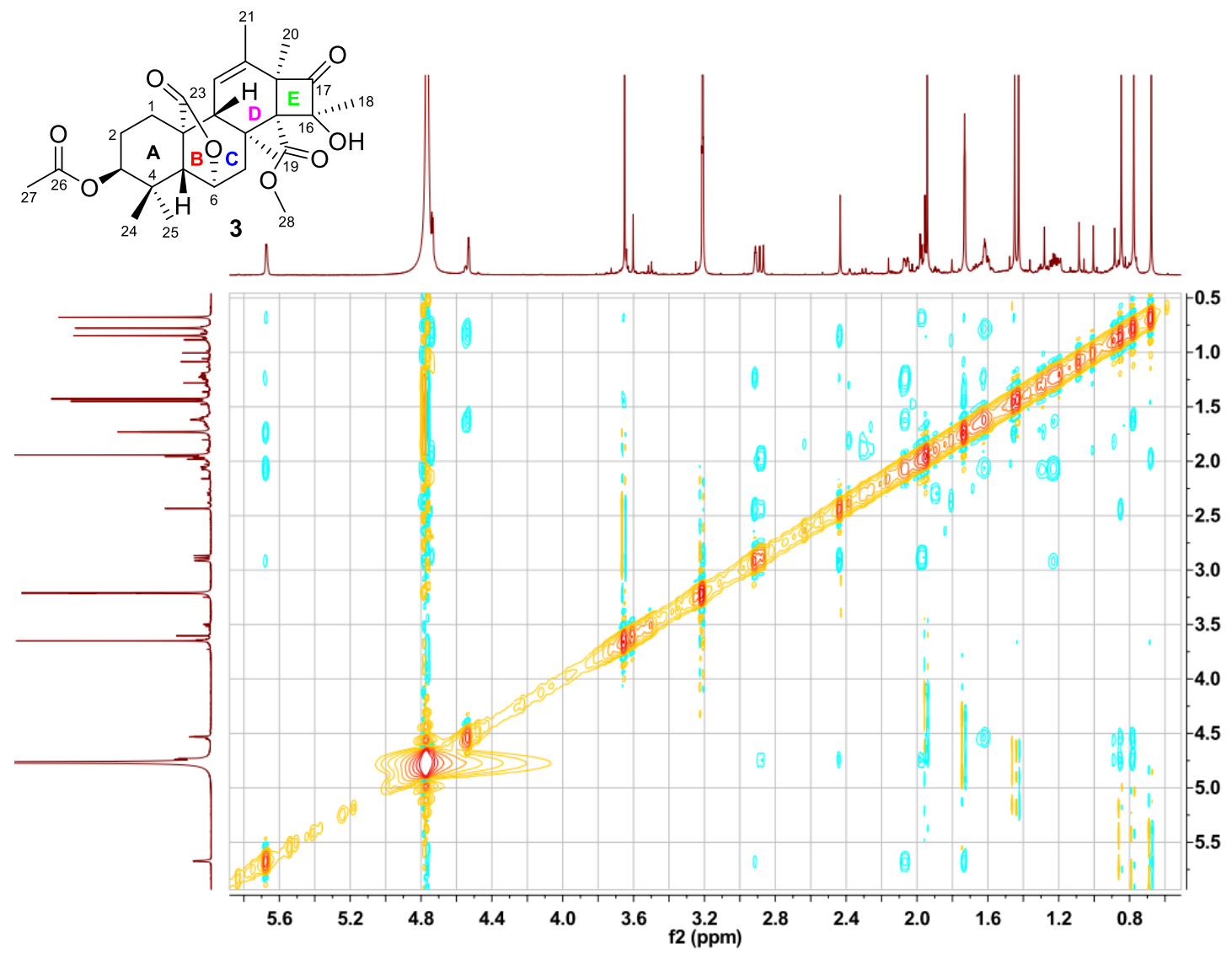

Figure S27. NOESY spectrum of $\mathbf{3}$ in methanol- $d_{4}(700 \mathrm{MHz})$.

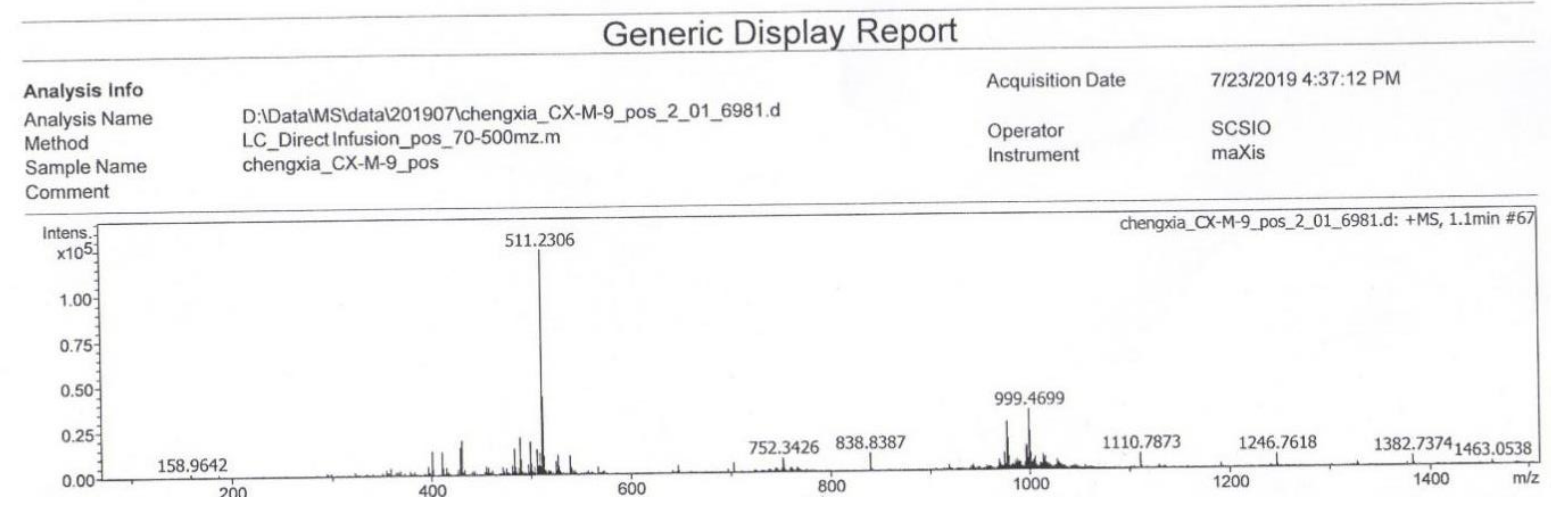

Figure S28. HRESIMS of 3. 


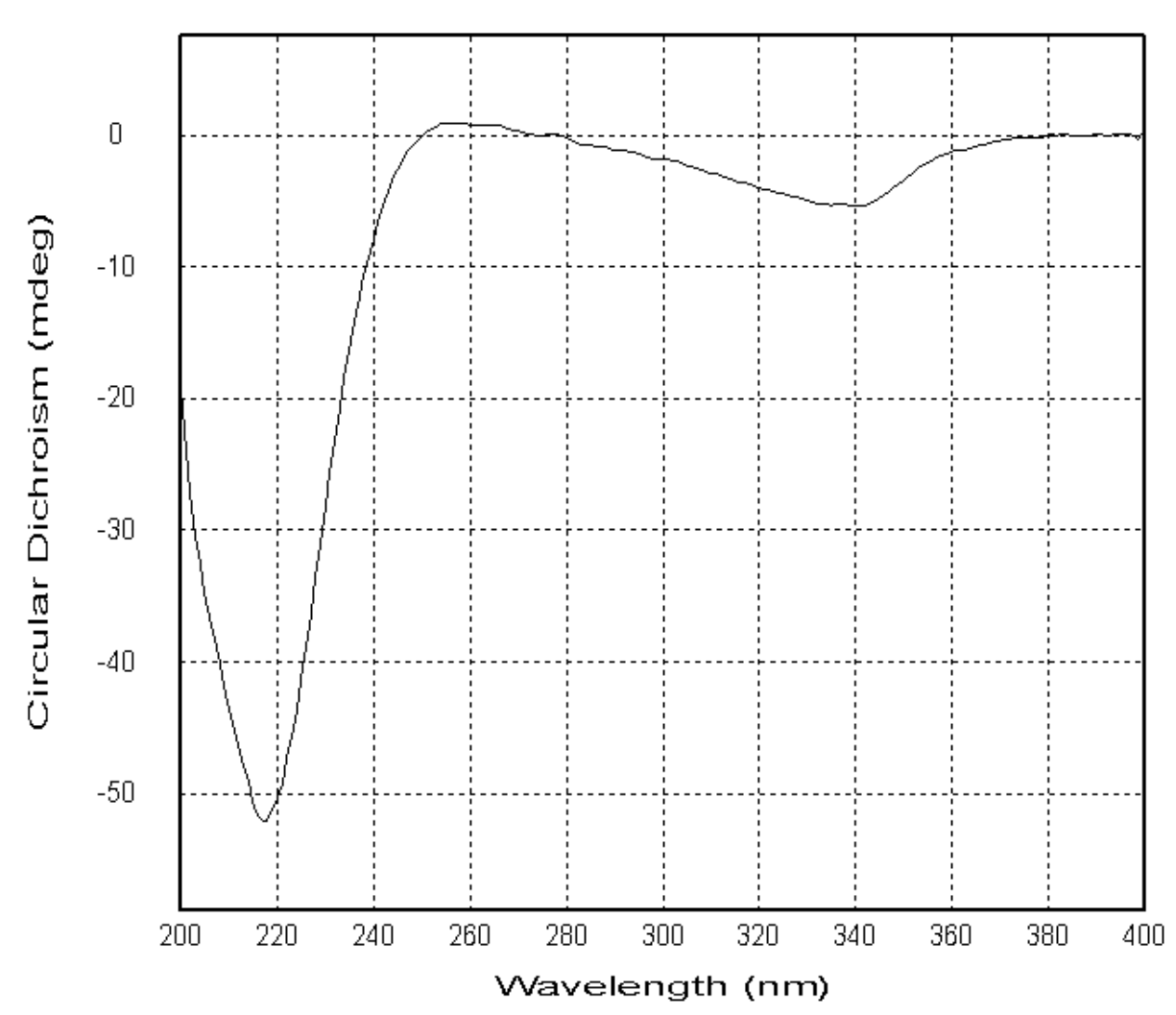

$\overline{C X-M}-9 . d s x:: S$ mooth (s):

Figure S29. CD spectrum of $\mathbf{3}$ in methanol.

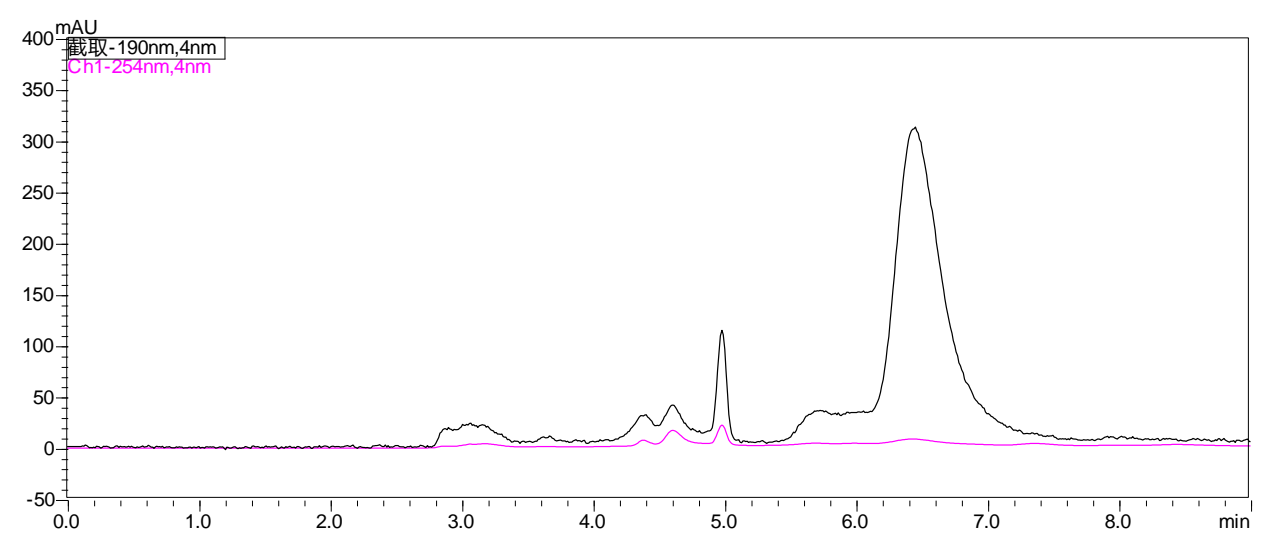

Figure S30. Chiral HPLC analysis of $\mathbf{3}$ ( $n$-hexane/isopropanol, 70:30; $\mathrm{T}=30{ }^{\circ} \mathrm{C}$; flow rate: $1.0 \mathrm{~mL} / \mathrm{min}$; wavelength: $190 \mathrm{~nm}$ and $254 \mathrm{~nm}$ ). 
Table S3. Stable conformers of 1 used for ECD calculations.

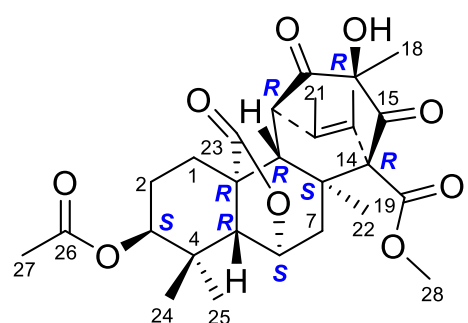

(3S, 5R,6S, 8S, 9R, 10R, 11R,14R,16R)-1

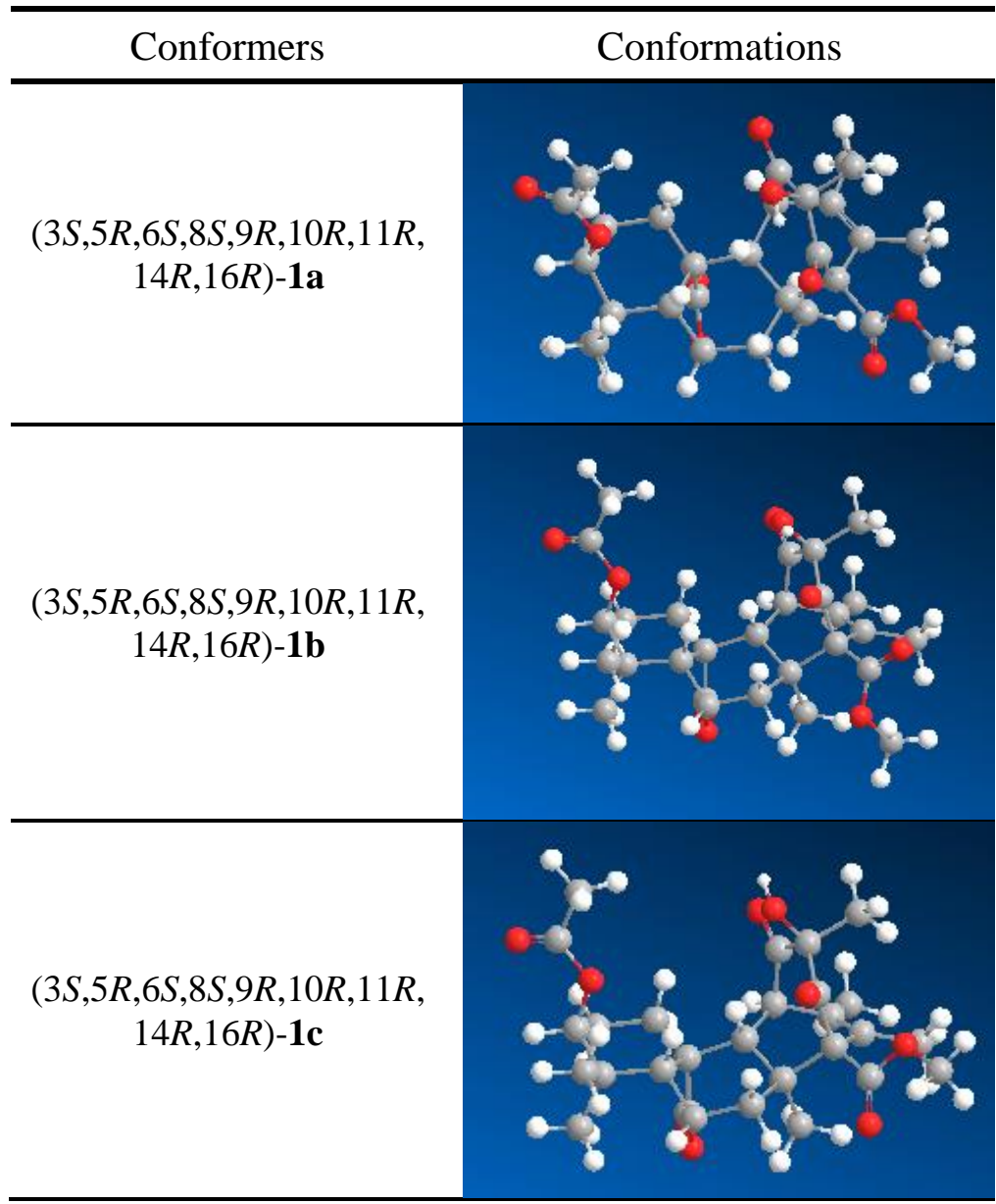


Table S4. Optimized Z-matrixes of 1 in the gas phase $(\AA)$ at B3LYP/6-311G(d,p) level.

\begin{tabular}{|c|c|c|c|c|c|c|c|}
\hline \multicolumn{4}{|c|}{$1 a$} & \multicolumn{4}{|c|}{$1 \mathrm{~b}$} \\
\hline $\mathrm{C}$ & -3.0831 & -0.3879 & -2.5011 & $\mathrm{C}$ & -3.198 & -0.5656 & -2.2134 \\
\hline $\mathrm{C}$ & -3.0081 & -1.8762 & -2.1457 & $\mathrm{C}$ & -2.9993 & -2.0485 & -1.8845 \\
\hline $\mathrm{C}$ & -1.5644 & -2.425 & -2.3365 & $\mathrm{C}$ & -1.5328 & -2.4904 & -2.1592 \\
\hline $\mathrm{C}$ & -0.5771 & -1.5793 & -1.4532 & $\mathrm{C}$ & -0.5621 & -1.5862 & -1.3164 \\
\hline $\mathrm{C}$ & -0.7155 & -0.0342 & -1.5415 & $\mathrm{C}$ & -0.813 & -0.0546 & -1.3743 \\
\hline $\mathrm{C}$ & -2.1646 & 0.4564 & -1.6193 & $\mathrm{C}$ & -2.2954 & 0.3323 & -1.3689 \\
\hline $\mathrm{C}$ & 0.9 & -1.6886 & -1.8122 & $\mathrm{C}$ & 0.897 & -1.5856 & -1.754 \\
\hline $\mathrm{C}$ & 1.8112 & -1.2089 & -0.6379 & $\mathrm{C}$ & 1.8359 & -1.0548 & -0.6252 \\
\hline $\mathrm{C}$ & 1.6118 & 0.2983 & -0.2737 & $\mathrm{C}$ & 1.5553 & 0.4321 & -0.2257 \\
\hline $\mathrm{C}$ & 0.0758 & 0.207 & -2.8065 & $\mathrm{C}$ & -0.1098 & 0.2563 & -2.6757 \\
\hline $\mathrm{O}$ & -0.0446 & 1.1454 & -3.5732 & $\mathrm{O}$ & -0.3362 & 1.1915 & -3.4221 \\
\hline $\mathrm{C}$ & 0.0634 & 0.5582 & -0.3067 & $\mathrm{C}$ & -0.0115 & 0.5777 & -0.1729 \\
\hline $\mathrm{O}$ & 1.0068 & -0.7998 & -2.9373 & $\mathrm{O}$ & 0.8839 & -0.6781 & -2.8687 \\
\hline $\mathrm{C}$ & -1.5135 & -3.894 & -1.8388 & $\mathrm{C}$ & -1.3514 & -3.9576 & -1.687 \\
\hline $\mathrm{C}$ & -1.2301 & -2.4754 & -3.845 & $\mathrm{C}$ & -1.2767 & -2.4998 & -3.6838 \\
\hline $\mathrm{O}$ & -3.3756 & -2.0347 & -0.7559 & $\mathrm{O}$ & -3.2793 & -2.2479 & -0.4797 \\
\hline $\mathrm{C}$ & -4.7077 & -2.1187 & -0.4856 & $\mathrm{C}$ & -4.5857 & -2.4289 & -0.1403 \\
\hline $\mathrm{C}$ & -4.9193 & -2.2404 & 0.9922 & $\mathrm{C}$ & -4.7085 & -2.58 & 1.3448 \\
\hline $\mathrm{O}$ & -5.6043 & -2.0977 & -1.3156 & $\mathrm{O}$ & -5.5247 & -2.4632 & -0.9216 \\
\hline $\mathrm{H}$ & -0.7314 & -1.9198 & -0.4201 & $\mathrm{H}$ & -0.6363 & -1.9487 & -0.2819 \\
\hline $\mathrm{C}$ & 2.0787 & 0.7603 & 1.1991 & $\mathrm{C}$ & 2.0631 & 0.9137 & 1.2269 \\
\hline $\mathrm{C}$ & 1.0964 & 0.1727 & 2.2576 & $\mathrm{C}$ & 1.1787 & 0.2415 & 2.3235 \\
\hline $\mathrm{C}$ & -0.1702 & 0.9498 & 2.7196 & $\mathrm{C}$ & -0.1109 & 0.9192 & 2.8695 \\
\hline $\mathrm{C}$ & -0.9602 & 1.7378 & 1.633 & $\mathrm{C}$ & -1.0168 & 1.6542 & 1.8377 \\
\hline $\mathrm{C}$ & -0.2882 & 1.9583 & 0.2696 & $\mathrm{C}$ & -0.4376 & 1.9396 & 0.4434 \\
\hline $\mathrm{O}$ & -2.0816 & 2.2096 & 1.8456 & $\mathrm{O}$ & -2.1587 & 2.035 & 2.1142 \\
\hline $\mathrm{O}$ & -1.0821 & -0.0676 & 3.2028 & $\mathrm{O}$ & -0.9184 & -0.1694 & 3.384 \\
\hline $\mathrm{C}$ & 0.1485 & 1.839 & 3.9175 & $\mathrm{C}$ & 0.206 & 1.8155 & 4.0619 \\
\hline $\mathrm{O}$ & 1.2562 & -0.9823 & 2.6864 & $\mathrm{O}$ & 1.4356 & -0.9121 & 2.7068 \\
\hline $\mathrm{C}$ & 3.5114 & 0.26 & 1.5115 & $\mathrm{C}$ & 3.5318 & 0.5517 & 1.5717 \\
\hline $\mathrm{O}$ & 3.7673 & 0.3179 & 2.8531 & $\mathrm{O}$ & 4.2674 & 0.2075 & 0.4841 \\
\hline $\mathrm{O}$ & 4.3397 & -0.0808 & 0.6771 & $\mathrm{O}$ & 3.9961 & 0.6341 & 2.7052 \\
\hline
\end{tabular}




\begin{tabular}{|c|c|c|c|c|c|c|c|}
\hline $\mathrm{C}$ & 5.0722 & -0.1329 & 3.2228 & $\mathrm{C}$ & 5.6353 & $\begin{array}{l}-0.0991 \\
\end{array}$ & 0.764 \\
\hline $\mathrm{C}$ & 0.8671 & 2.868 & 0.6845 & $\mathrm{C}$ & 0.6641 & 2.9299 & 0.8098 \\
\hline $\mathrm{C}$ & 1.9833 & 2.3105 & 1.2175 & $\mathrm{C}$ & 1.8443 & 2.4537 & 1.2792 \\
\hline $\mathrm{C}$ & 0.5859 & 4.3395 & 0.5167 & $\mathrm{C}$ & 0.263 & 4.3775 & 0.6814 \\
\hline $\mathrm{C}$ & 3.1419 & 3.0952 & 1.7812 & $\mathrm{C}$ & 2.9605 & 3.323 & 1.8059 \\
\hline $\mathrm{H}$ & -0.3415 & -0.1251 & 0.4512 & $\mathrm{H}$ & -0.3234 & -0.1432 & 0.5941 \\
\hline $\mathrm{C}$ & 2.4063 & 1.1522 & -1.3345 & $\mathrm{C}$ & 2.2183 & 1.3581 & -1.315 \\
\hline $\mathrm{H}$ & -4.1085 & -0.0251 & -2.3607 & $\mathrm{H}$ & -4.2375 & -0.2783 & -2.0138 \\
\hline $\mathrm{H}$ & -2.8446 & -0.2252 & -3.5569 & $\mathrm{H}$ & -3.0286 & -0.3747 & -3.2778 \\
\hline $\mathrm{H}$ & -3.6981 & -2.4485 & -2.7795 & $\mathrm{H}$ & -3.6802 & -2.6616 & -2.4893 \\
\hline $\mathrm{H}$ & -2.1998 & 1.4889 & -1.9875 & $\mathrm{H}$ & -2.423 & 1.3634 & -1.7199 \\
\hline $\mathrm{H}$ & -2.5943 & 0.4745 & -0.6096 & $\mathrm{H}$ & -2.6708 & 0.3086 & -0.3379 \\
\hline $\mathrm{H}$ & 1.1895 & -2.6991 & -2.1145 & $\mathrm{H}$ & 1.2403 & -2.5694 & -2.0865 \\
\hline $\mathrm{H}$ & 2.855 & -1.3831 & -0.9244 & $\mathrm{H}$ & 2.8679 & -1.1562 & -0.979 \\
\hline $\mathrm{H}$ & 1.6148 & -1.8441 & 0.2328 & $\mathrm{H}$ & 1.7362 & -1.7121 & 0.2454 \\
\hline $\mathrm{H}$ & -0.528 & -4.3397 & -2.0127 & $\mathrm{H}$ & -0.3476 & -4.3298 & -1.9191 \\
\hline $\mathrm{H}$ & -2.2525 & -4.5114 & -2.3625 & $\mathrm{H}$ & -2.0719 & -4.6202 & -2.1804 \\
\hline $\mathrm{H}$ & -1.7217 & -3.9725 & -0.7662 & $\mathrm{H}$ & -1.4959 & -4.0628 & -0.6063 \\
\hline $\mathrm{H}$ & -1.2261 & -1.4916 & -4.3187 & $\mathrm{H}$ & -1.3675 & -1.5129 & -4.1422 \\
\hline $\mathrm{H}$ & -0.2546 & -2.9383 & -4.0282 & $\mathrm{H}$ & -0.282 & -2.8897 & -3.9248 \\
\hline $\mathrm{H}$ & -1.9706 & -3.0799 & -4.3831 & $\mathrm{H}$ & -2.0003 & -3.1494 & -4.1913 \\
\hline $\mathrm{H}$ & -4.5122 & -1.3612 & 1.498 & $\mathrm{H}$ & -4.3371 & -1.6794 & 1.8404 \\
\hline $\mathrm{H}$ & -5.9913 & -2.2977 & 1.2014 & $\mathrm{H}$ & -5.7611 & -2.7148 & 1.6097 \\
\hline $\mathrm{H}$ & -4.4424 & -3.152 & 1.3607 & $\mathrm{H}$ & -4.1499 & -3.4594 & 1.6749 \\
\hline $\mathrm{H}$ & -0.9719 & 2.4942 & -0.394 & $\mathrm{H}$ & -1.195 & 2.429 & -0.1743 \\
\hline $\mathrm{H}$ & -0.5308 & -0.8154 & 3.5143 & $\mathrm{H}$ & -0.2948 & -0.8682 & 3.6725 \\
\hline $\mathrm{H}$ & 0.7002 & 1.2806 & 4.6826 & $\mathrm{H}$ & 0.8447 & 1.2936 & 4.7839 \\
\hline $\mathrm{H}$ & 0.7428 & 2.7154 & 3.648 & $\mathrm{H}$ & 0.711 & 2.7406 & 3.7742 \\
\hline $\mathrm{H}$ & -0.7721 & 2.1973 & 4.3928 & $\mathrm{H}$ & -0.7108 & 2.0922 & 4.5957 \\
\hline $\mathrm{H}$ & 5.1519 & -0.0803 & 4.312 & $\mathrm{H}$ & 6.1174 & -0.3801 & -0.1763 \\
\hline $\mathrm{H}$ & 5.2217 & -1.1722 & 2.914 & $\mathrm{H}$ & 6.1481 & 0.7791 & 1.1683 \\
\hline $\mathrm{H}$ & 5.837 & 0.5173 & 2.7869 & $\mathrm{H}$ & 5.7052 & -0.9445 & 1.4556 \\
\hline $\mathrm{H}$ & 0.2889 & 4.5445 & -0.5176 & $\mathrm{H}$ & -0.1194 & 4.5683 & -0.3274 \\
\hline $\mathrm{H}$ & -0.2315 & 4.6463 & 1.177 & $\mathrm{H}$ & -0.5272 & 4.6168 & 1.4002 \\
\hline $\mathrm{H}$ & 1.4434 & 4.9803 & 0.7257 & $\mathrm{H}$ & 1.0837 & 5.0788 & 0.8376 \\
\hline
\end{tabular}




\begin{tabular}{|c|c|c|c|c|c|c|c|}
\hline $\mathrm{H}$ & 2.9891 & 4.1753 & 1.7657 & $\mathrm{H}$ & 2.7171 & 4.3864 & 1.8241 \\
\hline $\mathrm{H}$ & 3.3059 & 2.829 & 2.8299 & $\mathrm{H}$ & 3.1972 & 3.0515 & 2.8394 \\
\hline $\mathrm{H}$ & 4.0564 & 2.8955 & 1.2142 & $\mathrm{H}$ & 3.8589 & 3.2122 & 1.1905 \\
\hline $\mathrm{H}$ & 2.7365 & 0.5695 & -2.1987 & $\mathrm{H}$ & 2.5647 & 0.8075 & -2.1941 \\
\hline $\mathrm{H}$ & 1.8215 & 1.997 & -1.7115 & $\mathrm{H}$ & 1.5399 & 2.1435 & -1.6624 \\
\hline $\mathrm{H}$ & 3.3354 & 1.5649 & -0.9283 & $\mathrm{H}$ & 3.1184 & 1.8616 & -0.9477 \\
\hline
\end{tabular}

\begin{tabular}{|l|l|l|l|}
\hline \multicolumn{5}{|c|}{$1 \mathrm{c}$} \\
\hline $\mathrm{C}$ & -2.8398 & -0.3818 & -2.7525 \\
\hline $\mathrm{C}$ & -2.8508 & -1.8615 & -2.3565 \\
\hline $\mathrm{C}$ & -1.4162 & -2.4628 & -2.3943 \\
\hline $\mathrm{C}$ & -0.4855 & -1.6239 & -1.4448 \\
\hline $\mathrm{C}$ & -0.5588 & -0.0786 & -1.5879 \\
\hline $\mathrm{C}$ & -1.9769 & 0.4562 & -1.8106 \\
\hline $\mathrm{C}$ & 1.0133 & -1.7941 & -1.6623 \\
\hline $\mathrm{C}$ & 1.8298 & -1.3099 & -0.4225 \\
\hline $\mathrm{C}$ & 1.6551 & 0.2141 & -0.122 \\
\hline $\mathrm{C}$ & 0.3521 & 0.0967 & -2.7806 \\
\hline $\mathrm{O}$ & 0.3346 & 1.0154 & -3.5801 \\
\hline $\mathrm{C}$ & 0.1271 & 0.5281 & -0.3057 \\
\hline $\mathrm{O}$ & 1.2537 & -0.9442 & -2.7977 \\
\hline $\mathrm{C}$ & -1.4641 & -3.9171 & -1.8545 \\
\hline $\mathrm{C}$ & -0.9454 & -2.57 & -3.863 \\
\hline $\mathrm{O}$ & -3.3562 & -1.972 & -1.006 \\
\hline $\mathrm{C}$ & -4.7095 & -2.0218 & -0.8657 \\
\hline $\mathrm{C}$ & -5.0657 & -2.1252 & 0.5854 \\
\hline $\mathrm{O}$ & -5.5216 & -1.9846 & -1.778 \\
\hline $\mathrm{H}$ & -0.7471 & -1.9267 & -0.4216 \\
\hline $\mathrm{C}$ & 2.0009 & 0.7086 & 1.374 \\
\hline $\mathrm{C}$ & 0.9031 & 0.1838 & 2.3596 \\
\hline $\mathrm{C}$ & -0.3562 & 1.0521 & 2.6845 \\
\hline $\mathrm{C}$ & -1.0168 & 1.7972 & 1.4948 \\
\hline-0.222 & 1.9599 & 0.1938 \\
\hline $\mathrm{C}$ & -2.169 & 2.2355 & 1.593 \\
\hline
\end{tabular}




\begin{tabular}{|c|c|c|c|}
\hline $\mathrm{C}$ & -0.0739 & 1.9971 & 3.8507 \\
\hline $\mathrm{O}$ & 1.0028 & -0.9662 & 2.8107 \\
\hline $\mathrm{C}$ & 3.3798 & 0.1701 & 1.8337 \\
\hline $\mathrm{O}$ & 3.5213 & 0.2825 & 3.1887 \\
\hline $\mathrm{O}$ & 4.2646 & -0.2354 & 1.0907 \\
\hline $\mathrm{C}$ & 4.7622 & -0.214 & 3.6936 \\
\hline $\mathrm{C}$ & 0.9244 & 2.8419 & 0.6808 \\
\hline $\mathrm{C}$ & 1.9679 & 2.2634 & 1.327 \\
\hline $\mathrm{C}$ & 0.7177 & 4.315 & 0.4374 \\
\hline $\mathrm{C}$ & 3.1106 & 3.0242 & 1.9539 \\
\hline $\mathrm{H}$ & -0.37 & -0.1155 & 0.4325 \\
\hline $\mathrm{C}$ & 2.5765 & 1.0026 & -1.13 \\
\hline $\mathrm{H}$ & -3.8604 & 0.0181 & -2.7166 \\
\hline $\mathrm{H}$ & -2.4995 & -0.2562 & -3.7853 \\
\hline $\mathrm{H}$ & -3.4963 & -2.4272 & -3.0411 \\
\hline $\mathrm{H}$ & -1.9425 & 1.4787 & -2.2056 \\
\hline $\mathrm{H}$ & -2.4958 & 0.5155 & -0.8455 \\
\hline $\mathrm{H}$ & 1.2922 & -2.8225 & -1.9089 \\
\hline $\mathrm{H}$ & 2.888 & -1.5299 & -0.6056 \\
\hline $\mathrm{H}$ & 1.5302 & -1.9104 & 0.4434 \\
\hline $\mathrm{H}$ & -0.4835 & -4.4005 & -1.924 \\
\hline $\mathrm{H}$ & -2.1736 & -4.525 & -2.4278 \\
\hline $\mathrm{H}$ & -1.7726 & -3.9562 & -0.8042 \\
\hline $\mathrm{H}$ & -0.8643 & -1.6018 & -4.3612 \\
\hline $\mathrm{H}$ & 0.0265 & -3.0688 & -3.9415 \\
\hline $\mathrm{H}$ & -1.653 & -3.1671 & -4.4512 \\
\hline $\mathrm{H}$ & -4.693 & -1.2485 & 1.1213 \\
\hline $\mathrm{H}$ & -6.1538 & -2.1616 & 0.69 \\
\hline $\mathrm{H}$ & -4.644 & -3.0416 & 1.0059 \\
\hline $\mathrm{H}$ & -0.8275 & 2.4969 & -0.5408 \\
\hline $\mathrm{H}$ & -2.2229 & 0.7034 & 3.1966 \\
\hline $\mathrm{H}$ & 0.3444 & 1.4464 & 4.7012 \\
\hline $\mathrm{H}$ & 0.6231 & 2.7979 & 3.5959 \\
\hline $\mathrm{H}$ & -0.9973 & 2.4694 & 4.2064 \\
\hline $\mathrm{H}$ & 4.7452 & -0.1217 & 4.7829 \\
\hline
\end{tabular}




\begin{tabular}{|c|c|c|c|}
\hline $\mathrm{H}$ & 4.887 & -1.2708 & 3.4373 \\
\hline $\mathrm{H}$ & 5.5952 & 0.3815 & 3.3076 \\
\hline $\mathrm{H}$ & 0.5418 & 4.4931 & -0.6291 \\
\hline $\mathrm{H}$ & -0.1552 & 4.6707 & 0.9943 \\
\hline $\mathrm{H}$ & 1.5685 & 4.9353 & 0.721 \\
\hline $\mathrm{H}$ & 3.0107 & 4.1078 & 1.8771 \\
\hline $\mathrm{H}$ & 3.1742 & 2.8017 & 3.0233 \\
\hline $\mathrm{H}$ & 4.0593 & 2.7596 & 1.4767 \\
\hline $\mathrm{H}$ & 2.9592 & 0.3807 & -1.9437 \\
\hline $\mathrm{H}$ & 2.0634 & 1.8567 & -1.5829 \\
\hline $\mathrm{H}$ & 3.4818 & 1.3913 & -0.6528 \\
\hline
\end{tabular}

Table S5. Important thermodynamic parameters (a.u.) of 1 at B3LYP/6-311G(d,p) level in the gas phase.

\begin{tabular}{ccccc}
\hline Species & $E$ & $H$ & $G$ & $\begin{array}{c}\text { imaginary } \\
\text { frequencies }\end{array}$ \\
\hline 1a & -1765.019906 & -1765.018962 & -1765.121170 & 30.33 \\
1b & -1765.017027 & -1765.016082 & -1765.118155 & 31.78 \\
1c & -1765.014975 & -1765.014030 & -1765.117497 & 19.58 \\
\hline
\end{tabular}

$E$ : total energy; $H$ : enthalpy; $G$ : Gibbs free energy.

Table S6. Conformational analysis of $\mathbf{1 .}$

\begin{tabular}{lllll}
\hline Species & $\Delta E^{a}$ & $P_{E} \%^{b}$ & $\Delta G^{c}$ & $P_{G} \%^{b}$ \\
\hline 1a & 0.00 & 98.94 & 0.00 & 94.43 \\
1b & 1.81 & 0.53 & 1.89 & 3.87 \\
1c & 3.1 & 0.53 & 2.30 & 1.71
\end{tabular}

${ }^{a}$ Relative energy, and ${ }^{c}$ relative Gibbs free energy in $\mathrm{kcal} / \mathrm{mol} .{ }^{b}$ Conformational distribution calculated by using the respective parameters above at B3LYP/6$311 \mathrm{G}(\mathrm{d}, \mathrm{p})$ level in the gas phase. $\mathrm{T}=298 \mathrm{~K}$. 
Table S7. Stable conformers of $\mathbf{2}$ used for ECD calculations.

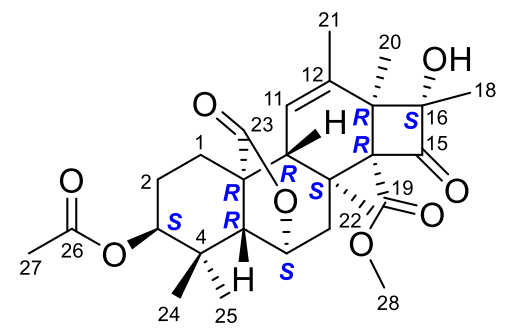

(3S,5R,6S, 8S, 9R,10R,13R,14R,16S)-2

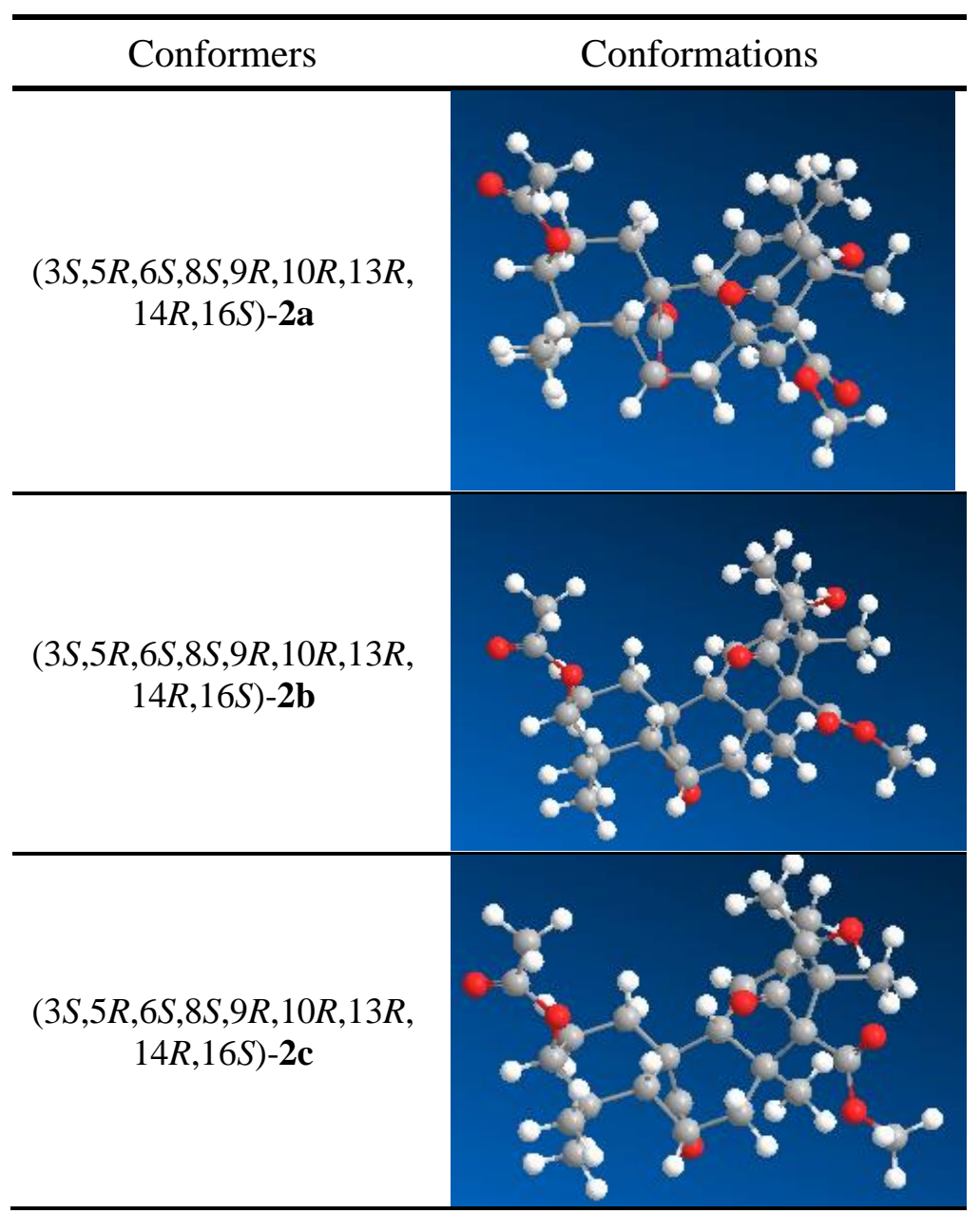


Table S8. Optimized Z-matrixes of 2 in the gas phase (A) at B3LYP/6-311G(d,p) level.

\begin{tabular}{|c|c|c|c|c|c|c|c|}
\hline \multicolumn{4}{|c|}{$2 a$} & \multicolumn{4}{|c|}{$2 b$} \\
\hline $\mathrm{C}$ & 2.2287 & 3.3124 & 0.3205 & $\mathrm{C}$ & 2.1281 & 3.3835 & 0.3059 \\
\hline $\mathrm{C}$ & 1.955 & 3.0906 & 1.8103 & $\mathrm{C}$ & 2.0474 & 3.0972 & 1.8076 \\
\hline $\mathrm{C}$ & 0.4334 & 2.9138 & 2.0794 & $\mathrm{C}$ & 0.5811 & 2.8214 & 2.2464 \\
\hline $\mathrm{C}$ & -0.1082 & 1.7198 & 1.2129 & $\mathrm{C}$ & 0.0067 & 1.626 & 1.4032 \\
\hline $\mathrm{C}$ & 0.2972 & 1.7028 & -0.2783 & $\mathrm{C}$ & 0.2309 & 1.6819 & -0.1249 \\
\hline $\mathrm{C}$ & 1.7477 & 2.1397 & -0.5314 & $\mathrm{C}$ & 1.6141 & 2.2128 & -0.5293 \\
\hline $\mathrm{C}$ & -1.62 & 1.6804 & 1.0336 & $\mathrm{C}$ & -1.511 & 1.502 & 1.4017 \\
\hline $\mathrm{C}$ & -2.0869 & 0.2664 & 0.6303 & $\mathrm{C}$ & -1.9434 & 0.077 & 0.9997 \\
\hline $\mathrm{C}$ & -1.4784 & -0.2325 & -0.7118 & $\mathrm{C}$ & -1.4758 & -0.339 & -0.4249 \\
\hline $\mathrm{C}$ & -0.7283 & 2.6618 & -0.8316 & $\mathrm{C}$ & -0.9052 & 2.5953 & -0.5152 \\
\hline $\mathrm{O}$ & -0.6142 & 3.364 & -1.8207 & $\mathrm{O}$ & -0.9515 & 3.3324 & -1.4842 \\
\hline $\mathrm{C}$ & 0.0095 & 0.2552 & -0.8316 & $\mathrm{C}$ & -0.0415 & 0.2385 & $\begin{array}{l}-0.6981 \\
\end{array}$ \\
\hline $\mathrm{O}$ & -1.8529 & 2.605 & -0.0395 & $\mathrm{O}$ & -1.9222 & 2.4453 & 0.4004 \\
\hline $\mathrm{C}$ & -0.2825 & 4.2672 & 1.8601 & $\mathrm{C}$ & -0.2298 & 4.136 & 2.1662 \\
\hline $\mathrm{C}$ & 0.2237 & 2.5548 & 3.5742 & $\mathrm{C}$ & 0.5718 & 2.402 & 3.7402 \\
\hline $\mathrm{O}$ & 2.6377 & 1.8879 & 2.2324 & $\mathrm{O}$ & 2.841 & 1.9242 & 2.0985 \\
\hline $\bar{C}$ & 3.9413 & 2.0269 & 2.5988 & $\mathrm{C}$ & 4.1695 & 2.1279 & 2.3137 \\
\hline $\mathrm{C}$ & 4.4962 & 0.6989 & 3.0134 & $\mathrm{C}$ & 4.8416 & 0.8225 & 2.6102 \\
\hline $\mathrm{O}$ & 4.5766 & 3.0706 & 2.5911 & $\mathrm{O}$ & 4.7416 & 3.2067 & 2.2698 \\
\hline $\mathrm{H}$ & 0.2366 & 0.7984 & 1.7029 & $\mathrm{H}$ & 0.4585 & 0.7114 & 1.8123 \\
\hline $\mathrm{C}$ & -1.448 & -1.8011 & -0.7801 & $\mathrm{C}$ & -1.3712 & -1.8985 & -0.5693 \\
\hline $\mathrm{C}$ & -0.5855 & -2.4019 & -2.0188 & $\mathrm{C}$ & -0.6231 & -2.4142 & -1.9194 \\
\hline $\mathrm{C}$ & 0.327 & -1.371 & -2.7193 & $\mathrm{C}$ & 0.146 & -1.3041 & -2.6737 \\
\hline $\mathrm{C}$ & 0.558 & -0.1601 & -2.1701 & $\mathrm{C}$ & 0.3681 & -0.1 & -2.1059 \\
\hline $\mathrm{C}$ & 0.9616 & -1.7431 & -4.0347 & $\mathrm{C}$ & 0.6529 & -1.5901 & -4.0645 \\
\hline $\mathrm{C}$ & -0.3944 & -2.4942 & 0.145 & $\mathrm{C}$ & -0.1763 & -2.5597 & 0.203 \\
\hline $\mathrm{C}$ & 0.1719 & -3.3808 & -1.0024 & $\mathrm{C}$ & 0.2943 & -3.3796 & -1.0308 \\
\hline $\mathrm{C}$ & -1.4272 & -3.1676 & -3.0568 & $\mathrm{C}$ & -1.5094 & -3.2054 & -2.8988 \\
\hline $\mathrm{O}$ & -0.0961 & -2.3866 & 1.3202 & $\mathrm{O}$ & 0.2613 & -2.4672 & 1.3347 \\
\hline $\mathrm{C}$ & 1.6942 & -3.4519 & -1.0274 & $\mathrm{C}$ & 1.8045 & -3.3701 & -1.2345 \\
\hline $\mathrm{O}$ & -0.3446 & -4.7385 & -0.9472 & $\mathrm{O}$ & -0.1444 & -4.7638 & -0.9657 \\
\hline $\mathrm{C}$ & -2.3905 & 0.2498 & -1.885 & $\mathrm{C}$ & -2.5468 & 0.1291 & -1.4608 \\
\hline
\end{tabular}




\begin{tabular}{|c|c|c|c|c|c|c|c|}
\hline $\mathrm{H}$ & 0.619 & -0.3465 & -0.1421 & $\mathrm{H}$ & 0.6772 & -0.3484 & -0.1082 \\
\hline $\mathrm{C}$ & -2.8515 & -2.4765 & -0.5049 & $\mathrm{C}$ & -2.6499 & -2.6793 & -0.0702 \\
\hline $\mathrm{O}$ & -3.8338 & -2.3955 & -1.2424 & $\mathrm{O}$ & -2.7873 & -3.2246 & 1.023 \\
\hline $\mathrm{O}$ & -2.8968 & -3.161 & 0.6798 & $\mathrm{O}$ & -3.6568 & -2.6572 & $\begin{array}{l}-0.9979 \\
\end{array}$ \\
\hline $\mathrm{C}$ & -4.1517 & -3.7831 & 0.9654 & $\mathrm{C}$ & -4.8509 & -3.3361 & -0.6017 \\
\hline $\mathrm{H}$ & 1.7667 & 4.242 & -0.0268 & $\mathrm{H}$ & 1.5771 & 4.2948 & 0.0523 \\
\hline $\mathrm{H}$ & 3.3069 & 3.4271 & 0.1554 & $\mathrm{H}$ & 3.1707 & 3.5677 & 0.0196 \\
\hline $\mathrm{H}$ & 2.3247 & 3.9475 & 2.3888 & $\mathrm{H}$ & 2.4358 & 3.9551 & 2.372 \\
\hline $\mathrm{H}$ & 2.4174 & 1.2901 & -0.3425 & $\mathrm{H}$ & 2.3476 & 1.399 & -0.4546 \\
\hline $\mathrm{H}$ & 1.8885 & 2.4121 & -1.5844 & $\mathrm{H}$ & 1.6124 & 2.5278 & -1.5799 \\
\hline $\mathrm{H}$ & -2.1646 & 2.0087 & 1.9234 & $\mathrm{H}$ & -1.9627 & 1.7677 & 2.3617 \\
\hline $\mathrm{H}$ & -3.1821 & 0.2626 & 0.5624 & $\mathrm{H}$ & -3.0368 & 0.0094 & 1.0629 \\
\hline $\mathrm{H}$ & -1.8361 & -0.4199 & 1.4474 & $\mathrm{H}$ & -1.5565 & -0.6192 & 1.7527 \\
\hline $\mathrm{H}$ & -1.3429 & 4.2142 & 2.1284 & $\mathrm{H}$ & -1.2459 & 4.011 & 2.555 \\
\hline $\mathrm{H}$ & 0.1623 & 5.0447 & 2.4932 & $\mathrm{H}$ & 0.2438 & 4.9177 & 2.7727 \\
\hline $\mathrm{H}$ & -0.2176 & 4.6263 & 0.8309 & $\mathrm{H}$ & -0.3086 & 4.5315 & 1.1515 \\
\hline $\mathrm{H}$ & 0.6789 & 1.5927 & 3.8334 & $\mathrm{H}$ & 1.1073 & 1.4608 & 3.906 \\
\hline $\mathrm{H}$ & 0.6687 & 3.3152 & 4.2264 & $\mathrm{H}$ & 1.0489 & 3.166 & 4.365 \\
\hline $\mathrm{H}$ & -0.841 & 2.4886 & 3.8234 & $\mathrm{H}$ & -0.4501 & 2.2644 & 4.11 \\
\hline $\mathrm{H}$ & 5.5412 & 0.8199 & 3.3126 & $\mathrm{H}$ & 4.7365 & 0.1497 & 1.7554 \\
\hline $\mathrm{H}$ & 3.9325 & 0.3116 & 3.8659 & $\mathrm{H}$ & 5.9065 & 0.9955 & 2.7897 \\
\hline $\mathrm{H}$ & 4.4523 & 0.0009 & 2.1734 & $\mathrm{H}$ & 4.4052 & 0.3765 & 3.5075 \\
\hline $\mathrm{H}$ & 1.197 & 0.5449 & -2.6988 & $\mathrm{H}$ & 0.9037 & 0.6584 & -2.6741 \\
\hline $\mathrm{H}$ & 0.2108 & -1.7681 & -4.8306 & $\mathrm{H}$ & -0.1782 & -1.6368 & -4.775 \\
\hline $\mathrm{H}$ & 1.7343 & -1.0262 & -4.3331 & $\mathrm{H}$ & 1.3428 & -0.8151 & -4.4158 \\
\hline $\mathrm{H}$ & 1.4397 & -2.725 & -3.9715 & $\mathrm{H}$ & 1.1945 & -2.5401 & -4.093 \\
\hline $\mathrm{H}$ & -2.0372 & -2.4841 & -3.6567 & $\mathrm{H}$ & -2.225 & -2.5498 & -3.4064 \\
\hline $\mathrm{H}$ & -0.7935 & -3.7482 & -3.7363 & $\mathrm{H}$ & -0.9093 & -3.7127 & -3.6623 \\
\hline $\mathrm{H}$ & -2.1066 & -3.8879 & -2.5904 & $\mathrm{H}$ & -2.0799 & -3.9938 & -2.3985 \\
\hline $\mathrm{H}$ & 2.0457 & -3.9388 & -1.9425 & $\mathrm{H}$ & 2.0693 & -3.8101 & -2.2011 \\
\hline $\mathrm{H}$ & 2.0686 & -4.0346 & -0.1783 & $\mathrm{H}$ & 2.3037 & -3.958 & -0.456 \\
\hline $\mathrm{H}$ & 2.1572 & -2.4624 & -0.9644 & $\mathrm{H}$ & 2.2231 & -2.3599 & -1.19 \\
\hline $\mathrm{H}$ & -0.056 & -5.0849 & -0.0817 & $\mathrm{H}$ & 0.2178 & -5.1059 & -0.1258 \\
\hline $\mathrm{H}$ & -3.4455 & 0.0433 & -1.6747 & $\mathrm{H}$ & -3.5563 & -0.1391 & -1.1302 \\
\hline $\mathrm{H}$ & -2.3281 & 1.3176 & -2.0871 & $\mathrm{H}$ & -2.562 & 1.2038 & -1.6324 \\
\hline
\end{tabular}




\begin{tabular}{|c|c|c|c|c|c|c|c|}
\hline $\mathrm{H}$ & -2.1661 & -0.2526 & -2.8296 & $\mathrm{H}$ & -2.4152 & -0.3346 & -2.4424 \\
\hline $\mathrm{H}$ & -4.06 & -4.3048 & 1.9219 & $\mathrm{H}$ & -5.5693 & -3.2619 & -1.4226 \\
\hline $\mathrm{H}$ & -4.9399 & -3.0293 & 1.0557 & $\mathrm{H}$ & -4.6457 & -4.3948 & -0.4154 \\
\hline $\mathrm{H}$ & -4.3999 & -4.5173 & 0.1927 & $\mathrm{H}$ & -5.2849 & -2.8605 & 0.2831 \\
\hline
\end{tabular}

\begin{tabular}{|c|c|c|c|}
\hline \multicolumn{4}{|c|}{$2 \mathrm{c}$} \\
\hline $\mathrm{C}$ & 2.126 & 3.366 & 0.1525 \\
\hline $\mathrm{C}$ & 2.1001 & 3.0845 & 1.6569 \\
\hline $\mathrm{C}$ & 0.6508 & 2.8079 & 2.1481 \\
\hline $\mathrm{C}$ & 0.0501 & 1.6075 & 1.331 \\
\hline $\mathrm{C}$ & 0.2184 & 1.6569 & -0.2033 \\
\hline $\mathrm{C}$ & 1.5847 & 2.1914 & -0.6595 \\
\hline $\mathrm{C}$ & -1.4647 & 1.4814 & 1.3824 \\
\hline $\mathrm{C}$ & -1.915 & 0.0561 & 1.0021 \\
\hline $\mathrm{C}$ & -1.493 & -0.3856 & -0.4308 \\
\hline $\mathrm{C}$ & -0.9341 & 2.5622 & -0.5616 \\
\hline $\mathrm{O}$ & -1.0199 & 3.2877 & -1.5366 \\
\hline $\mathrm{C}$ & -0.0691 & 0.2098 & -0.7575 \\
\hline $\mathrm{O}$ & -1.9151 & 2.4185 & 0.3924 \\
\hline $\mathrm{C}$ & -0.1655 & 4.1204 & 2.0901 \\
\hline $\mathrm{C}$ & 0.695 & 2.3956 & 3.6433 \\
\hline $\mathrm{O}$ & 2.9048 & 1.9132 & 1.9227 \\
\hline $\mathrm{C}$ & 4.2404 & 2.1186 & 2.0876 \\
\hline $\mathrm{C}$ & 4.9249 & 0.8144 & 2.3595 \\
\hline $\mathrm{O}$ & 4.8085 & 3.1984 & 2.0218 \\
\hline $\mathrm{H}$ & 0.517 & 0.6955 & 1.7285 \\
\hline $\mathrm{C}$ & -1.3612 & -1.9508 & -0.5614 \\
\hline $\mathrm{C}$ & -0.6564 & -2.4439 & -1.9447 \\
\hline $\mathrm{C}$ & 0.0681 & -1.3314 & -2.7323 \\
\hline $\mathrm{C}$ & 0.2956 & -0.1236 & -2.1779 \\
\hline $\mathrm{C}$ & 0.5299 & -1.6216 & -4.1378 \\
\hline-0.1242 & -2.5791 & 0.1672 \\
\hline $\mathrm{C}$ & -1.6093 & -3.2106 & -2.8827 \\
\hline $\mathrm{C}$ & 0.3082 & -2.4639 & 1.2982 \\
\hline
\end{tabular}




\begin{tabular}{|c|c|c|c|}
\hline $\mathrm{C}$ & 1.8244 & -3.3357 & -1.345 \\
\hline $\mathrm{O}$ & -0.0523 & -4.802 & -1.0521 \\
\hline $\mathrm{C}$ & -2.5891 & 0.0661 & -1.4493 \\
\hline $\mathrm{H}$ & 0.675 & $\begin{array}{l}-0.3688 \\
\end{array}$ & -0.1919 \\
\hline $\mathrm{C}$ & -2.5486 & -2.8562 & -0.035 \\
\hline $\mathrm{O}$ & -2.4669 & -4.0794 & 0.1126 \\
\hline $\mathrm{O}$ & -3.7006 & -2.1766 & 0.2289 \\
\hline $\mathrm{C}$ & -4.7857 & -2.9822 & 0.6972 \\
\hline $\mathrm{H}$ & 1.5644 & 4.2754 & -0.0842 \\
\hline $\mathrm{H}$ & 3.1572 & 3.5512 & -0.1718 \\
\hline $\mathrm{H}$ & 2.5072 & 3.9446 & 2.2045 \\
\hline $\mathrm{H}$ & 2.323 & 1.3801 & -0.6095 \\
\hline $\mathrm{H}$ & 1.5439 & 2.5038 & -1.7101 \\
\hline $\mathrm{H}$ & -1.883 & 1.7516 & 2.3562 \\
\hline $\mathrm{H}$ & -3.0066 & 0.0208 & 1.0953 \\
\hline $\mathrm{H}$ & -1.522 & -0.6402 & 1.7515 \\
\hline $\mathrm{H}$ & -1.1663 & 3.9956 & 2.5169 \\
\hline $\mathrm{H}$ & 0.3283 & 4.9068 & 2.674 \\
\hline $\mathrm{H}$ & -0.2829 & 4.5093 & 1.0765 \\
\hline $\mathrm{H}$ & 1.2385 & 1.4566 & 3.7946 \\
\hline $\mathrm{H}$ & 1.1916 & 3.1638 & 4.2474 \\
\hline $\mathrm{H}$ & -0.3129 & 2.2572 & 4.0493 \\
\hline $\mathrm{H}$ & 4.7874 & 0.1402 & 1.5104 \\
\hline $\mathrm{H}$ & 5.9958 & 0.9888 & 2.4972 \\
\hline $\mathrm{H}$ & 4.5243 & 0.3692 & 3.2737 \\
\hline $\mathrm{H}$ & 0.8015 & 0.6388 & -2.7676 \\
\hline $\mathrm{H}$ & -0.3237 & -1.6648 & -4.8215 \\
\hline $\mathrm{H}$ & 1.2126 & -0.8504 & -4.5109 \\
\hline $\mathrm{H}$ & 1.0645 & -2.5748 & -4.183 \\
\hline $\mathrm{H}$ & -2.333 & -2.5355 & -3.3516 \\
\hline $\mathrm{H}$ & -1.0574 & -3.7263 & -3.6764 \\
\hline $\mathrm{H}$ & -2.1819 & -3.985 & -2.3668 \\
\hline $\mathrm{H}$ & 2.0763 & -3.7535 & -2.3248 \\
\hline $\mathrm{H}$ & 2.3612 & -3.9202 & -0.5892 \\
\hline $\mathrm{H}$ & 2.2137 & -2.3142 & -1.2957 \\
\hline
\end{tabular}




\begin{tabular}{|c|c|c|c|}
\hline $\mathrm{H}$ & -0.8874 & -4.8563 & -0.5402 \\
\hline $\mathrm{H}$ & -3.5903 & -0.2354 & -1.1287 \\
\hline $\mathrm{H}$ & -2.6373 & 1.144 & -1.5947 \\
\hline $\mathrm{H}$ & -2.4509 & -0.3693 & -2.442 \\
\hline $\mathrm{H}$ & -5.6408 & -2.3249 & 0.8767 \\
\hline $\mathrm{H}$ & -5.0677 & -3.7202 & -0.06 \\
\hline $\mathrm{H}$ & -4.5199 & -3.4712 & 1.6394 \\
\hline
\end{tabular}

Table S9. Important thermodynamic parameters (a.u.) of 2 at B3LYP/6-311G(d,p) level in the gas phase.

\begin{tabular}{ccccc}
\hline Species & $E$ & $H$ & $G$ & $\begin{array}{c}\text { imaginary } \\
\text { frequencies }\end{array}$ \\
\hline $\mathbf{2 a}$ & -1651.698954 & -1651.698010 & -1651.799140 & 24.40 \\
$\mathbf{2 b}$ & -1651.696671 & -1651.695726 & -1651.797121 & 25.57 \\
$\mathbf{2 c}$ & -1651.702387 & -1651.701443 & -1651.800949 & 27.04 \\
\hline
\end{tabular}

$E$ : total energy; $H$ : enthalpy; $G$ : Gibbs free energy.

Table S10. Conformational analysis of 2 .

\begin{tabular}{lllll}
\hline Species & $\Delta E^{a}$ & $P_{E} \%^{b}$ & $\Delta G^{c}$ & $P_{G} \%^{b}$ \\
\hline 2a & 2.15 & 2.29 & 1.14 & 12.00 \\
2b & 3.59 & 0.19 & 2.40 & 1.32 \\
$\mathbf{2 c}$ & 0.00 & 97.52 & 0.00 & 86.67
\end{tabular}

${ }^{a}$ Relative energy, and ${ }^{c}$ relative Gibbs free energy in $\mathrm{kcal} / \mathrm{mol} .{ }^{b}$ Conformational distribution calculated by using the respective parameters above at B3LYP/6$311 \mathrm{G}(\mathrm{d}, \mathrm{p})$ level in the gas phase. $\mathrm{T}=298 \mathrm{~K}$. 
Table S11. Stable conformers of $\mathbf{3}$ used for ECD calculations.

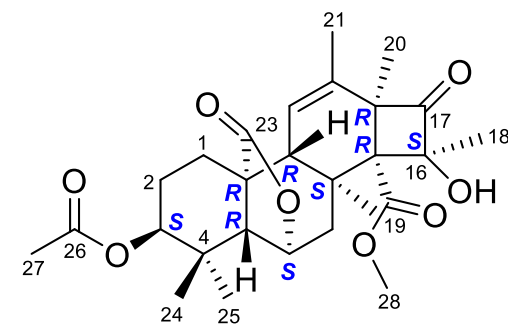

$(3 S, 5 R, 6 S, 8 S, 9 R, 10 R, 13 R, 14 R, 16 S)-3$

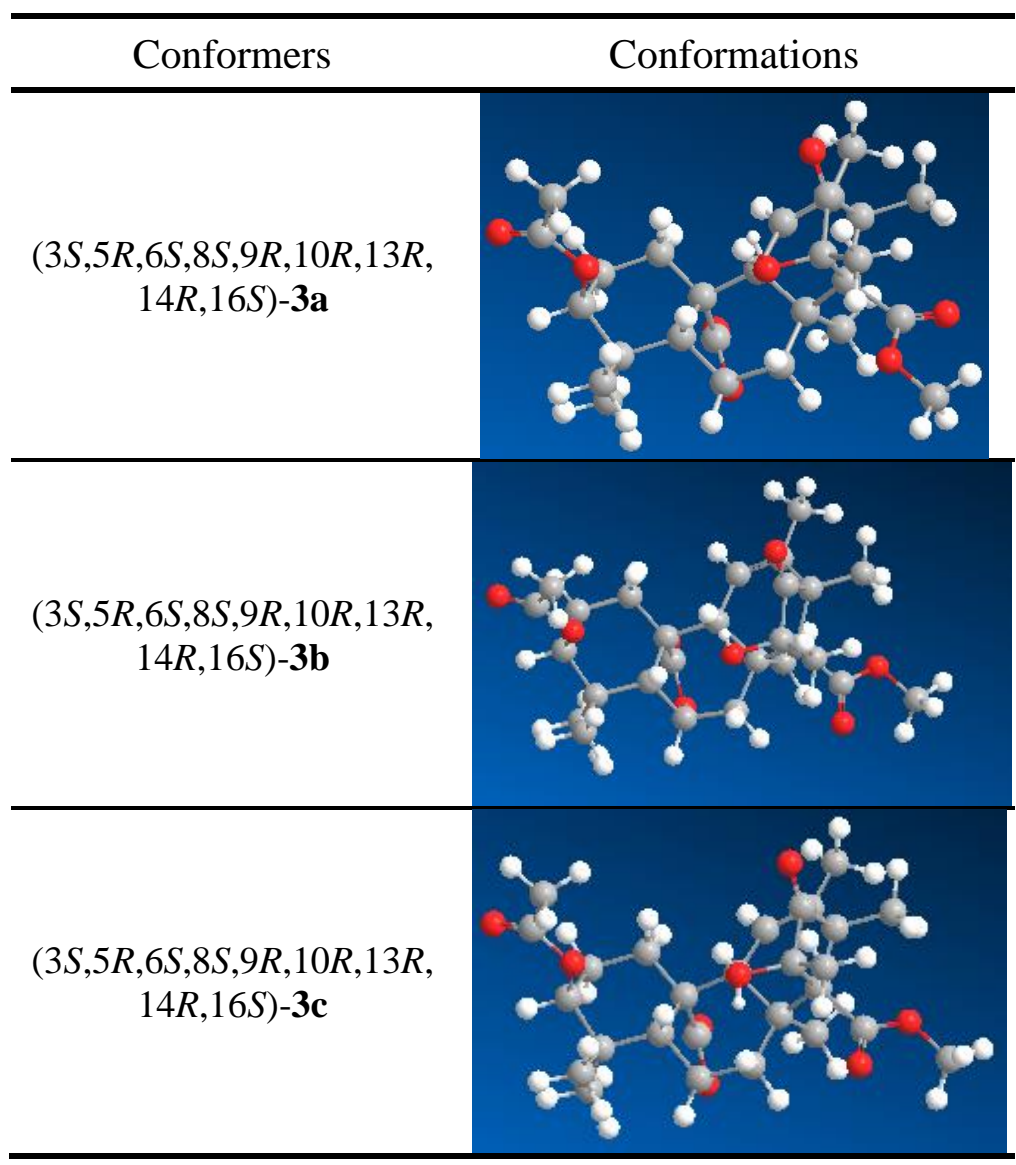


Table S12. Optimized Z-matrixes of 3 in the gas phase $(\AA)$ at B3LYP/6-311G(d,p) level.

\begin{tabular}{|c|c|c|c|c|c|c|c|}
\hline \multicolumn{4}{|c|}{$3 \mathbf{a}$} & \multicolumn{4}{|c|}{$3 \mathbf{b}$} \\
\hline $\mathrm{C}$ & -3.2125 & -0.1858 & -2.4387 & $\mathrm{C}$ & -2.2301 & -0.1628 & -3.3793 \\
\hline $\mathrm{C}$ & -2.7785 & -1.6536 & -2.4655 & $\mathrm{C}$ & -2.19 & -1.6639 & -3.0813 \\
\hline $\mathrm{C}$ & -1.2556 & -1.7813 & -2.754 & $\mathrm{C}$ & -0.7364 & -2.1399 & -2.7995 \\
\hline $\mathrm{C}$ & -0.4545 & -0.9648 & -1.6763 & $\mathrm{C}$ & -0.1386 & -1.3022 & -1.6115 \\
\hline $\mathrm{C}$ & -0.9454 & 0.4689 & -1.3843 & $\mathrm{C}$ & -0.3239 & 0.229 & -1.6794 \\
\hline $\mathrm{C}$ & -2.4752 & 0.6095 & -1.3635 & $\mathrm{C}$ & -1.6961 & 0.6666 & -2.2136 \\
\hline $\mathrm{C}$ & 0.9837 & -0.6349 & -2.0495 & $\mathrm{C}$ & 1.3788 & -1.3384 & -1.4909 \\
\hline $\mathrm{C}$ & 1.8193 & -0.303 & -0.7984 & $\mathrm{C}$ & 1.8341 & -0.9389 & -0.0738 \\
\hline $\mathrm{C}$ & 1.2747 & 0.9037 & 0.0226 & $\mathrm{C}$ & 1.3724 & 0.4856 & 0.3545 \\
\hline $\mathrm{C}$ & -0.2936 & 0.932 & -0.0275 & $\mathrm{C}$ & -0.0403 & 0.8107 & -0.2438 \\
\hline $\mathrm{C}$ & 1.7167 & 0.827 & 1.553 & $\mathrm{C}$ & 1.2786 & 0.6215 & 1.9407 \\
\hline $\mathrm{C}$ & 0.8481 & 1.8625 & 2.4906 & $\mathrm{C}$ & 0.4419 & 1.9587 & 2.4 \\
\hline $\mathrm{C}$ & -0.2625 & 2.6494 & 1.7805 & $\mathrm{C}$ & -0.1519 & 2.8012 & 1.2594 \\
\hline $\mathrm{C}$ & -0.7682 & 2.2064 & 0.6118 & $\mathrm{C}$ & -0.3569 & 2.2526 & 0.0439 \\
\hline $\mathrm{C}$ & -0.9818 & -1.3815 & -4.223 & $\mathrm{C}$ & 0.0769 & -2.0939 & -4.1145 \\
\hline $\mathrm{C}$ & -0.8419 & -3.2717 & -2.6305 & $\mathrm{C}$ & -0.7682 & -3.6295 & -2.3664 \\
\hline $\mathrm{O}$ & -3.0535 & -2.2409 & -1.1731 & $\mathrm{O}$ & -2.9956 & -1.9246 & -1.9092 \\
\hline $\mathrm{C}$ & -4.3138 & -2.7187 & -0.9808 & $\mathrm{C}$ & -4.3295 & -2.0998 & -2.1172 \\
\hline $\mathrm{O}$ & -5.2181 & -2.6965 & -1.8023 & $\mathrm{O}$ & -4.8942 & -2.0577 & -3.2 \\
\hline $\mathrm{C}$ & -4.4375 & -3.2814 & 0.4017 & $\mathrm{C}$ & -5.0177 & -2.3519 & -0.811 \\
\hline $\mathrm{C}$ & -0.2882 & 1.2036 & -2.5275 & $\mathrm{C}$ & 0.8209 & 0.5847 & -2.5964 \\
\hline $\mathrm{O}$ & -0.6747 & 2.2304 & -3.0575 & $\mathrm{O}$ & 0.8904 & 1.5458 & -3.3424 \\
\hline $\mathrm{O}$ & 0.8596 & 0.5307 & -2.8783 & $\mathrm{O}$ & 1.8151 & -0.3538 & -2.4413 \\
\hline $\mathrm{C}$ & 1.9193 & 2.2138 & -0.5575 & $\mathrm{C}$ & 2.4684 & 1.509 & -0.1164 \\
\hline $\mathrm{C}$ & 3.3194 & 1.0118 & 1.6513 & $\mathrm{C}$ & 2.7501 & 0.4149 & 2.5604 \\
\hline $\mathrm{O}$ & 3.9291 & 2.0368 & 1.9418 & $\mathrm{O}$ & 3.2797 & -0.6709 & 2.7902 \\
\hline $\mathrm{O}$ & 3.9691 & -0.1509 & 1.3332 & $\mathrm{O}$ & 3.3994 & 1.5968 & 2.7804 \\
\hline $\mathrm{C}$ & 5.3962 & -0.0633 & 1.3539 & $\mathrm{C}$ & 4.732 & 1.4656 & 3.2823 \\
\hline $\mathrm{C}$ & -0.8152 & 3.8921 & 2.425 & $\mathrm{C}$ & -0.551 & 4.2278 & 1.525 \\
\hline $\mathrm{C}$ & 1.1974 & -0.3966 & 2.4866 & $\mathrm{C}$ & 0.1967 & -0.2885 & 2.7477 \\
\hline $\mathrm{C}$ & 1.6205 & 2.7105 & 3.5088 & $\mathrm{C}$ & 1.0011 & 2.814 & 3.5445 \\
\hline $\mathrm{C}$ & 2.1444 & -1.0335 & 3.5034 & $\mathrm{C}$ & 0.587 & -0.9094 & 4.0885 \\
\hline
\end{tabular}




\begin{tabular}{|c|c|c|c|c|c|c|c|}
\hline $\mathrm{O}$ & 0.5042 & -1.4757 & 1.802 & $\mathrm{O}$ & -0.4901 & -1.3124 & 1.9774 \\
\hline $\mathrm{C}$ & 0.2289 & 0.6027 & 3.1692 & $\mathrm{C}$ & -0.657 & 0.9886 & 2.9395 \\
\hline $\mathrm{O}$ & -0.6741 & 0.4201 & 3.9655 & $\mathrm{O}$ & -1.7815 & 1.1392 & 3.3818 \\
\hline $\mathrm{H}$ & -0.4784 & -1.5611 & -0.7545 & $\mathrm{H}$ & -0.5997 & -1.6924 & -0.6948 \\
\hline $\mathrm{H}$ & -0.6747 & 0.1684 & 0.6608 & $\mathrm{H}$ & -0.7988 & 0.2853 & 0.3473 \\
\hline $\mathrm{H}$ & -3.066 & 0.2823 & -3.4174 & $\mathrm{H}$ & -1.6706 & 0.069 & -4.2913 \\
\hline $\mathrm{H}$ & -4.2866 & -0.1209 & -2.227 & $\mathrm{H}$ & -3.2642 & 0.15 & -3.5679 \\
\hline $\mathrm{H}$ & -3.3368 & -2.1929 & -3.2421 & $\mathrm{H}$ & -2.5911 & -2.2241 & -3.9362 \\
\hline $\mathrm{H}$ & -2.8531 & 0.2838 & -0.3853 & $\mathrm{H}$ & -2.4317 & 0.6164 & $\begin{array}{l}-1.3999 \\
\end{array}$ \\
\hline $\mathrm{H}$ & -2.7666 & 1.6616 & -1.4684 & $\mathrm{H}$ & -1.6675 & 1.7149 & -2.5348 \\
\hline $\mathrm{H}$ & 1.4718 & -1.433 & -2.6161 & $\mathrm{H}$ & 1.8054 & -2.3106 & -1.7538 \\
\hline $\mathrm{H}$ & 2.848 & -0.0973 & -1.1197 & $\mathrm{H}$ & 2.9289 & -1.0002 & -0.0328 \\
\hline $\mathrm{H}$ & 1.8797 & -1.2045 & -0.1813 & $\mathrm{H}$ & 1.4759 & -1.6986 & 0.6274 \\
\hline $\mathrm{H}$ & -1.56 & 2.7696 & 0.1221 & $\mathrm{H}$ & -0.7869 & 2.8564 & -0.7526 \\
\hline $\mathrm{H}$ & 0.0647 & -1.5459 & -4.5008 & $\mathrm{H}$ & 1.0817 & -2.5098 & -3.9859 \\
\hline $\mathrm{H}$ & -1.5865 & -1.99 & -4.9065 & $\mathrm{H}$ & -0.4132 & -2.6938 & -4.8911 \\
\hline $\mathrm{H}$ & -1.2222 & -0.3379 & -4.4364 & $\mathrm{H}$ & 0.1839 & -1.0852 & -4.5187 \\
\hline $\mathrm{H}$ & -0.9786 & -3.6528 & -1.6127 & $\mathrm{H}$ & -1.2611 & -4.2481 & -3.1253 \\
\hline $\mathrm{H}$ & -1.4392 & -3.9013 & -3.3003 & $\mathrm{H}$ & 0.2432 & -4.0255 & -2.2239 \\
\hline $\mathrm{H}$ & 0.2115 & -3.4167 & -2.8935 & $\mathrm{H}$ & -1.3091 & -3.7719 & -1.4245 \\
\hline $\mathrm{H}$ & -4.2511 & -2.4963 & 1.1389 & $\mathrm{H}$ & -4.6171 & -3.2582 & -0.3501 \\
\hline $\mathrm{H}$ & -5.4517 & -3.6638 & 0.5482 & $\mathrm{H}$ & -4.8836 & -1.4919 & -0.15 \\
\hline $\mathrm{H}$ & -3.732 & -4.1061 & 0.5305 & $\mathrm{H}$ & -6.0879 & -2.4937 & -0.9865 \\
\hline $\mathrm{H}$ & 2.9929 & 2.082 & -0.7365 & $\mathrm{H}$ & 3.4769 & 1.1418 & 0.1067 \\
\hline $\mathrm{H}$ & 1.4899 & 2.5353 & -1.5052 & $\mathrm{H}$ & 2.4518 & 1.7154 & -1.1853 \\
\hline $\mathrm{H}$ & 1.8332 & 3.0638 & 0.1271 & $\mathrm{H}$ & 2.3825 & 2.4779 & 0.3858 \\
\hline $\mathrm{H}$ & 5.7981 & -1.0423 & 1.0788 & $\mathrm{H}$ & 5.1441 & 2.4701 & 3.4115 \\
\hline $\mathrm{H}$ & 5.7448 & 0.6726 & 0.6228 & $\mathrm{H}$ & 4.7262 & 0.9651 & 4.2554 \\
\hline $\mathrm{H}$ & 5.749 & 0.1866 & 2.3591 & $\mathrm{H}$ & 5.3582 & 0.923 & 2.5673 \\
\hline $\mathrm{H}$ & -0.0492 & 4.6714 & 2.4841 & $\mathrm{H}$ & 0.3255 & 4.837 & 1.7659 \\
\hline $\mathrm{H}$ & -1.658 & 4.3069 & 1.8614 & $\mathrm{H}$ & -1.0368 & 4.6867 & 0.6569 \\
\hline $\mathrm{H}$ & -1.1786 & 3.6707 & 3.4335 & $\mathrm{H}$ & -1.261 & 4.2784 & 2.3566 \\
\hline $\mathrm{H}$ & 2.1217 & 3.5544 & 3.0232 & $\mathrm{H}$ & 1.7944 & 3.4827 & 3.1947 \\
\hline $\mathrm{H}$ & 0.9609 & 3.1097 & 4.2873 & $\mathrm{H}$ & 0.2211 & 3.4318 & 4.0038 \\
\hline $\mathrm{H}$ & 2.3796 & 2.1205 & 4.0328 & $\mathrm{H}$ & 1.4083 & 2.1933 & 4.3495 \\
\hline
\end{tabular}




\begin{tabular}{|c|c|c|c|c|c|c|c|}
\hline $\mathrm{H}$ & 2.8531 & -1.7088 & 3.014 & $\mathrm{H}$ & 1.2414 & -1.7749 & 3.9443 \\
\hline $\mathrm{H}$ & 2.7125 & -0.2829 & 4.0614 & $\mathrm{H}$ & 1.1002 & -0.1934 & 4.738 \\
\hline $\mathrm{H}$ & 1.5834 & -1.6285 & 4.2332 & $\mathrm{H}$ & -0.3016 & -1.2596 & 4.6259 \\
\hline $\mathrm{H}$ & -0.1111 & -1.8344 & 2.4719 & $\mathrm{H}$ & -1.3419 & -1.4373 & 2.4402 \\
\hline
\end{tabular}

\begin{tabular}{|c|c|c|c|}
\hline \multicolumn{4}{|c|}{$3 c$} \\
\hline $\mathrm{C}$ & -3.4038 & -0.186 & -2.2133 \\
\hline $\mathrm{C}$ & -3.0426 & -1.6734 & -2.2469 \\
\hline $\mathrm{C}$ & -1.5548 & -1.8775 & -2.6517 \\
\hline $\mathrm{C}$ & -0.6357 & -1.0895 & -1.6496 \\
\hline $\mathrm{C}$ & -1.034 & 0.3698 & -1.3434 \\
\hline $\mathrm{C}$ & -2.5492 & 0.5881 & -1.212 \\
\hline $\mathrm{C}$ & 0.7851 & -0.8363 & -2.1335 \\
\hline $\mathrm{C}$ & 1.728 & -0.535 & -0.9517 \\
\hline $\mathrm{C}$ & 1.3005 & 0.7024 & -0.1074 \\
\hline $\mathrm{C}$ & -0.2631 & 0.8146 & -0.0448 \\
\hline $\mathrm{C}$ & 1.8476 & 0.6211 & 1.3912 \\
\hline $\mathrm{C}$ & 1.1058 & 1.7058 & 2.3706 \\
\hline $\mathrm{C}$ & -0.0003 & 2.5547 & 1.7226 \\
\hline $\mathrm{C}$ & -0.6156 & 2.1252 & 0.6018 \\
\hline $\mathrm{C}$ & -1.3766 & -1.5061 & -4.1424 \\
\hline $\mathrm{C}$ & -1.2039 & -3.3847 & -2.5396 \\
\hline $\mathrm{O}$ & -3.2373 & -2.2271 & -0.9259 \\
\hline $\mathrm{C}$ & -4.4996 & -2.6303 & -0.6151 \\
\hline $\mathrm{O}$ & -5.4679 & -2.5767 & -1.3587 \\
\hline $\mathrm{C}$ & -4.5342 & -3.155 & 0.7874 \\
\hline $\mathrm{C}$ & -0.4278 & 1.0586 & -2.542 \\
\hline $\mathrm{O}$ & -0.7987 & 2.0994 & -3.0557 \\
\hline $\mathrm{O}$ & 0.6569 & 0.3256 & -2.9664 \\
\hline $\mathrm{C}$ & 1.9658 & 1.972 & -0.7545 \\
\hline $\mathrm{C}$ & 3.4505 & 0.6137 & 1.3477 \\
\hline $\mathrm{O}$ & 4.1393 & -0.3858 & 1.1441 \\
\hline $\mathrm{O}$ & 3.9961 & 1.8522 & 1.5228 \\
\hline $\mathrm{C}$ & 5.4231 & 1.8975 & 1.4433 \\
\hline $\mathrm{C}$ & -0.4328 & 3.8359 & 2.383 \\
\hline
\end{tabular}




\begin{tabular}{|c|c|c|c|}
\hline $\mathrm{C}$ & 1.3258 & -0.5733 & 2.3738 \\
\hline $\mathrm{C}$ & 1.9725 & 2.5091 & 3.3497 \\
\hline $\mathrm{C}$ & 2.2922 & -1.2254 & 3.3674 \\
\hline $\mathrm{O}$ & 0.553 & -1.6267 & 1.7348 \\
\hline $\mathrm{C}$ & 0.4452 & 0.4908 & 3.0971 \\
\hline $\mathrm{O}$ & -0.4062 & 0.4059 & 3.9636 \\
\hline $\mathrm{H}$ & -0.619 & -1.6735 & -0.7199 \\
\hline $\mathrm{H}$ & -0.6342 & 0.083 & 0.6826 \\
\hline $\mathrm{H}$ & -3.3119 & 0.2607 & -3.2085 \\
\hline $\mathrm{H}$ & -4.4542 & -0.0662 & -1.9212 \\
\hline $\mathrm{H}$ & -3.6861 & -2.1978 & -2.9655 \\
\hline $\mathrm{H}$ & -2.8682 & 0.2972 & -0.2023 \\
\hline $\mathrm{H}$ & -2.7954 & 1.6519 & -1.3146 \\
\hline $\mathrm{H}$ & 1.1894 & -1.6634 & -2.724 \\
\hline $\mathrm{H}$ & 2.7392 & -0.3801 & -1.3487 \\
\hline $\mathrm{H}$ & 1.7972 & -1.4334 & -0.3326 \\
\hline $\mathrm{H}$ & -1.4086 & 2.7251 & 0.1603 \\
\hline $\mathrm{H}$ & -0.364 & -1.725 & -4.4975 \\
\hline $\mathrm{H}$ & -2.0616 & -2.0904 & -4.769 \\
\hline $\mathrm{H}$ & -1.5812 & -0.454 & -4.351 \\
\hline $\mathrm{H}$ & -1.279 & -3.7485 & -1.509 \\
\hline $\mathrm{H}$ & -1.8805 & -3.9915 & -3.1525 \\
\hline $\mathrm{H}$ & -0.1822 & -3.5833 & -2.881 \\
\hline $\mathrm{H}$ & -3.867 & -4.0159 & 0.8773 \\
\hline $\mathrm{H}$ & -4.2414 & -2.3662 & 1.4849 \\
\hline $\mathrm{H}$ & -5.5515 & -3.4751 & 1.0298 \\
\hline $\mathrm{H}$ & 3.0154 & 1.7841 & -1.009 \\
\hline $\mathrm{H}$ & 1.4856 & 2.3023 & -1.6742 \\
\hline $\mathrm{H}$ & 1.9708 & 2.835 & -0.0812 \\
\hline $\mathrm{H}$ & 5.7368 & 2.9338 & 1.5952 \\
\hline $\mathrm{H}$ & 5.8691 & 1.2808 & 2.2296 \\
\hline $\mathrm{H}$ & 5.7611 & 1.5738 & 0.4541 \\
\hline $\mathrm{H}$ & 0.3808 & 4.5676 & 2.3791 \\
\hline $\mathrm{H}$ & -1.2848 & 4.295 & 1.8697 \\
\hline $\mathrm{H}$ & -0.7409 & 3.6493 & 3.4166 \\
\hline
\end{tabular}




\begin{tabular}{|c|c|c|c|}
\hline $\mathrm{H}$ & 2.4642 & 3.3508 & 2.851 \\
\hline $\mathrm{H}$ & 1.378 & 2.9112 & 4.1779 \\
\hline $\mathrm{H}$ & 2.7472 & 1.8865 & 3.8087 \\
\hline $\mathrm{H}$ & 2.9791 & -1.9113 & 2.8616 \\
\hline $\mathrm{H}$ & 2.8889 & -0.4828 & 3.9058 \\
\hline $\mathrm{H}$ & 1.74 & -1.8081 & 4.1134 \\
\hline $\mathrm{H}$ & 1.1654 & -2.375 & 1.6178 \\
\hline
\end{tabular}

Table S13. Important thermodynamic parameters (a.u.) of 3 at B3LYP/6-311G(d,p) level in the gas phase.

\begin{tabular}{ccccc}
\hline Species & $E$ & $H$ & $G$ & $\begin{array}{c}\text { imaginary } \\
\text { frequencies }\end{array}$ \\
\hline 3a & -1651.696303 & -1651.695359 & -1651.795307 & 27.26 \\
3b & -1651.695790 & -1651.694846 & -1651.794707 & 26.81 \\
3c & -1651.694107 & -1651.693162 & -1651.792961 & 26.49 \\
\hline
\end{tabular}

$E$ : total energy; $H$ : enthalpy; $G$ : Gibbs free energy.

Table S14. Conformational analysis of 3 .

\begin{tabular}{lllll}
\hline Species & $\Delta E^{a}$ & $P_{E} \%^{b}$ & $\Delta G^{c}$ & $P_{G} \%^{b}$ \\
\hline 3a & 0.00 & 60.18 & 0.00 & 64.13 \\
3b & 0.32 & 34.36 & 0.40 & 31.76 \\
3c & 1.38 & 5.46 & 1.58 & 4.11
\end{tabular}

${ }^{a}$ Relative energy, and ${ }^{c}$ relative Gibbs free energy in $\mathrm{kcal} / \mathrm{mol} .{ }^{b}$ Conformational distribution calculated by using the respective parameters above at B3LYP/6$311 \mathrm{G}(\mathrm{d}, \mathrm{p})$ level in the gas phase. $\mathrm{T}=298 \mathrm{~K}$. 
Table S15. Inhibiting activity of $\mathbf{1}-\mathbf{3}$ against 11 enzymes

\begin{tabular}{|c|c|c|c|c|c|c|c|c|c|c|c|}
\hline \multirow[t]{2}{*}{ Comp. } & \multicolumn{4}{|c|}{ Inhibition ratio at concentration of $40 \mu \mathrm{g} / \mathrm{mL}$} & \multicolumn{7}{|c|}{ Inhibition ratio at concentration of $6.7 \mu \mathrm{g} / \mathrm{mL}$ towards PTP } \\
\hline & trypsin & HLE & cathepsin L & xanthine oxidase & PTP1B & CD45 & ТСРТР & SHP1 & MEG2 & SHP2 & $\mathrm{CDC} 25 \mathrm{~B}$ \\
\hline 1 & $36.6 \%$ & $29.4 \%$ & $12.7 \%$ & $10.9 \%$ & $-9.6 \%$ & $24.2 \%$ & $-0.8 \%$ & $31.2 \%$ & $1.4 \%$ & $14.4 \%$ & $35.8 \%$ \\
\hline 2 & $40.1 \%$ & $51.1 \%$ & $35.0 \%$ & $10.5 \%$ & $-21.8 \%$ & $0.7 \%$ & $-14.8 \%$ & $24.3 \%$ & $14.8 \%$ & $13.9 \%$ & $41.3 \%$ \\
\hline \multirow[t]{2}{*}{3} & $27.8 \%$ & $24.0 \%$ & $13.2 \%$ & $13.3 \%$ & $-13.0 \%$ & $0.9 \%$ & $-5.0 \%$ & $34.1 \%$ & $11.3 \%$ & $14.4 \%$ & $43.8 \%$ \\
\hline & \multicolumn{11}{|c|}{ Enzyme inhibition $\mathrm{IC}_{50}(\mu \mathrm{M})$ for compounds $1-3$ and positive control } \\
\hline 1 & $>100$ & $>100$ & $>100$ & $>100$ & $>50$ & $32.0 \pm 5.4$ & $>50$ & $22.0 \pm 5.8$ & $>50$ & $>50$ & $20.0 \pm 4.1$ \\
\hline 2 & $>100$ & $80 \pm 5.2$ & $>100$ & $>100$ & $>50$ & $>50$ & $>50$ & $34.0 \pm 6.1$ & $>50$ & $>50$ & $19.0 \pm 2.8$ \\
\hline 3 & $>100$ & $>100$ & $>100$ & $>100$ & $>50$ & $>50$ & $>50$ & $23.0 \pm 3.2$ & $>50$ & $>50$ & $18.0 \pm 2.0$ \\
\hline $\mathrm{Na}_{3} \mathrm{O}_{4}$ & - & - & - & - & 1.6 & - & 2.4 & 4.4 & 3.2 & 6.2 & - \\
\hline Menadione & - & - & - & _ & - & - & - & - & - & - & 14.2 \\
\hline Allopurinol & - & - & - & 1.8 & - & - & - & - & - & - & - \\
\hline Ulinastatin & _- & 1.1 & _ & $\ldots$ & - & - & - & - & - & - & - \\
\hline
\end{tabular}

